

\section{Cavidades para dentición infantil}

Beatriz Gurrola Martínez Víctor Javier Álvarez Bañuelos 


\section{Universidad Nacional Autónoma de México}

Facultad de Estudios Superiores Zaragoza

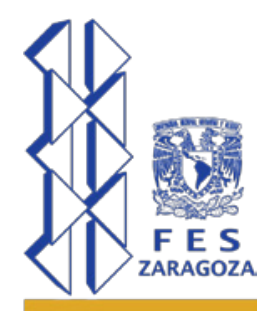

\section{Datos para catalogación bibliográfica}

Autores: Beatriz Gurrola Martínez y Víctor Javier Álvarez Bañuelos

\section{Cavidades para dentición infantil.}

UNAM, FES Zaragoza, enero de 2018.

Peso: 8.2 MB.

Diseño de portada: Raziel Leaños Castillo.

Formación de interiores: Claudia Ahumada Ballesteros.

Retoque digital: Gabriel Romero Nuñez.

ISBN: 978-607-30-0116-8.

\section{DERECHOS RESERVADOS}

Queda prohibida la reproducción o transmisión total o parcial del texto o las ilustraciones de la presente obra bajo cualesquiera formas, electrónicas o mecánicas, incluyendo fotocopiado, almacenamiento en algún sistema de recuperación de información, dispositivo de memoria digital o grabado sin el consentimiento previo y por escrito del editor.

\section{Cavidades para dentición infantil.}

\section{D.R. ( ) Universidad Nacional Autónoma de México}

Av. Universidad \# 3000, Col. Universidad Nacional Autónoma de México, C.U., Delegación Coyoacán, C.P. 04510, México, D.F.

Facultad de Estudios Superiores Zaragoza

Av. Guelatao \# 66, Col. Ejército de Oriente, Delegación Iztapalapa, C.P. 09230, México, D.F. 


\section{Prólogo}

$\mathrm{E}$ ste libro intenta explicar la diferencia y realización de cavidades en pacientes infantiles, reúne a dos autores considerados pilares de la odontología, el Dr. Black y el Dr. Bronner; quienes desde 1930 sentaron las bases para llevar a cabo este procedimiento.

Actualmente la tecnología llega también al campo de odontología, motivo por el cual es necesario incorporar materiales e instrumentos que probablemente seguirán cambiando. Todo con el propósito de brindar mejores tratamientos a los pacientes.

Es por ello que decidimos realizar una explicación y apreciación desde el enfoque profesor-alumno, además de procurar realizar una edición que resultara accesible a todo el grupo odontológico que lo requiera. Si bien en un principio fue destinado principalmente a los estudiantes de primer año de odontología, una vez terminado se consideró también que podía ser material educativo para la carrera de Cirujano Dentista. Es un complemento de la teoría y se muestran imágenes; confiamos que aunque muchas personas ya tienen conocimiento del tema disfrutarán al leerlo.

También esperamos sea una herramienta de estudio para los que buscan resolver dudas de la teoría recibida. Si bien nuestros objetivos están planteados para ser alcanzados, consideramos que será posible llegar a muchos odontólogos de práctica general, ya que al realizar el libro de forma electrónica, se tienen las siguientes ventajas: se pueden observar en una buena resolución las imágenes y no tienen que pagar nada por descargarlo. 



\section{Índice}

$7 \quad$ Introducción

8 Justificación

9 Vinculación del Plan de Estudios y relación del programa

11 Objetivo general

12 Antecedentes

15 Principios generales

16 Tejidos del diente esmalte dentina pulpa

17 Definición de cavidad

$25 \quad$ Nomenclatura

28 Localización de las superficies que abarcan las cavidades

33 Condiciones

36 Pasos a seguir en la preparación de cavidades

40 Diseño de la cavidad clase I

41 Ejercicio: Cavidades clase I

43 Cavidades clase II

47 Ejercicio: Cavidades clase II

49 Cavidades clase III

53 Ejercicio: Cavidades de clase III

54 Cavidades clase IV

55 Ejercicio: Cavidades de clase IV

56 Cavidades clase V

59 Ejercicio: Cavidades de clase V

60 Técnica de realización de la cavidad clase I

65 Técnica de realización de la cavidad clase II

70 Técnica de realización de la cavidad clase III

72 Preparación de muñón

76 Reducción oclusal

79 Recapitulación

81 Recomendaciones

84 Eliminación de la caries

86 Limpieza de la cavidad

88 Glosario

92 Referencias bibliográficas 



\section{Introducción}

$\mathrm{E}$ 1 siguiente trabajo muestra a los estudiantes de la carrera de odontología, la técnica para la preparación de cavidades en pacientes infantiles. El estudiante debe tener conocimiento teórico en temas que versan al respecto de la preparación y elaboración de cavidades dentales. A este se le proporciona la información actualizada en la teoría del Módulo Prevención en Estomatología. Por lo que este es material que acompaña a las actividades en el laboratorio, al respecto de cómo deben de realizarse las preparaciones de las cavidades en las superficies dentarias así como la clasificación. Considerando la nomenclatura de las superficies, y se agregan ejercicios de autoevaluación. Este material de apoyo proporciona las herramientas teóricas metodológicas para que los alumnos de primer año de la carrera de Cirujano Dentista complementen la realización de las cavidades en tipodontos infantiles, como un paso previo para realizarlas en la práctica clínica en los niños. Se mostrara como se diseñan y los pasos para la ejecución de las cavidades tipo Bronner, para ir familiarizando al alumno en esta actividad ya que ellos, después, llevaran a cabo estas en el tipodonto de acrílico, en el laboratorio. Es un refuerzo a la teoría impartida, para el módulo, en él se muestran imágenes también, de pacientes infantiles compiladas en la Clínica Zaragoza. Se proporcionan herramientas para que el alumno pueda dar el Diagnóstico, en el caso de tratar a un niño con caries.

\section{Descripción de las principales características del módulo Prevención en Estomatología}

"Prevención en Estomatología", tiene como fundamento la "Prevención Integral", que al mismo tiempo se constituye en una función profesional prioritaria en la formación y ejercicio profesional del futuro egresado. La Prevención Integral es una orientación filosófica del quehacer cotidiano, que implica el desarrollo de un conjunto de acciones estratégicas encaminadas a intervenir en el proceso salud enfermedad del individuo y la comunidad, para promover, mantener y restaurar las condiciones óptimas de las estructuras y funciones del Sistema Estomatognático. La prevención como un valor social implica que se aborden los problemas del proceso salud-enfermedad en su dimensión amplia, es decir, evitar que ocurra la enfermedad en los individuos y que se expanda en la comunidad, o bien, prevenir su evolución una vez que ya se ha manifestado, de atenderla lo más tempranamente posible. Lo anterior es de particular importancia en los sectores de la sociedad que enfrentan condiciones socioeconómicas adversas, y/o baja instrucción educacional, en quienes las posibilidades de acceso a los servicios de atención estomatológica, son limitados de alta complejidad y costosos. En este módulo se obtienen las bases teóricas, técnicas y metodológicas para la ejecución de la prevención y tratamiento de las patologías bucales que desde la perspectiva epidemiológica se encuentran con mayor frecuencia en la población: caries y gingivitis, con prácticas en simuladores y entre estudiantes que le permiten estar preparados para cumplir en la clínica, las funciones de asistente dental, higienista y como parte de éstas, de Educación para la Salud. Mediante las estrategias de Educación para la Salud, se forma al futuro egresado en la responsabilidad y compromiso con respecto a la problemática de salud general y bucal del individuo y de la comunidad. Preparar al estudiante en la figura de asistente dental, es conformar un elemento del equipo de salud al participar de manera directa de apoyo al estomatólogo en las actividades propias de la clínica estomatológica integral, mediante el acomodo de charolas e intercambio de instrumental; dosificación y manipulación de materiales dentales; a fin de que los procesos se simplifiquen para optimizar el tiempo y los recursos disponibles, con los lineamientos de bioseguridad y control de infecciones que exige el trabajo profesional. ${ }^{1}$ 


\section{Justificación}

L a enseñanza de la odontología se ha modificado y reconoce la importancia que tienen la educación a la salud y la prevención de las enfermedades, la atención al paciente con bioética y de manera integral considerándolo como parte de una comunidad. En este sentido la Facultad de Estudios Superiores Zaragoza como institución formadora de recursos humanos y prestadora de servicios de salud contempla en el Plan de Estudio vigente las funciones profesionales que el alumno del primer año de la carrera deberá realizar al término de ese año escolar, fundamentado en la Estrategia de Atención Primaria, y su eje de referencia es el proceso salud-enfermedad del sistema estomatognático en la sociedad. Asimismo, en el proceso educativo se contemplan los planes de tratamiento y programas de atención odontológica con un enfoque de prevención integral entendido, "como el principio que considera las determinantes sociales y biológicas del proceso salud-enfermedad del sistema estomatognático a nivel individual y colectivo y se orienta al mejoramiento de hábitos higiénicos, alimentarios, eliminación de hábitos nocivos, funcionales y para funcionales; para la conservación de ambas denticiones; a orientar y vigilar el uso, consumo, y empleo de medidas de protección específica, al diagnóstico temprano, al tratamiento y control de enfermedades; así como a la rehabilitación como medidas que limitan la presencia de daños mayores". ${ }^{1}$

El modelo explicativo de la manera como se produce el nivel salud en una población fue desarrollado Lalonde; este menciona que los factores que inciden en el proceso de producción social de la salud pueden ser agrupados en cuatro categorías: - Factores biológicos, que se refieren a todos aquellos elementos de salud, tanto física como mental, desarrollados dentro del cuerpo humano como consecuencia de la biología básica y de aspectos orgánicos del individuo, por ejemplo: la carga genética, el proceso de envejecimiento, los sistemas internos del organismo y otros.

Factores ambientales, incluyendo los relacionados con el hábitat humano (condiciones de saneamiento básico y de vivienda, el medio laboral, el escolar y otros). Factores socioeconómicos y culturales (estilos de vida, decisiones y hábitos, ingreso económico, nivel educativo, aspectos culturales, empleo, recreación, participación política). Factores relacionados con servicios de salud de atención a las personas (acceso, cantidad, calidad, oportunidad y organización de estos servicios de salud). No es posible mejorar la salud sin manejar de manera adecuada los determinantes sociales de ésta, lo cual se logrará mediante la estrategia de la promoción de la salud, utilizando la definición de la Carta de Ottawa: "proporcionar a los pueblos los medios necesarios para mejorar su salud y ejercer un mayor control sobre la misma. Trasciende la idea de formas de vidas sanas para incluir las condiciones y requisitos para la salud que son: paz, vivienda, educación, alimentación, renta, ecosistema estable, recursos sostenibles, justicia social y equidad". ${ }^{1,2}$ Constituye un proceso político y social global que abarca no solo las acciones orientadas a fortalecer las habilidades y capacidades de los individuos, sino también las dirigidas a modificar las condiciones sociales, ambientales y económicas, con el fin de mitigar su impacto en la salud pública e individual. 


\section{Vinculación del Plan de Estudios relación del programa con otros módulos afines}

\begin{tabular}{|c|c|c|c|c|c|c|}
\hline \multicolumn{3}{|c|}{ Relación Horizontal } & \multicolumn{2}{|l|}{ Módulos } & & \\
\hline $\begin{array}{l}\text { 1. Prevención en } \\
\text { estomatología }\end{array}$ & $\begin{array}{l}\text { 2. Bases para } \\
\text { el diagnóstico } \\
\text { del Sistema } \\
\text { Estomatognático }\end{array}$ & $\begin{array}{l}\text { 3. Sistema } \\
\text { Estomatognático }\end{array}$ & $\begin{array}{l}\text { 4. Introducción } \\
\text { al Proceso } \\
\text { Salud- } \\
\text { Enfermedad, } \\
\text { Nutrición, } \\
\text { Metabolismo } \\
\text { y Bases } \\
\text { Farmacológicas }\end{array}$ & $\begin{array}{l}\text { 5. Estomatología } \\
\text { Social I }\end{array}$ & $\begin{array}{l}\text { 6. Introducción } \\
\text { al Proceso } \\
\text { Salud- } \\
\text { Enfermedad, } \\
\text { Nutrición, } \\
\text { Metabolismo } \\
\text { y Bases } \\
\text { Farmacológicas }\end{array}$ & $\begin{array}{l}\text { 7. Metodología } \\
\text { de la } \\
\text { Investigación I }\end{array}$ \\
\hline
\end{tabular}

$\mathrm{E}$ 1 alumno de primer año adquirirá los conocimientos teórico-metodológicos en las áreas biológica, social y clínica en los módulos que se imparten de manera simultánea y conjuntándose para su aplicación en el módulo de Clínica en Prevención, posibilitando la prevención integral, y la promoción a la salud del proceso salud-enfermedad del sistema estomatognático a nivel individual.

Contenidos de los módulos con los que se relaciona horizontalmente son: Prevención en estomatología.

En este módulo se correlaciona el proceso salud enfermedad del sistema estomatognático con la prevención integral, a través de la investigación clínica y epidemiológica.

- Bases para el Diagnóstico del Sistema Estomatognático. En él se estudian las características morfo funcionales de la cavidad bucal, así como la aplicación de los fundamentos y los medios de diagnóstico de la salud-enfermedad tanto en el orden bucal como sistémico.

- Sistema Estomatognático. En este módulo se profundiza en el conocimiento histo-embriológico, cráneo facial, en apoyo al diagnóstico integral del individuo, al correlacionar el desarrollo y crecimiento de las estructuras del aparato estomatognático.

- Introducción al Proceso Salud-Enfermedad, Nutrición, Metabolismo y Bases Farmacológicas. En él se integra el conocimiento microbiológico, bioquímica de la cavidad oral, la placa dentobacteriana como factor etiopatogénico de las enfermedades de tipo infeccioso y de la respuesta del organismo ante procesos como la caries, gingivitis, periodontitis, así como la fundamentación de las acciones para el control de infecciones en los procedimientos preventivos y/o restaurativos en la práctica clínica.

- Estomatología Social I. Se analiza el proceso salud-enfermedad, como expresión de la vida social en su dimensión histórica.

- Metodología de la Investigación I. 


\section{Gurrola Martínez B \& Álvarez Bañuelos VJ}

\section{Relación vertical o diacrónica}

El primer año de la carrera brinda las bases teórico-prácticas en los módulos de Clínica Estomatológica Integral I, II y III de los siguientes años escolares para ser ampliadas y relacionándose en forma directa de la siguiente manera:

\section{Con el segundo año}

El Eje de referencia es la "atención al grupo poblacional de niños y adolescentes" y los módulos en su conjunto estudian los aspectos teóricos del diagnóstico, tratamiento y evaluación con relación a caries, periodontopatías, maloclusiones y de las lesiones traumáticas de los tejidos duros y blandos.

Se aplica el método clínico en la atención individual en la práctica clínica, al mismo tiempo que se estudia el "Proceso Salud-Enfermedad" a partir de la elaboración de un perfil de este grupo poblacional, ejerce una práctica profesional alternativa con un sustento epidemiológico que incluye el apoyo de la bioestadística, la planeación y la programación.

\section{En el tercer año}

El eje de referencia es la "atención a la población adulta y la mujer gestante e integra la atención al niño y al adolescente" en quienes los problemas que se presentan son de mayor complejidad, ya sea por el grado de evolución local o por sus implicaciones sistémicas, que en consecuencia requieren tratamientos de mayor complejidad en relación a caries, periodontopatías, maloclusiones y lesiones de tejidos duros y blandos, que en muchos casos hace necesaria la intervención quirúrgica, por lo que se suman los contenidos: bases universales en cirugía equipo rojo de urgencias y procedimientos clínicos de emergencias.

Para complementar la atención a los casos de pérdida dentaria por caries o periodontopatías, se capacita al alumno para el diseño y elaboración de aparatos protésicos así como de la elaboración de férulas y guardas oclusales como parte del tratamiento integral.

Con respecto a las alteraciones en tejidos duros y blandos se abordan; el diagnóstico, prevención y tratamiento de infecciones bacterianas, virales, micóticas en relación a las afecciones ulceradas, hiperplásicas, quísticas y neoplásicas, lo que permite que al alumno lleve a cabo el tratamiento y/o canalización del paciente a otros niveles de atención.

\section{El cuarto año}

Los módulos que lo conforman son: 5, en estos módulos el alumno integra los conceptos, métodos y técnicas para el diagnóstico y tratamiento como forma de abordaje del proceso salud-enfermedad estomatognático relacionándolo con las áreas biológica, clínica y social lo que permitirá realizar prevención integral, para brindar servicios de salud tomando como base la bioseguridad y el control de infecciones en los diferentes grupos etáreos en mayor grado de complejidad en relación a años escolares anteriores a nivel individual y colectivo. ${ }^{1}$ 


\begin{tabular}{|l|l|l|}
\multicolumn{2}{|c}{ Segundo año } & \multicolumn{1}{c|}{$\begin{array}{c}\text { Telación Vertical } \\
\text { Tercer año }\end{array}$} \\
\hline Clínica Estomatológica Integral I & Clínica Estomatológica Integral II & Clínica Estomatológica Integral III \\
\hline Estomatología I & $\begin{array}{l}\text { Mecanismos Infecciosos y } \\
\text { Respuesta Inmune del Sistema } \\
\text { Estomatognático }\end{array}$ & Estomatología III \\
\hline Estomatología Social II & Estomatología Social III & $\begin{array}{l}\text { Manejo Estomatológico del paciente } \\
\text { geriátrico }\end{array}$ \\
\hline & Alteraciones Bucales & Gerontología Social \\
\hline & & Estomatología Integral \\
\hline
\end{tabular}

\section{Objetivo General}

$\mathrm{P}$ roporcionar información actualizada para que los alumnos del primer año de la carrera de Cirujano Dentista complementen la actividad de la práctica de laboratorio sobre la preparación de cavidades, en pacientes infantiles, como previo acercamiento al paciente infantil en la correcta realización de las cavidades, para recordar los criterios teóricos metodológicos que deben utilizar los alumnos para un mejor desarrollo en la preparación de las cavidades en dentición infantil al realizar la práctica clínica. 


\section{Antecedentes}

L a Organización Mundial de la Salud OMS, 1997 durante muchos años, se evitó intencionalmente el registro de las lesiones de caries que no es "una cavidad" debido a la creencia de que no era posible conseguir un diagnóstico fiable de la fase temprana de caries sin cavidad. ${ }^{2}$ No obstante, varios estudios contradicen esta afirmación Pitts and Fyffe, 1988, Mount., 1989; Ismail et al. 3,4,5 Por otra parte Nyvad et al. 1997 ,desarrollaron criterios de diagnóstico diferenciando las lesiones de caries activas de las inactivas de acuerdo con una combinación de criterios visuales y táctiles, el índice desarrollado identifica tres niveles de gravedad, dependiendo de la profundidad de las lesiones (superficie intacta, discontinuidad superficial en el esmalte o cavidad evidente en la dentina. ${ }^{6,7}$

Por otro lado autores como: Casanova y Pereyra señalan que la caries continúa siendo un problema de salud pública en nuestro país. ${ }^{89}$. En países desarrollados el 35\% de los niños de cinco años de edad presentan caries y el $9 \%$ tiene más de cuatro dientes sin tratamiento. ${ }^{3}$ Estudios en niños mexicanos informan prevalencias de caries por arriba del $75 \%$, con más de cinco dientes afectados en la etapa preescolar, lo que implica la gran necesidad de tratamientos restaurativos. ${ }^{9,10,11 .}$

Al respecto uno de los paradigmas de la odontología actual es la búsqueda de técnicas no invasivas que conserven al máximo las estructuras dentarias, la caries dental sigue siendo un problema relevante, ya que hay grandes segmentos de la población en los que sigue siendo un problema mayor. Estas disparidades de salud detalladas en el informe "Salud Oral en América" de la Organización Panamericana de la Salud (OPS/OMS, 2002; PAHO, 2002), ${ }^{2}$ tienden a concentrarse en una minoría de niños especialmente en los económicamente no privilegiados, que tienen un menor acceso a la asistencia odontológica, en su informe sobre salud bucal, afirmó que la caries dental sigue siendo un aspecto fundamental de las condiciones generales de salud en las Américas por la importancia que tiene como parte de la carga global de morbilidad, los costos relacionados con su tratamiento (de operatoria y rehabilitación bucal), la pérdida de dientes y la posibilidad de aplicar medidas eficaces de prevención.

La caries dental es aún una de las enfermedades de mayor prevalencia en la población mundial, esta condición afecta millones de personas en el mundo y algunas poblaciones presentan mayores índices comparadas con otras. ${ }^{2}$ En América Latina, a pesar de haber logrado una disminución en la prevalencia de caries en los últimos años, todavía se presenta como un problema prioritario de salud pública principalmente en niños. ${ }^{2}$ Aunque se haya visto un fortalecimiento general en la región durante las últimas décadas en ámbitos como la economía, tecnología, infraestructura e inversión extranjera; los grandes problemas que afectan al continente como la desigualdad, pobreza y barreras de acceso a salud y educación, determinan muchas de las políticas de salud que los gobiernos implementan, así como las prioridades en la creación y desarrollo de los currículos de las instituciones de educación superior. En este sentido, y gracias al impacto social y económico que la Caries Dental confiere a las poblaciones, es de gran importancia, que los estudiantes de odontología tengan acceso a una educación profunda en esta área y que además que esté basada en las mejores evidencias científicas disponibles, como futuros dentistas responsables del cuidado oral de la población. ${ }^{12}$

En lo que se refiere al diagnóstico de caries es el índice de la Organización Mundial de la Salud (OMS) el más utilizado como criterio de detección de lesiones. No obstante, se han adoptado índices que incluyen lesiones iniciales 
como el Sistema Internacional para la Detección y Evaluación de Caries (ICDAS) es un nuevo sistema internacional de detección y diagnóstico de caries, consensuado en Baltimore, Maryland, USA, en el año 2005, para la práctica clínica, la investigación y el desarrollo de programas de salud pública. El objetivo era desarrollar un método visual para la detección de la caries, en fase tan temprana como fuera posible, y que además detectara la gravedad y el nivel de actividad de la misma. Un estudio llevado a cabo por el Departamento de Cariología, Ciencias de la Restauración y Endodoncia de la Facultad de Odontología de la Universidad de Michigan en 2007 demostró que el sistema es práctico, tiene validez de contenido, validez discriminatoria y validez de correlación con el examen histológico de las fosas y fisuras en dientes extraídos. ${ }^{13}$ Es un método especialmente útil para la detección temprana de caries de esmalte y la planificación de la terapia de remineralización individual; así como para el seguimiento del patrón de caries de una determinada población. El sistema tiene 70 al 85\% de sensibilidad y una especificidad de 80 al $90 \%$; en detectar caries, en dentición temporaria y permanente; dependiendo esta diferencia por el grado de entrenamiento y calibración del personal examinador. Índice de concordancia Kappa => 0.65 (11) y el Índice de Nyvad 2003 ${ }^{14}$, así como la valoración de actividad de las lesiones. También se mencionada la baja adhesión al examen visual en comparación con el examen visual-táctil tradicional (con uso de explorador de punta aguda). Por otro lado algunas facultades de odontología reportan el uso de la valoración de riesgo de sus pacientes como parte del proceso de diagnóstico de caries y toma de decisiones terapéuticas. En la mayoría predomina el manejo quirúrgico (invasivo) de lesiones con remoción total del tejido cariado, que muchas veces está asociado a los requisitos de restauraciones mínimas exigidas a los estudiantes. Sin embargo, existe también en la mayoría de facultades abordajes preventivos como el uso de fluoruros y agentes antimicrobianos y remineralizantes. Es necesario citar la importancia de la educación de los pacientes en hábitos saludables e higiene oral para control de factores de riesgo como eje fundamental en el manejo de la enfermedad. Así como el uso de tratamientos mínimamente invasivos para lesiones iniciales y se recalca la importancia del diagnóstico precoz para evitar tratamientos restauradores. La remoción profesional de placa bacteriana, tratamiento restaurador atraumático (ART), remoción parcial de tejido cariado, monitoreando lesiones inactivas, uso de sellantes de fosas y fisuras entre otros. ${ }^{14}$

Por otra parte se han introducido criterios diagnósticos más sensibles para el registro de caries dental ya que la medida tradicional de la caries en la fase de cavidad, excluyendo las fases de pre-cavidad de la OMS no resulta suficiente para reflejar los cambios lentos registrados en la incidencia de caries en las poblaciones actuales, además, se ha demostrado que el diagnóstico de la caries registrado sólo a nivel de la cavidad conduce a una sub-valoración importante de la prevalencia real de la enfermedad como es señalado por autores como: Piovano ${ }^{15}$, quien cita a Marthaler y Pitts, 2004, Manji et al., 1989; 1992; Bjarnason, 1993; Kuzmina et al., 1995; Sköld et al., 1995; Machiulskiene et al.,1998 y Fontana y Zero, 2006.

Piovano señala que durante muchos años, se evitó intencionalmente el registro de las lesiones de caries que no es "una cavidad" debido a la creencia de que no era posible conseguir un diagnóstico fiable de la fase temprana de caries sin cavidad (OMS, 1997). No obstante, varios estudios contradicen esta afirmación como Pitts y Fyffe, 1988, ${ }^{16}$ y se ha demostrado que no se reduce la fiabilidad del interexaminador / intraexaminador cuando se incluyen las caries tempranas sin formación de cavidad en el sistema de registro, si los observadores que realizan las exploraciones tienen una formación rigurosa y están calibrados antes de realizar el estudio. ${ }^{16}$

Nyvad, Machiulskiene, $1999,{ }^{14}$ desarrollaron criterios de diagnóstico diferenciando las lesiones de caries activas de las inactivas de acuerdo con una combinación de criterios visuales y táctiles. El índice desarrollado identifica tres niveles de gravedad, dependiendo de la profundidad de las lesiones (superficie intacta, discontinuidad superficial en el esmalte o cavidad evidente en la dentina. La técnica recomienda el uso de exploradores para 


\section{Gurrola Martínez B \& Álvarez Bañuelos VJ}

limpiar suavemente la superficie de la pieza, eliminando los depósitos bacterianos y para comprobar si se evidencia pérdida de estructura dentaria (cavidad pequeña o micro cavidad) así como la textura de superficie (duro o rugosa /blando).

Evita la exploración de las lesiones utilizando este procedimiento únicamente cuando no existan criterios visuales evidentes como la opacidad y por lo tanto, no suficientes para reconocer la lesión como activa o inactiva. La textura de la superficie es considerada un indicador más fiable de actividad que el color de la lesión, hecho que condiciona que no se emplee como único criterio de diagnóstico el color. Las lesiones "con una mezcla" de características de caries activas e inactivas deben ser consideradas como activas.

\begin{tabular}{|c|c|c|}
\hline & & Índice Nyvad: Criterios diagnósticos 1999 \\
\hline Score & Categoría & Criterio \\
\hline Sc 1 & Sano & $\begin{array}{l}\text { Translucidez y textura normal del esmalte (se permite una pequeña coloración de la } \\
\text { fisura sana). }\end{array}$ \\
\hline Sc 2 & $\begin{array}{l}\text { Caries activa } \\
\text { (superficie } \\
\text { intacta) }\end{array}$ & $\begin{array}{l}\text { La superficie del esmalte presenta una opacidad blanquecina/amarillenta con } \\
\text { pérdida del brillo, cuando la punta de una sonda es desplazada sobre la superficie } \\
\text { (generalmente cubierta de placa) se aprecia una sensación rugosa. Superficie lisa: la } \\
\text { lesión se sitúa típicamente al margen gingival. } \\
\text { Fosas y fisuras: morfología intacta; la lesión se extiende a las paredes de la fisura. }\end{array}$ \\
\hline Sc 3 & $\begin{array}{l}\text { Caries activa } \\
\text { (discontinuidad } \\
\text { superficial }\end{array}$ & $\begin{array}{l}\text { Caries activa (discontinuidad superficial) los mismos criterios que en el Score } 1 . \\
\text { Defecto superficial (micro-cavidad o cavidad muy pequeña) solo en el esmalte. } \\
\text { No se puede detectar un fondo de cavidad reblandecido. }\end{array}$ \\
\hline Sc 4 & $\begin{array}{l}\text { Caries activa } \\
\text { (cavidad) }\end{array}$ & $\begin{array}{l}\text { Cavidad en esmalte y dentina fácilmente visible a simple vista. La superficie de la } \\
\text { cavidad se nota blanda. Puede o no estar afectada la pulpa. }\end{array}$ \\
\hline Sc 5 & $\begin{array}{l}\text { Caries inactiva } \\
\text { (superficie } \\
\text { intacta) }\end{array}$ & $\begin{array}{l}\text { Los mismos criterios que en el Score } 4 \text {. Defecto superficial (microcavidad o cavidad } \\
\text { muy pequeña) No se puede detectar un fondo de cavidad reblandecido. }\end{array}$ \\
\hline Sc 6 & $\begin{array}{l}\text { Caries inactiva } \\
\text { (discontinuidad } \\
\text { superficial) }\end{array}$ & Cavidad en el esmalte y dentina fácilmente visible a simple vista. \\
\hline Sc7 & $\begin{array}{l}\text { Obturación } \\
\text { (superficie sana) }\end{array}$ & Obturación (superficie sana). \\
\hline Sc 8 & $\begin{array}{l}\text { Obturación }+ \\
\text { caries activa }\end{array}$ & La lesión de caries puede ser una cavidad o no. \\
\hline Sc 9 & $\begin{array}{l}\text { Obturación }+ \\
\text { caries inactiva }\end{array}$ & La lesión de caries puede ser una cavidad o no. \\
\hline
\end{tabular}




\section{Principios generales}

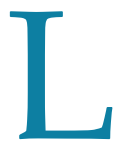

a operatoria dental en Odontopediatria, señala Finn, 1989, que cada pieza dental en la boca tiene diferente susceptibilidad a la

caries. ${ }^{17} \mathrm{Al}$ repasar la susceptibilidad de las piezas primarias, $\mathrm{y}$ al compararlas con su morfología, algunos estudios han demostrado que los segundos molares son los que tienen mayor índice de ataque cariogénico, seguidos por los primeros molares, caninos e incisivos. Sin embargo en todas las piezas existen ciertas áreas en que se vuelven cariadas más rápida y frecuentemente que otras; estas áreas son fosetas y fisuras en molares y piezas anteriores, áreas cervicales y proximales de todas las piezas, Figura 1.

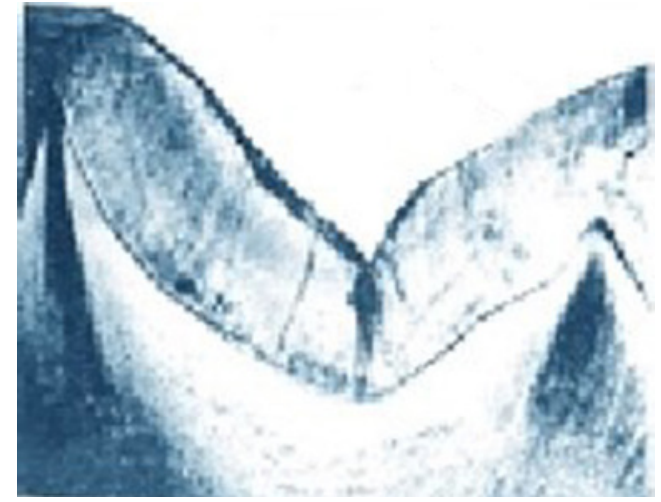

FIGURA 1

La caries es una enfermedad progresiva, comenzando siempre en zonas superficiales del esmalte en contacto con el medio bucal. La rapidez del avance depende de varios factores, agresividad de la placa bacteriana, bacterias presentes, capacidad de defensa de la saliva $\mathrm{pH}$ y el propio diente, calidad del esmalte, sistema inmunitario del individuo, Figura 2.
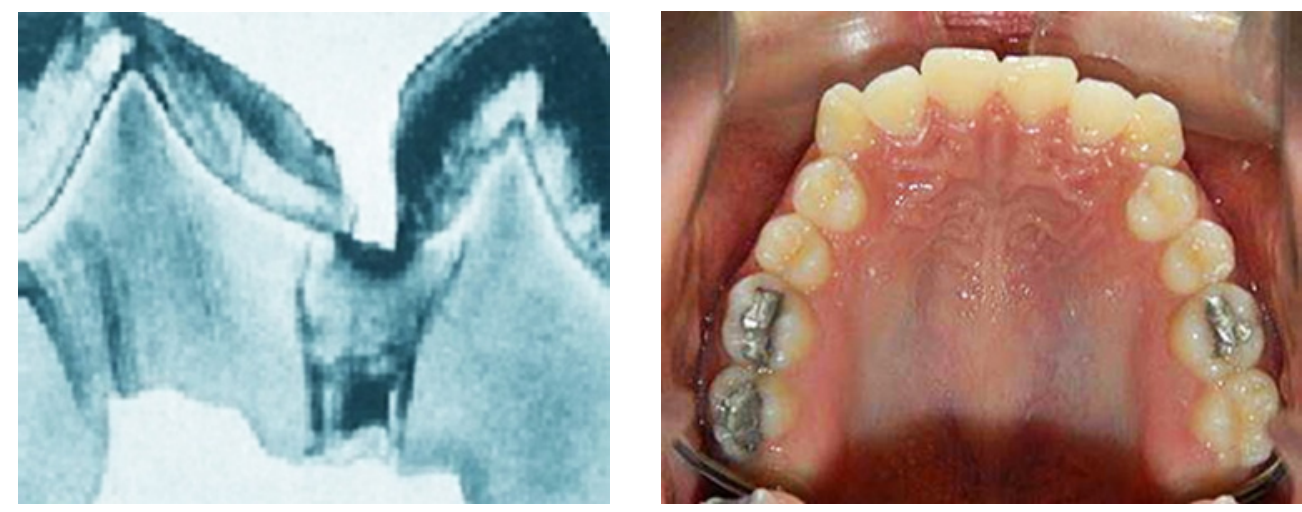

FIGURA 2

Por otro lado cuando un diente ha sufrido una pérdida de sustancia en sus tejidos duros, es necesario restaurarlo utilizando materiales y técnicas adecuados. Este procedimiento debe llevarse a cabo a causa de la incapacidad del diente de neoformar sus tejidos duros destruidos, los objetivos de los procedimientos de restauración son proporcionar función, estética, y restablecer la salud.

Para realizar estos procedimientos de restauración es necesario conocer en donde se ubican los tejidos dentarios. Si bien es cierto que la pulpa puede formar nueva dentina, lo hace en la profundidad de la cámara y como defensa ante el ataque recibido, no para reparar la pérdida de sustancia en la superficie del diente, Figura 3. 


\section{6 \\ Gurrola Martínez B \& Álvarez Bañuelos VJ}
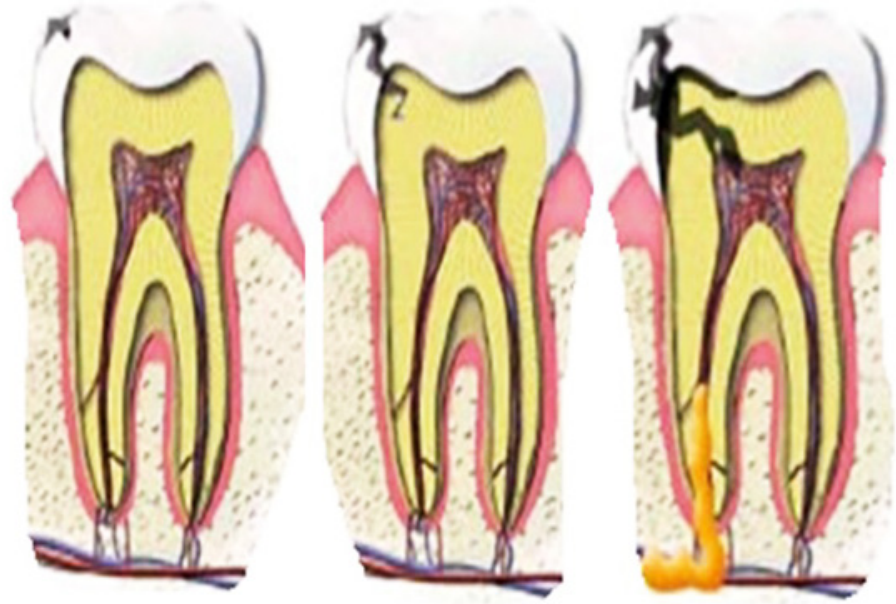

FIGURA 3

Como los tejidos duros remanentes pueden haber quedado afectados por el proceso que causó la destrucción parcial del diente.

Es necesario actuar sobre ellos con el objeto de eliminar los tejidos enfermos, infectados o debilitados que resultarían incapaces de mantener al material de relleno durante mucho tiempo en su sitio, Figuras 4 y 5.

A este respecto cabe señalar que aún los investigadores todavía no se ponen de acuerdo respecto a los materiales que tienen mayor adhesión, algunos a favor de las amalgamas, otros con las resinas.

Pero de lo que sí se está seguro es que se deben extirpar áreas reducidas de tejido sano para asegurar la permanencia de la

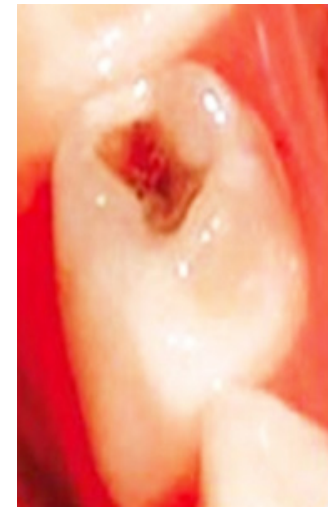

FIGURA 4

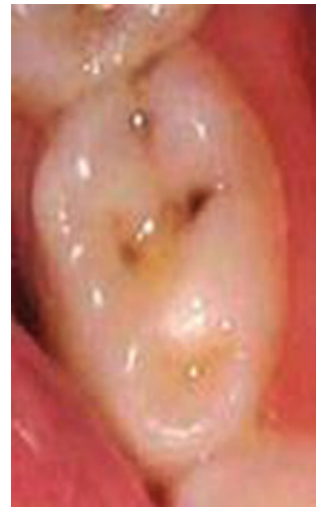

FIGURA 5 obturación en boca mediante las maniobras de retención y anclaje.

\section{Tejidos del diente esmalte dentina pulpa}

$\mathrm{E}$ s necesario tener presentes las consideraciones anatómicas de los dientes temporales, ya que presentan algunos rasgos morfológicos que los diferencian de los dientes permanentes y que deberemos de tener en cuenta en el momento de realizar algún procedimiento sobre ellos, para evitar tratamientos o reconstrucciones inadecuadas. Respecto a las dimensiones de esmalte-dentina y pulpa cabe destacar que el espesor medio del esmalte en los dientes temporales será de aproximadamente de 1 milímetro, el espesor medio de la dentina es muy variable. A continuación ver los valores medios de la siguiente tabla y el esquema de la comparación de los dientes infantiles y los permanentes. 


\begin{tabular}{|l|c|c|c|c|}
\multicolumn{2}{r}{ Espesor del esmalte } & $1^{\mathbf{0}}$ Sup. & $1^{\mathbf{0}}$ Sup. & $1^{\mathbf{0}}$ Sup. \\
\hline $\begin{array}{l}\text { Cuernos de pulpa mesiales a la cúspide } \\
\text { correspondiente }\end{array}$ & 1.8 & 2.9 & 2.2 & 3.0 \\
\hline $\begin{array}{l}\text { Cuernos de pulpa distales a la cúspide } \\
\text { correspondiente }\end{array}$ & 2.1 & 2.8 & 2.4 & 3.2 \\
\hline Pulpa mesial en el cérvix & 1 & 1.4 & 1 & 1.8 \\
\hline Pulpa distal en el cérvix & 1.8 & 1.5 & 1.1 & 1.8 \\
\hline
\end{tabular}

Diferencias morfológicas de los dientes infantiles y la dentición permanente

\section{Dentición infantil}

\section{Esmalte menos duro}

\section{Coloración de esmalte} azulada y traslúcida

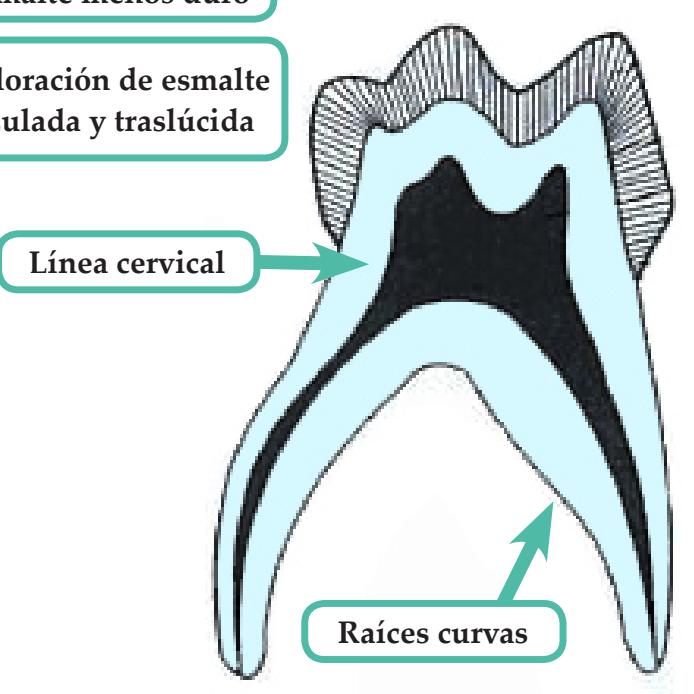

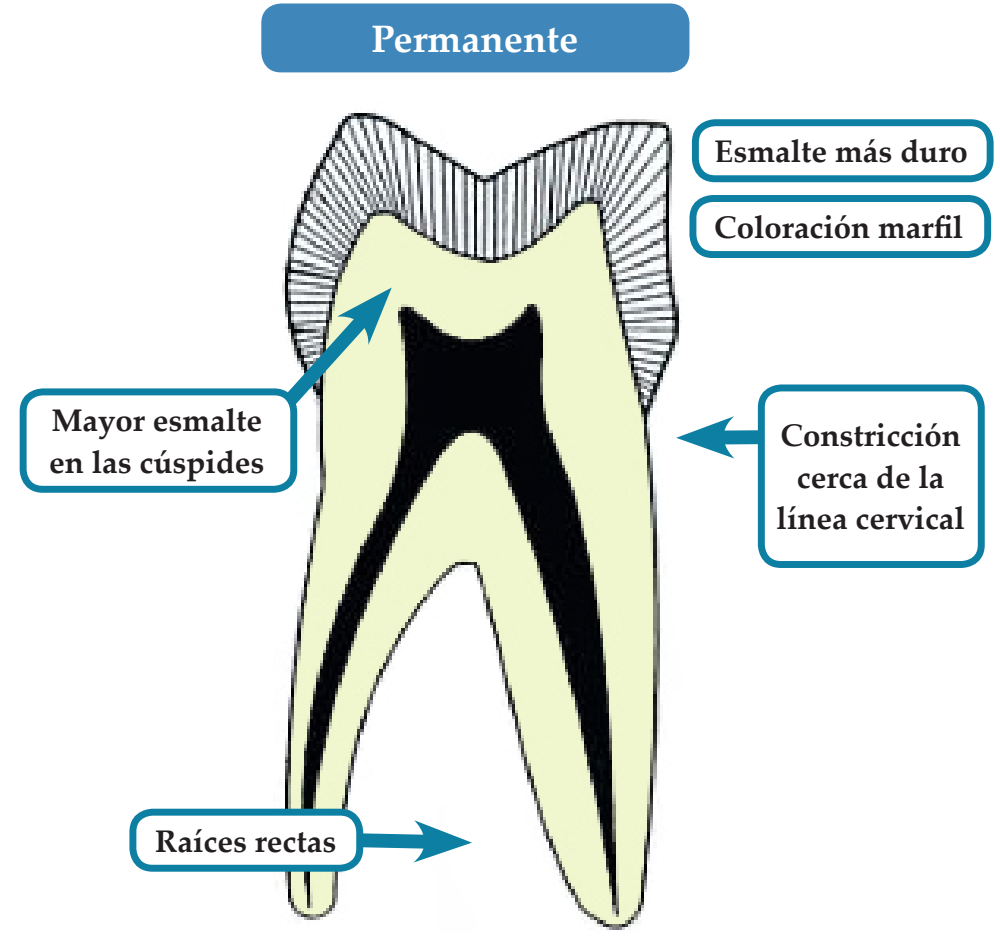

Permanente

Fuente: propia, elaborado con datos de Finn SB. Odontología pediátrica. México: McGraw-Hill Interamericana; $1989 .{ }^{17}$

\section{Definición de cavidad}

$\mathrm{M}$ etodología consistente en el ordenamiento de las maniobras necesarias para la preparación cavitaria cumpliendo con los requisitos biológicos, mecánicos y estéticos indispensables.

Preparación realizada mecánicamente, capaz de mantener con firmeza en su sitio el material resturador, cuando sobre ella actúen las fuerzas que se desarrollan durante la masticación. La sustancia restauradora devuelve al diente su forma, fisiología y estética, cumple la finalidad profiláctica de evitar recidivas de caries y en algunos casos (Incrustaciones) protege las paredes cavitarias. 


\section{Gurrola Martínez B \& Álvarez Bañuelos VJ}

Cavidad es la forma interna que se le da a un diente, siguiendo el proceso carioso, para reconstruirlo con materiales y técnicas adecuadas que le devuelvan la función masticatoria.

Fundamentos.- Para normalizar las maniobras operatorias que toda preparación cavitaria requiere es necesario adoptar un plan de trabajo y cumplirlo fielmente.

¿Cuáles son los objetivos de realizar los tiempos operatorios?

1o Obtener la forma cavitaria prevista siguiendo una secuencia lógica, fácil de memorizar y sin interferencias, secuencia de los tiempos operatorios. $2^{\underline{o}}$ Evitar la repetición o superposición de maniobras completando cada uno de los pasos en su totalidad. $3^{\circ}$ Reducir al mínimo el número de instrumentos utilizados, permite al operador concentrarse en su tarea evitando las maniobras dilatorias. Todo cambio de instrumento, manual o rotatorio, exige de 6 a 8 movimientos de dedos, brazos y cuerpo y obliga a quitar la vista del campo operatorio lo que distrae y fatiga al operador. $4^{\circ}$ Completar la preparación cavitaria en el menor tiempo posible sin poner en riesgo la biología del diente. Consecuencia lógica de todas las maniobras efectuadas de acuerdo con un ordenamiento metódico, racional y con criterio biomecánico. Fases en la preparación de la cavidad, el éxito de un ejercicio práctico será mejor si el operador tiene en su mente una imagen clara del resultado antes de empezar. Esto se adquiere por el estudio y la práctica. Black (1908) sugirió 6 fases en la preparación de la cavidad, que eran: ${ }^{18,19,20}$

1. Establecimiento de la forma del contorno.

2. Obtención de la forma de resistencia y retención.

3. Obtención de la forma de conveniencia.

4. Extirpación de la caries restante.

5. Terminación de las paredes del esmalte y los bordes.

6. Realización de la limpieza de la cavidad.

Esta enumeración de las fases en el procedimiento de Black no sólo facilita la descripción, sino que proporciona al operador una guía que le ayuda a reducir tiempo y a obtener un mejor resultado que el que lograría con métodos desordenados. Black, sentó las bases para su obturación con amalgama de plata (aleación en frío de plata y mercurio). A causa de su nula adhesión a las paredes cavitarias, la amalgama debía de colocarse en una cavidad con paredes retentivas, lo que se realizaba habitualmente mediante la orientación convergente de las paredes vestibular y lingual hacia la cara oclusal de la pieza dentaria tratada. ${ }^{13,14}$

Por otro lado es necesario mencionar que en la actualidad se utiliza más, los materiales adhesivos como: el composite, o resinas epoxy, ya que al utilizar adhesivo nos permite no necesitar cavidades retentivas, esto se traduce en una cavidad mucho más conservadora y aunque no se sigan utilizando las cavidades con su forma para amalgama, la numeración de estas cavidades se sigue utilizando. ${ }^{14}$

Sin embargo cabe señalar y no olvidar que el tipo de cavidades a las que se hace referencia en este trabajo son para la realización de cavidades Bronner ${ }^{19}$ fue uno de los primeros en sugerir que los principios biomecánicos para hacer 
las preparaciones de cavidades, podían aplicarse de una manera en que el resultado fueran restauraciones más conservadoras. Él sugiere una preparación donde la porción proximal en lugar, de tener paredes casi paralelas, presentaran una convergencia hacia oclusal, manteniendo solamente la extensión por prevención en la zona donde era más factible el desarrollo de nueva lesión por caries. Esto también redujo la apertura oclusal de la porción proximal dándole mayor resistencia a la porción remanente de la cresta marginal. Bronner, también fue uno de los primeros autores en sugerir que en la porción proximal podría aplicarse individualmente cada uno de los principios de la preparación para cavidades y poder así funcionar en forma independiente de la porción oclusal. ${ }^{19}$

Por otra parte es necesario considerar otros puntos importantes para obtener el éxito en nuestra restauración; las características del material que va a ser utilizado para la obturación de la cavidad que se va a preparar, la anatomía de la pieza dentaria, la edad del paciente, hábitos de higiene oral, la situación económica de la persona que acude a recibir el tratamiento dental, Figura 6.

Por último, y para evitar la repetición del proceso destructivo en zonas vecinas, en algunos casos es necesario extender los límites de la restauración a regiones más accesibles a la limpieza o más seguras. Bronner, fue uno de los primeros en sugerir que los principios biomecánicos para hacer las preparaciones de cavidades, podían aplicarse de una manera en que el resultado fueran restauraciones más

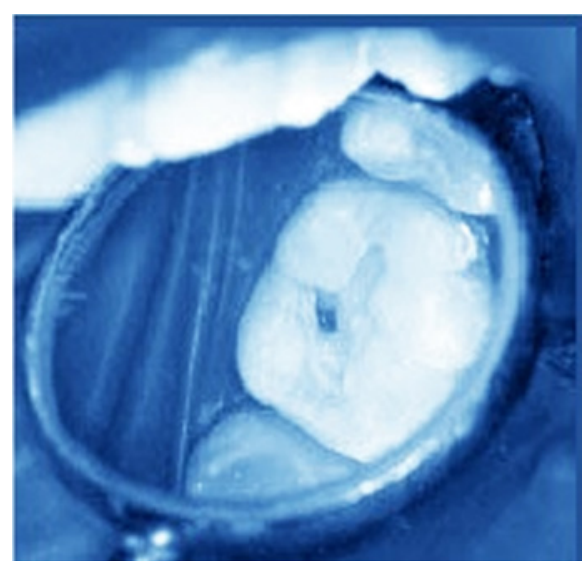

FIGURA 6 conservadoras. Es el socavado (preparación) que se hace en una pieza dentaria, cuando ésta ha perdido su equilibrio biológico y se hará una restauración en la misma estará constituida por paredes y piso o base. ${ }^{18,19,20}$

Él sugiere una preparación cavitaria donde la porción proximal en lugar de tener paredes casi paralelas, presentaran una convergencia hacia oclusal, manteniendo solamente la extensión por prevención en la zona donde era más factible el desarrollo de nueva lesión por caries. ${ }^{19}$

Esto también redujo la apertura oclusal de la porción proximal dándole mayor resistencia a la porción remanente de la cresta marginal. Bronner, también fue uno de los primeros autores en sugerir que en la porción proximal podría aplicarse individualmente cada uno de los principios de la preparación para cavidades y poder así funcionar en forma independiente de la porción oclusal. La anatomía de los molares primarios, con sus superficies oclusales fisuradas y áreas de contacto interproximal planas y amplias, los hacen que sean los dientes deciduos más propensos a caries. Las coronas de acero inoxidable, la amalgama y las resinas compuestas son los materiales que se utilizan en la restauración de estos dientes. ${ }^{19,20,21}$

En la imagen del molar se observan los límites de la cavidad, en el ecuador del diente, Figura 7 en la cual es necesario cuidar la pared o zona de la superficie del diente continuo, al momento de realizar la cavidad en la pieza afectada por el proceso carioso.

Ésta se puede proteger con una banda matriz, para proteger la pared, de tal forma que al momento de hacer la cavidad en la pieza donde localizamos el proceso carioso, para que no afectar el diente que se encuentra cercano a la pared que vamos a trabajar22, Figura 8. 


\section{Gurrola Martínez B \& Álvarez Bañuelos VJ}

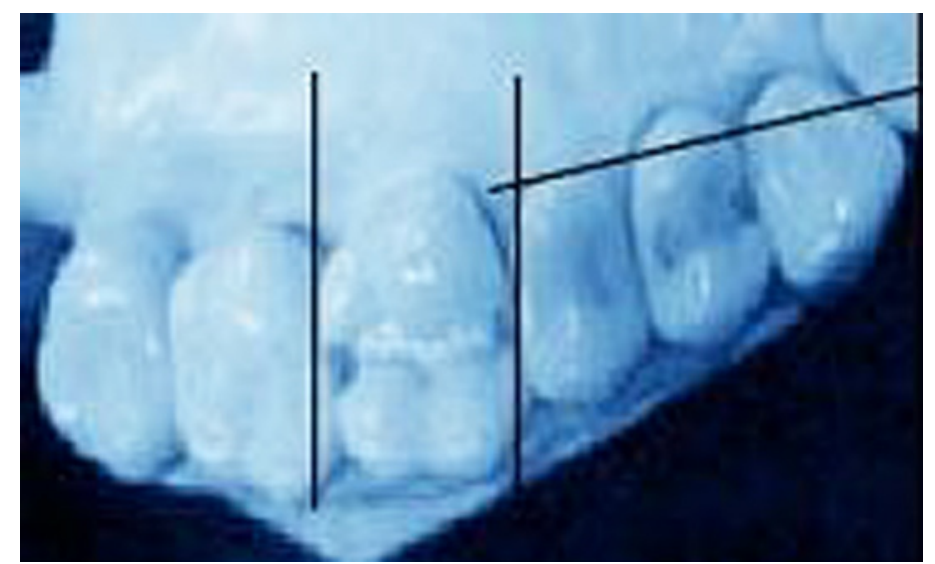

FIGURA 7

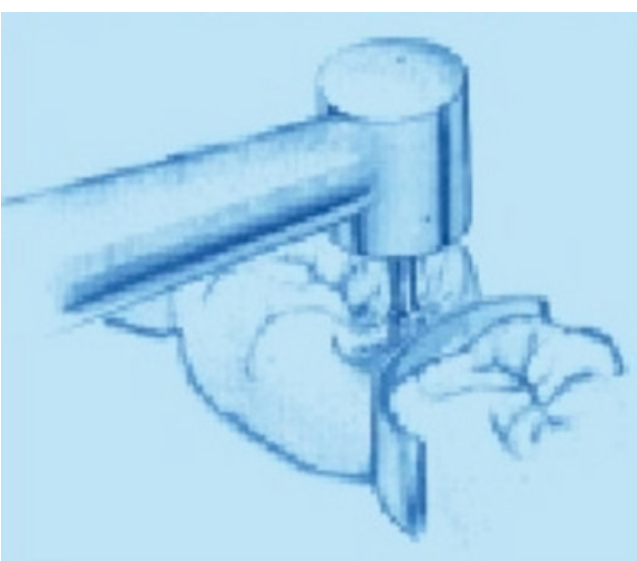

FIGURA 8

\section{¿Qué es una cavidad?}

Una cavidad es la forma artificial que realiza el odontólogo en el diente, siguiendo la forma de la caries, Figura 6, para poder reconstruirlo con materiales y técnicas adecuadas que le devuelvan su función dentro del aparato masticatorio, Figura 9.

Es también la brecha, hueco o deformación producida en el diente por procesos patológicos o traumáticos o defectos congénitos como la hipoplasia.

Cavidad es, por extensión del concepto, la forma interna o externa que seda a un diente para efectuarle una restauración con fines preventivos, estéticos, de apoyo, de sostén o reemplazo de otras piezas ausentes, Figura 10.

Las cavidades, para su estudio y ejecución se clasifican según su extensión: como simples, compuestas y complejas. Por su finalidad: terapéutica, estética, protésica, preventiva y mixta. ${ }^{17}$

De acuerdo a las caras comprometidas: oclusal, mesio oclusal, disto oclusal, mesio ocluso distal. Según su etiología, basada en las áreas de los dientes que presentan susceptibilidad a la caries y zonas de difícil acceso.

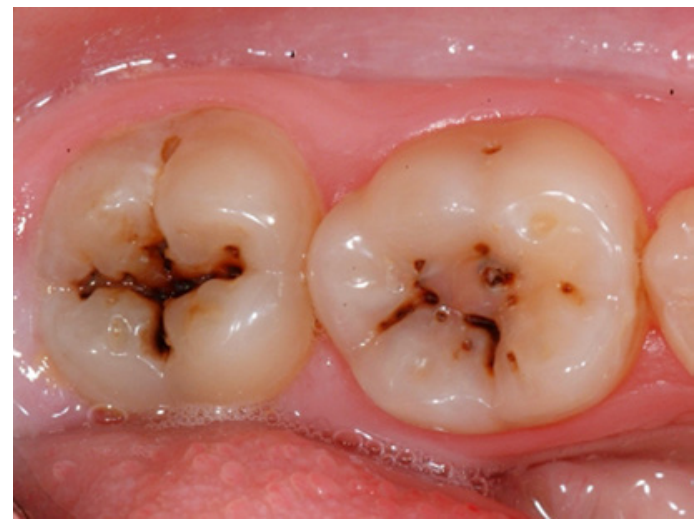

FIGURA 9

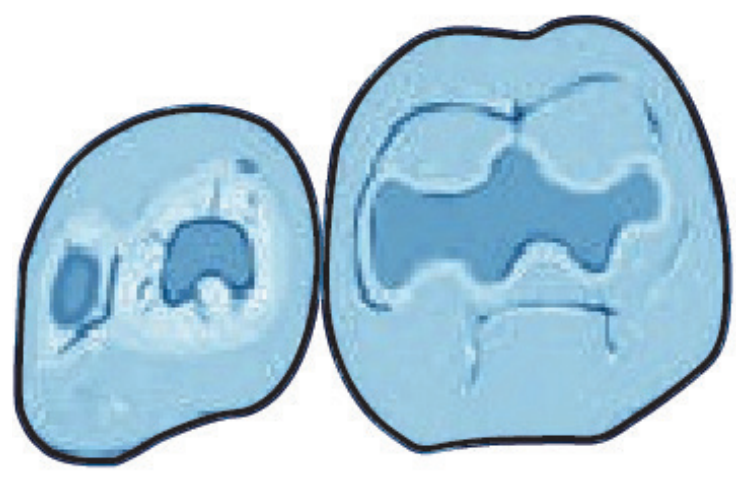

FIGURA 10

Autores como Mount y Hume ${ }^{21}$ idearon un sistema para la clasificación de las cavidades que vincula la localización, el tamaño y la susceptibilidad. Reconoce tres localizaciones: (a) puntos y fisuras, (b) áreas de contacto y (c) áreas cervicales. El tamaño de la lesión es considerada como: (1) lesión inicial, con posibilidad de remineralizción 
profesional, (2) lesión de caries más allá de la remineralización, (3) cúspides socavadas por caries o posible fractura cúspidea debida a caries y (4) pérdida de la cúspide o del borde incisal.

La clasificación de las cavidades reúne ambos criterios construyendo un índice compuesto, que fue revisado incluyendo la categoría de no hay cavidad expresada con el cero (Mount et al.; Lanata 2008) La localización permite diferenciar tres zonas de susceptibilidad (Zonas 1 a 3$)^{21,23 .}$

\section{ZONA 1}

Fosas, fisuras y defectos del esmalte en las superficies oclusales de los dientes posteriores y otros defectos en superficies lisas así como los cíngulos y fosas de los dientes anteriores.

\section{ZONA 2}

Zona proximal de cualquier diente (anterior o posterior) situada inmediatamente por debajo del punto de contacto de dientes adyacentes.

\section{ZONA 3}

Tercio gingival de la corona o en caso de recesión gingival, raíz expuesta.

Índice de Mount y Hume: tienen una clasificación de lesiones en superficies dentarias. Sobre el tamaño lo que permite diferenciar 5 niveles: 0: Lesión activa sin cavidad que representa la etapa inicial de la desmineralización, como la "mancha blanca". No requiere tratamiento restaurador. Tratamiento recomendado: remineralización y/o sellante..$^{21}$

- Tamaño 1: Lesiones con alteración superficial que ha progresado y donde la remineralización resulta insuficiente y se requiere tratamiento restaurador. Restauración sobre una preparación mínimamente invasiva.

- Tamaño 2: Lesión moderada con cavidad localizada, la cual ha progresado dentro de la dentina sin producir debilitamiento de las cúspides. Requiere tratamiento restaurador. Restauración/preparación mínimamente invasiva, aunque de mayor tamaño.

- Tamaño 3: Lesión avanzada con cavidad que ha progresado en dentina ocasionando debilitamiento de cúspides. Requiere tratamiento restaurador. Preparación de una cavidad para una restauración de tipo directo o indirecto, para el restablecimiento de la función y el reforzamiento de la estructura dental remanente.

- Tamaño 4: Lesión avanzada concavidad, que ha progresado al punto donde hay destrucción de una o más cúspides. Requiere tratamiento restaurador. Cavidad extensa para restauración indirecta para el restablecimiento de la función y el reforzamiento de la estructura dental remanente, presentaron un concepto moderno de la clasificación de cavidades que es por los sitios y los estadios. Existen 3 sitios de susceptibilidad a la caries que son las áreas donde la placa dental o biofilm tiende a acumularse. Cuadro 1. 


\section{Gurrola Martínez B \& Álvarez Bañuelos VJ}

\begin{tabular}{l|l|l|}
\multicolumn{3}{|c|}{ Sitios de susceptibilidad a la caries } \\
$\begin{array}{l}\text { Lesiones cariosas iniciadas } \\
\text { en hoyos, fisuras, fosas } \\
\text { en superficies oclusales, } \\
\text { vestibulares y linguales } \\
\text { de todos los dientes y } \\
\text { otros defectos sobre todas } \\
\text { las superficies planas de } \\
\text { la corona (excepto las } \\
\text { proximales). }\end{array}$ & $\begin{array}{l}\text { Lesiones cariosas iniciadas } \\
\text { sobre superficies proximales } \\
\text { de todos los dientes. }\end{array}$ & $\begin{array}{l}\text { Lesiones cariosas iniciadas } \\
\text { sobre superficies coronarias o } \\
\text { radiculares en el área cervical } \\
\text { de todos los dientes. }\end{array}$ \\
\hline \multicolumn{1}{|c|}{ (I y VI) } & & Sito 3 \\
\hline
\end{tabular}

CUADRO 1. MOUNT Y HUME.

Cada sitio tiene 4 estadios de progresión a la caries que corresponden a la extensión y tamaño de la lesión con referencia a guías anatómicas y radiológicas. Cuadro 2. Esta clasificación excluye lesiones cariosas detectables diagnosticadas para tratamientos no invasivos.

\begin{tabular}{|l|c|c|c|c|c|}
\hline \multicolumn{1}{|c|}{ Tamaño Zona } & $\begin{array}{c}\text { No hay } \\
\text { cavidad }\end{array}$ & $\begin{array}{c}\text { Tamaño 1 } \\
\text { Mínimo }\end{array}$ & $\begin{array}{c}\text { Tamaño 2 } \\
\text { Moderado }\end{array}$ & $\begin{array}{c}\text { Tamaño 3 } \\
\text { Grande }\end{array}$ & $\begin{array}{c}\text { Tamaño 4 } \\
\text { Extenso }\end{array}$ \\
\hline 1. Fosas y fisuras & 1.0 & 1.1 & 1.2 & 1.3 & 1.4 \\
\hline 2. Proximal & 2.0 & 2.1 & 2.2 & 2.3 & 2.4 \\
\hline 3. Cervical & 3.0 & 3.1 & 3.2 & 3.3 & 3.4 \\
\hline
\end{tabular}

\section{CUADRO 2. ÍNDICE DE MOUNT Y HUME.} CLASIFICACIÓN DE LESIONES EN SUPERFICIES DENTALES 2006.

Etapa 0 : Lesión activa sin cavitación, tratamiento restaurador no necesario.

Etapa 1: Lesiones con alteración al esmalte dental, requiere de tratamiento restaurador.

Etapa 2: Lesiones moderadas con cavitación localizada, ha progresado dentro de la dentina sin producir debilitamiento de cúspides, requiere de tratamiento restaurador.

Etapa 3: Lesiones avanzadas con cavitación que ha progresado en dentina ocasionando debilitamiento de cúspides, requiere de tratamiento restaurador.

Etapa 4: Lesiones avanzadas con cavitación que ha progresado y destruido una o más cúspides, requiere de tratamiento restaurador.

Recordando que la clasificación de cavidades tiene una finalidad. 


\begin{tabular}{|l|l|l|}
\multicolumn{3}{|c|}{ Clasificación cavidades } \\
\hline Terapéutica & Estética & Protésica su Finalidad \\
\hline Preventiva & Mixta & \\
\hline \multicolumn{3}{|c|}{ Según su Extensión } \\
\hline Simple & Compuestas & Complejas \\
\hline \multicolumn{3}{|c|}{ Según su Etiología } \\
\hline Fosas y fisuras & Superficies lisas & \\
\hline
\end{tabular}

Las cavidades terapéuticas, se pueden clasificar teniendo en cuenta su situación, su extensión y su etiología, Figura 11.

Las proximales, que también se denominan intersticiales, son las cavidades que afectan las paredes mesiales, dístales o mesio-ocluso-distales.

Las expuestas son las cavidades oclusales, bucales o linguales, en la imagen se observa un corte de tajada en la pared proximal, Figura 12.

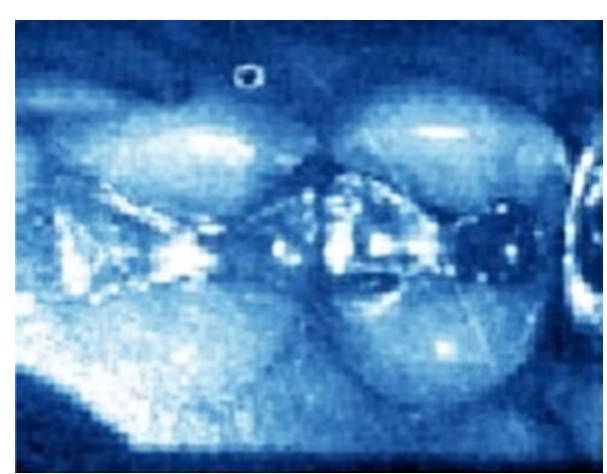

FIGURA 11

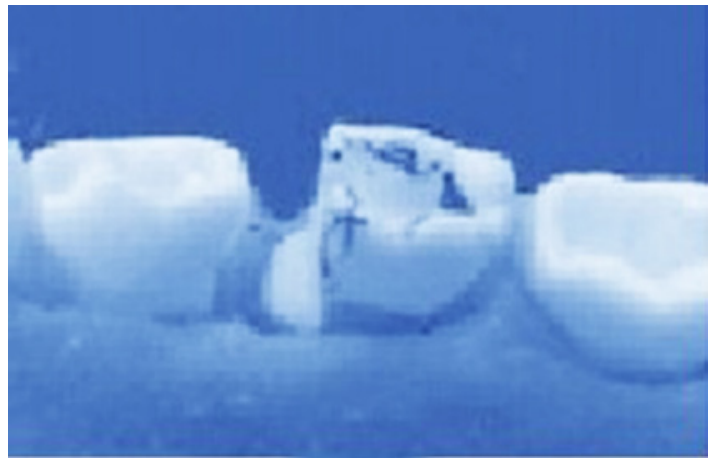

FIGURA 12

Según su extensión: simples, compuestas y complejas: Las simples incluyen solo una superficie del diente, como la cara oclusal de la Figura 13.

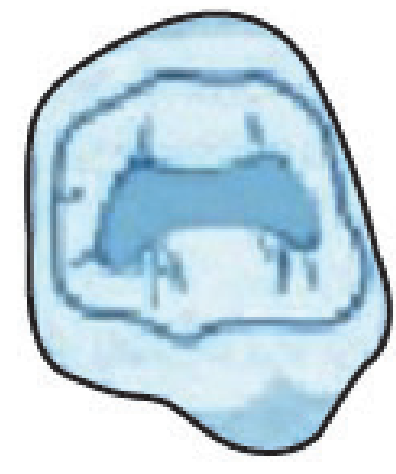




\section{Gurrola Martínez B \& Álvarez Bañuelos VJ}

Las compuestas abarcan dos superficies, pueden ser en una superficie ocupando la misma cara oclusal, en la imagen se observa el surco lingual y la cara oclusal, según su situación pueden ser: proximales y expuestas, Figura 14.
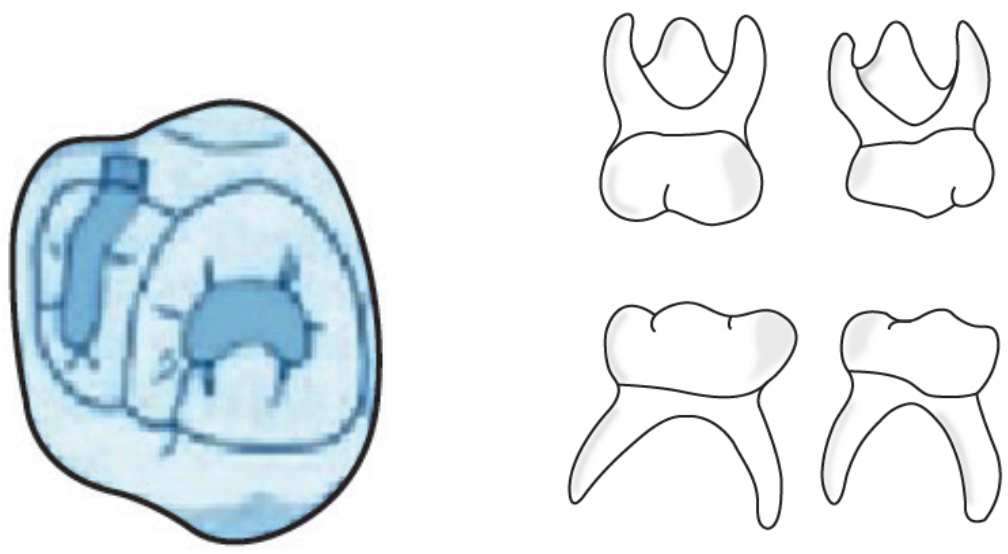

FIGURA 14

\section{Las complejas}

Cuando abarcan más de tres superficies como la vestíbulo-ocluso-palatino, por otro lado, es necesario conocer e identificar lo que es una fosa, punto, surco y fisura para la realización de la preparación de cavidades, Figura 15.

Existen diversos conceptos de acuerdo a los autores Zabotinsky y Siutti, citados por Parula ${ }^{22}$ ejemplo: Estos términos se emplean comúnmente para denominar a los accidentes anatómicos habituales en la topografía dentaria, hablan de defectos estructurales al referirse a un surco o una fosa que llegue a dentina, y los denomina surco y fosa fisurados respectivamente, Figura 16. Siutti, citado por Parula, los definen de la manera siguiente: Los puntos y las fisuras representan situaciones patológicas porque difieren de la estructura normal dentaria. ${ }^{22}$

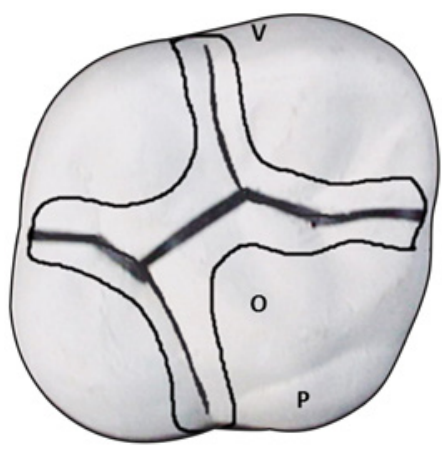

FIGURA 15

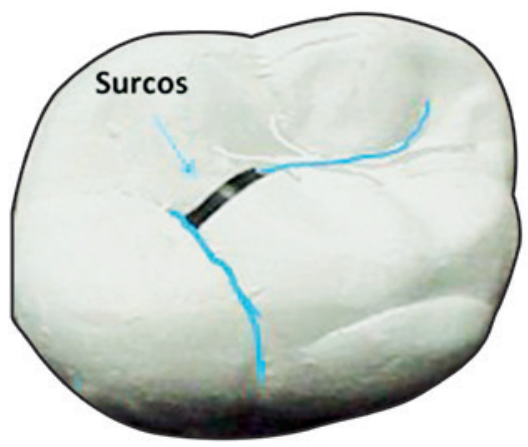

FIGURA 16

Por lo que deben ser considerados en toda preparación cavitaria pues representan sitios ideales para la iniciación y el desarrollo de la fosa, Figura 17, que es la depresión que da origen a 1 o más surcos con fondo en esmalte. 
Punto: fosa que llega a dentina. Surco: extensión lineal de la depresión, sin atravesar el esmalte. Fisura: surco que llega a dentina, la caries se observa en el corte sagital.
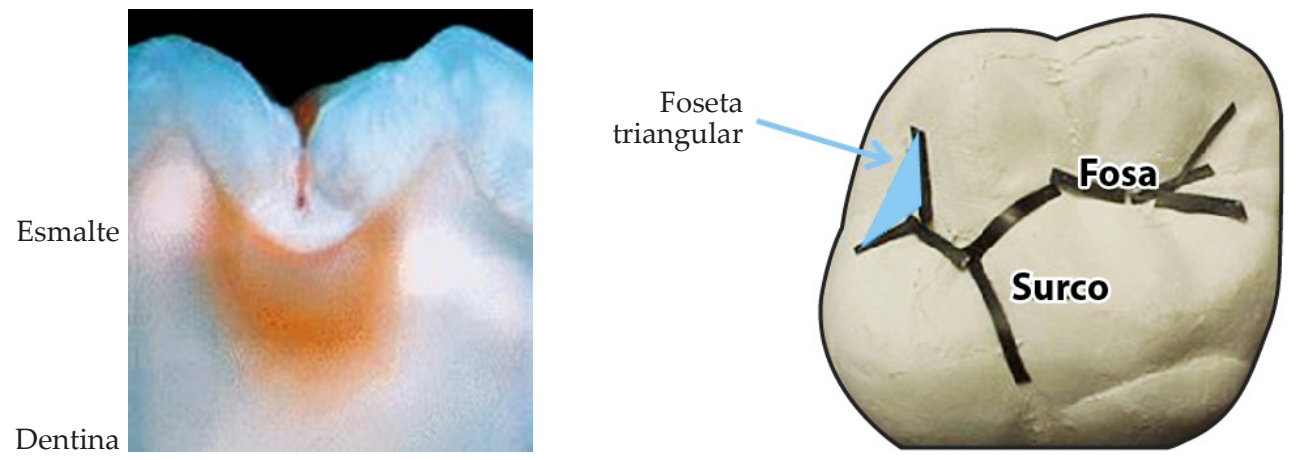

FIGURA 17

\section{Nomenclatura}

$\mathrm{E}$ n la preparación de cavidades dentarias se utiliza una terminología específica para referirse a cada una de las paredes, los ángulos, las caras, superficies dentarias. Éstas las pueden relacionar con los cuerpos geométricos. Poseen caras, ángulos diedros: axiopulpar. Ángulos triedros como: axio, pulpo distal.

Cuando iniciamos la excavación para preparar una cavidad en un diente para su posterior restauración, siempre tendremos cuidado en referirnos adecuadamente con el nombre que le corresponde al sitio donde estemos trabajando, al realizar la cavidad. ${ }^{22}$

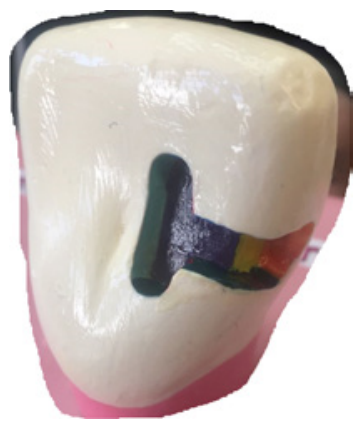

Así por ejemplo recordemos que los ángulos diedros son ángulos internos, redondeados para reducir la tensión interna del diente durante la masticación, que podría determinar la fractura dentaria. Están formados por la unión de 2 paredes, son una combinación de las paredes circundantes que son los límites internos de la cavidad. O una pared circundante y pared de fondo reciben el nombre de la cara del diente vestibular, palatina o lingual mesial, distal en color verde. Pared de fondo corresponde al piso de la cavidad se dividen en Axial que es la paralela al eje longitudinal del diente (vertical), pulpar perpendicular al eje longitudinal del diente horizontal rojo, gingivo axial.

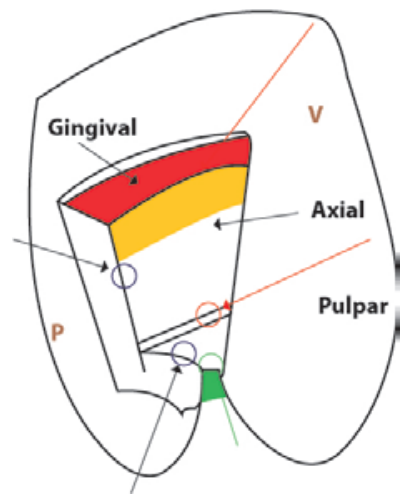




\section{6

En las cavidades encontramos también ángulos triedros, estos se localizan cuando se encuentran 3 superficies en una arista, dos paredes circundantes y una de fondo entonces para nombrar el punto, decimos la combinación de los nombres de las superficies mesio-pulpo-vestibular. $\mathrm{O}$ dos de fondo y una circundante por ejemplo: axiogingivo-palatino.
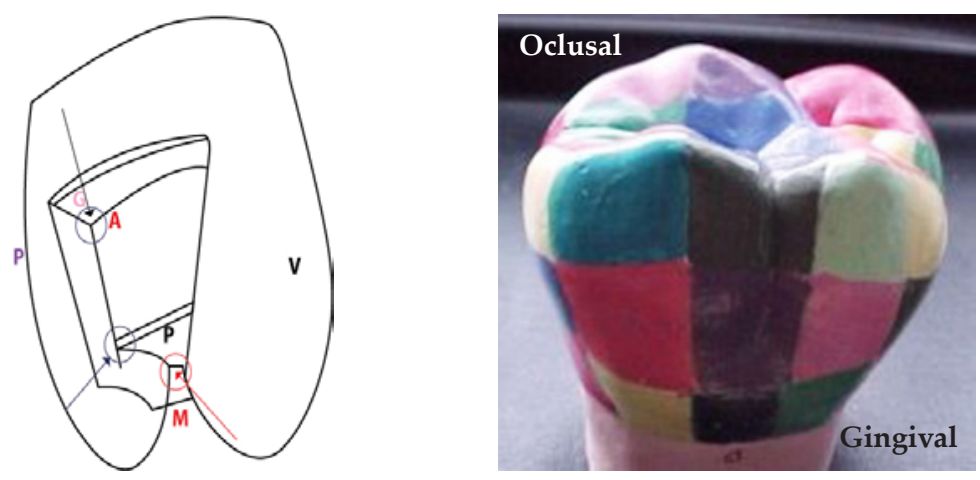

Recordar que es necesario conocer y tomar en cuenta el nombre de cada una de las superficies, de la pieza dentaria para poder formar los nombres de los ángulos, paredes y planos.

De acuerdo al corte y plano imaginario en el que estés trabajando como: axial paralelo, horizontal, vertical, oclusal y tercios.

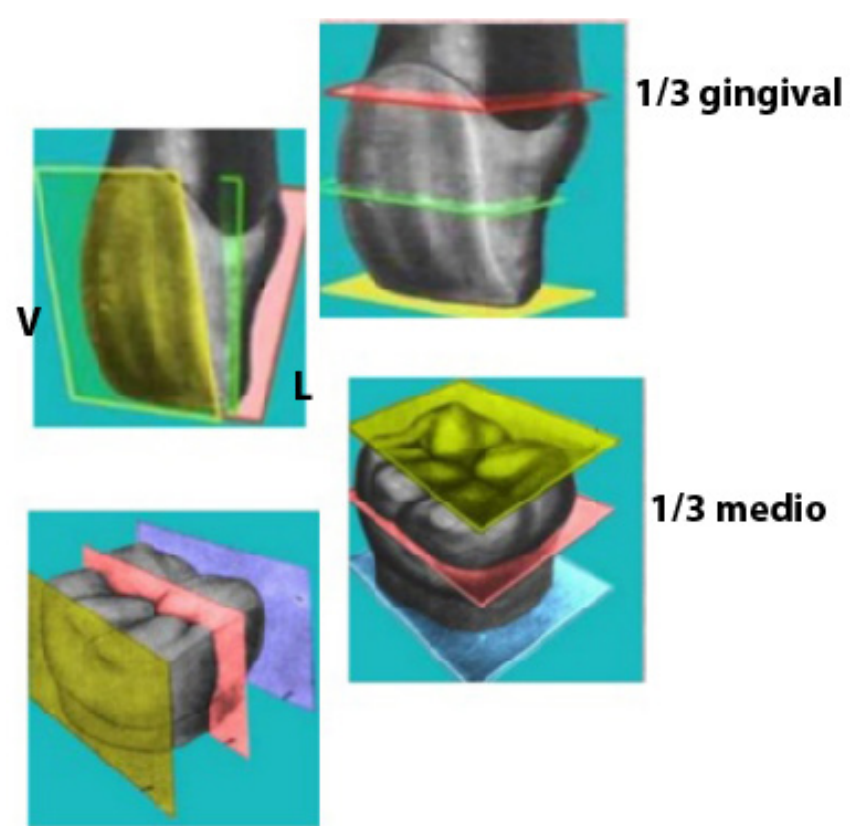

Porque en la preparación de una cavidad tendremos paredes, ángulos, los cuales nos ayudan a referir exactamente el sitio hasta donde está delimitada nuestra cavidad. Así por ejemplo, en la cavidad primera clase se pueden identificar los siguientes: 
Paredes:

1. Bucal

2. Lingual

3. Mesial

4. Distal

5. Piso pulpar

Ángulos diedros:

6. Mesiodistal

7. Mesiolingual

8. Bucopulpar

9. Mesiopulpar

Ángulos cavosuperficiales:

10. Ángulo cavosuperficial bucal

11. Ángulo cavosuperficial lingual bucal

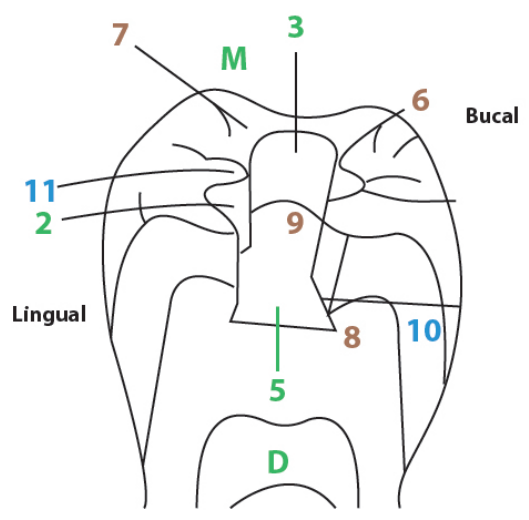

Para indicar exactamente el sitio donde se hace la cavidad, de acuerdo a esta nomenclatura, tenemos entonces las siguientes: paredes en las piezas dentarias anteriores bucal, labial, vestibular, mesial, distal, incisal y palatina para las piezas superiores, Figura 18.

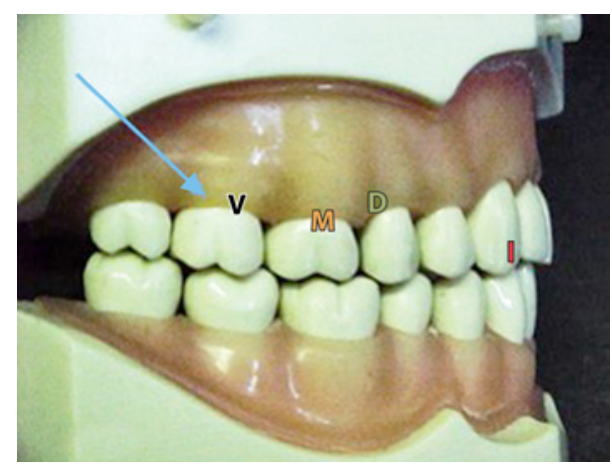

FIGURA 18

Las caras toman el nombre del reparo anatómico más cercano que varía según la ubicación del diente dentro del aparato masticatorio.

En incisivos y caninos es el borde incisal y en molares oclusal. Todo lo que mira hacia la línea media de la boca, en sentido antero-posterior se denomina mesial y la cara opuesta se llama distal, Figura 19.

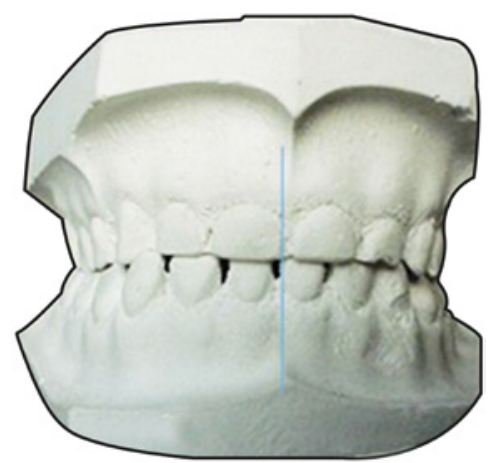

FIGURA 19 


\section{8 \\ Gurrola Martínez B \& Álvarez Bañuelos VJ}

En el caso de las piezas inferiores se le da el nombre de lingual en lugar de palatina, por estar más cerca de la lengua.

Con la respectiva división de los tercios horizontales: oclusal o incisal, medio y cervical, Figura 20.

Así mismo todas las piezas dentarias las dividimos en sentido vertical de tal forma que tenemos tercio proximal distal, tercio medio, tercio mesial. La nomenclatura que tenemos para piezas dentarias posteriores inferiores bucal, mesial, distal, oclusal y lingual, Figura 20.
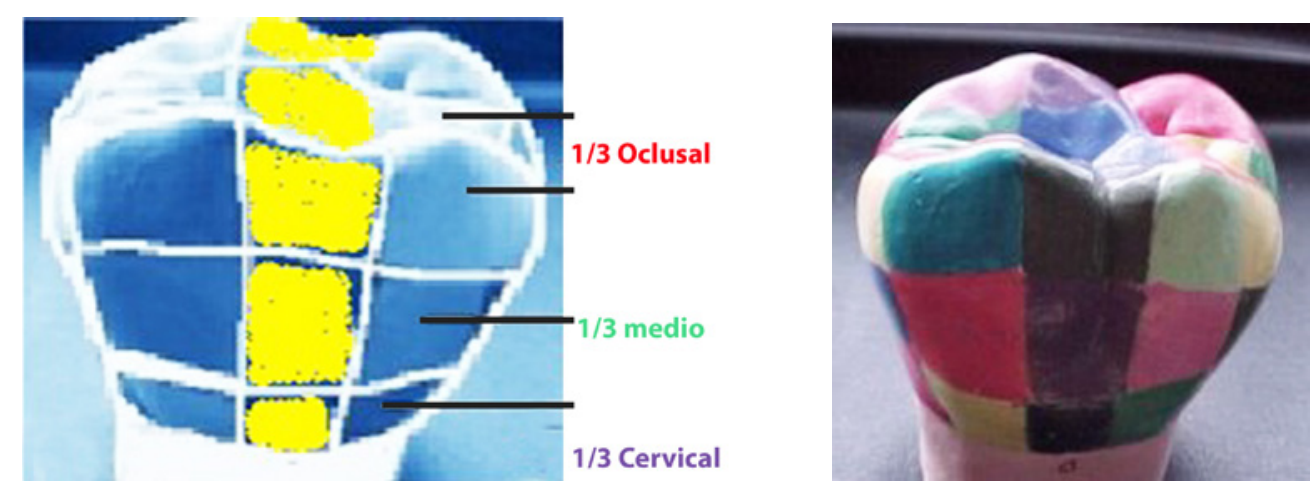

FIGURA 20

Se muestran las generalidades de la clasificación de cavidades de Black, por ser la base para la preparación de cavidades, en dentición infantil y permanente. Para las tipo Bronner la cual fue introducida en 1931 se explicará más adelante.

\section{Localización de las superficies que abarcan las cavidades}

\section{Cavidades clase I}

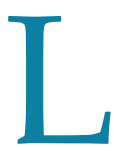

a cavidad es una forma diseñada, creada, determinada, producida por el odontólogo con el objetivo de restaurar la pieza dentaria afectada por caries, de forma Interna y externa. Se localizan en las paredes dentinarias, según Black dependiendo de la profundidad. Cuando comienzan en las caras oclusales, se pueden desarrollar, en los defectos de la superficie dentaría en:

Fosas, puntos, surcos o fisuras oclusales de dientes posteriores molares, Figura 21, o en la cara lingual (o palatina) de incisivos y caninos fosas y

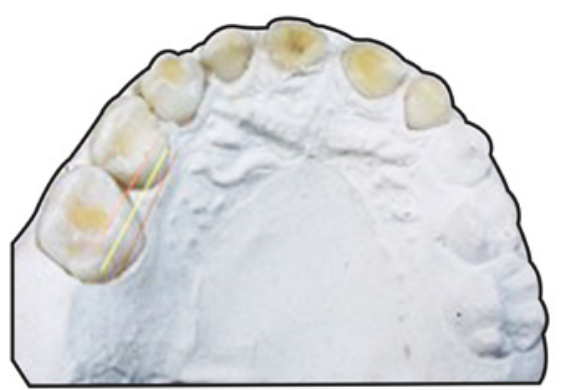

FIGURA 21 también en surcos bucales o linguales de molares, ya sean superiores o inferiores. 
En este caso, considerando que ya se tienen los conocimientos teóricos, ¿cuál sería la indicación para obturar el primer molar de la siguiente imagen? Lo indicado, seria realizar una cavidad clase I. Y se restauraría con amalgama, o con resina fotopolimerizable, en cualquier de los casos el diseño deberán sustituir y abarcar todas las fisuras de retención y las áreas que tengan caries, pero debe ser lo más conservadora posible, como se observa en la imagen inferior, respetando lo más posible de las cúspides y crestas marginales.
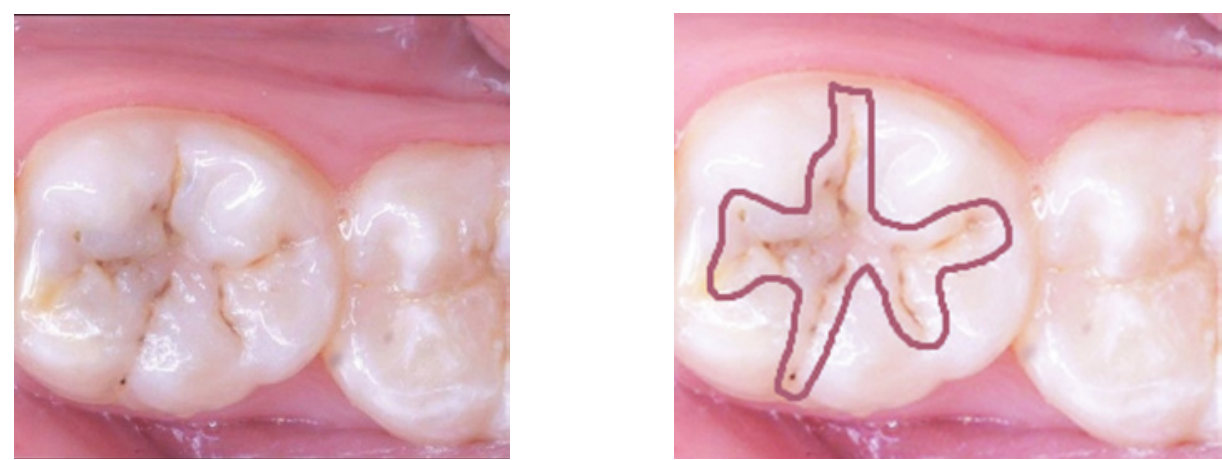

El diseño se hará considerado: la superficie cariada, la anatomía del diente, la posición en la arcada, la edad del paciente. Seria superficial dependiendo de la profundidad de la caries, aunque por lo regular en este tipo de caries superficial, lo normal como sugiere la literatura es con una profundidad hacia el piso pulpar no mayor de $0.5 \mathrm{~mm}$, Figura 22.
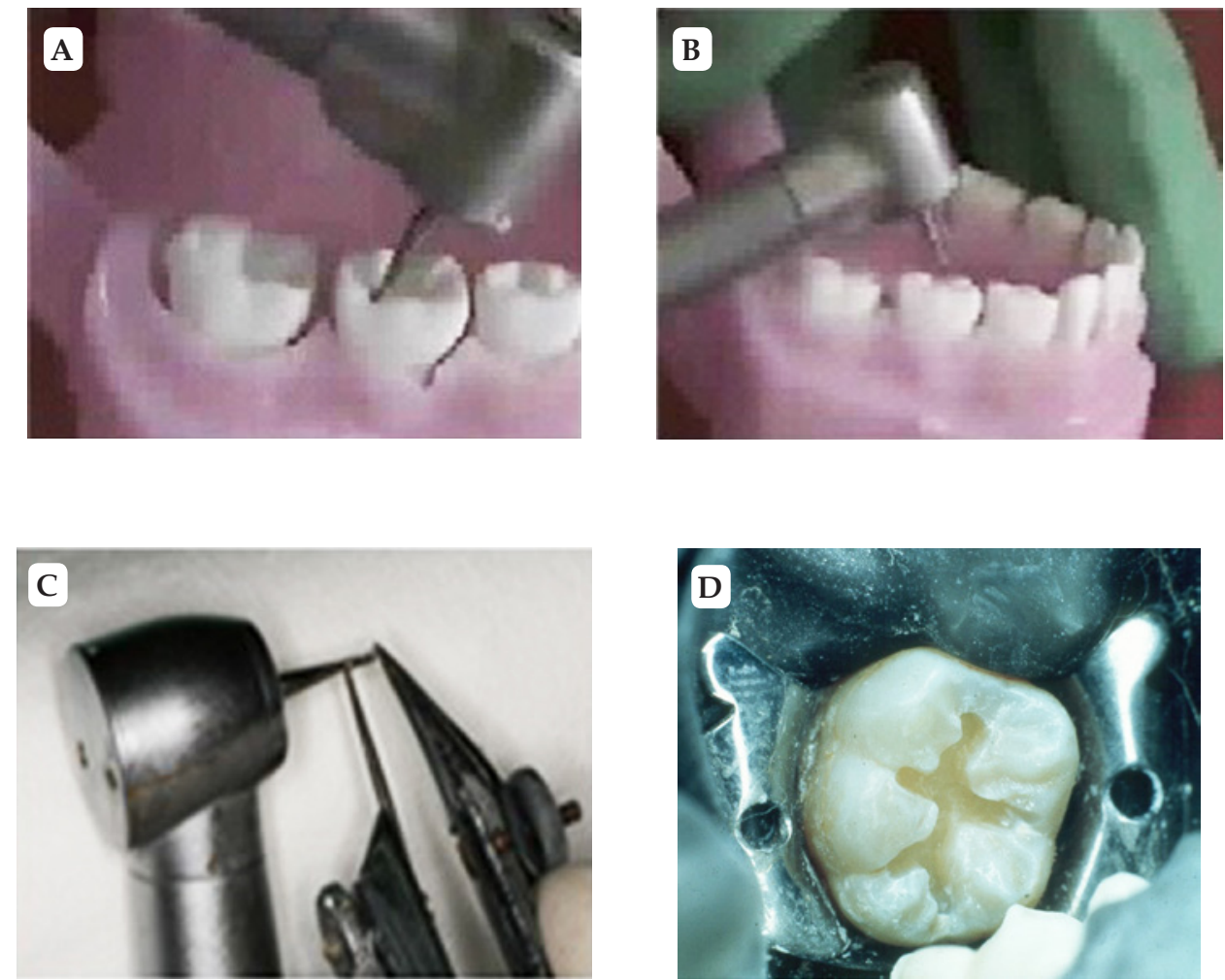

FIGURA 22 
En la imagen Figura 22b se puede ver el tamaño de la fresa medida con el vernier, indicando la profundidad de la cavidad, la inclinación de la pieza de mano y la cavidad ya terminada Figura 22d.

\section{Cavidades clase II}

De acuerdo a Black, éstas se realizan en las superficies proximales de piezas posteriores como premolares y molares; en el caso de la dentición infantil, las tipo Bronner sólo en los molares, Figura 23a.

Los tiempos operatorios, es el método utilizado para el ordenamiento de las maniobras necesarias para la preparación cavitaria; las cuales deben cumplir con requerimientos biológicos, mecánicos, estéticos y preventivos.

Estas pueden extenderse y ocupar caras o superficies dentarias mesial y distal, además de la cara oclusal, Figura 23a 23b, 23c. En la imagen del molar infantil el diseño de la cavidad será mayor está, en la pared proximal, Figura 23d.
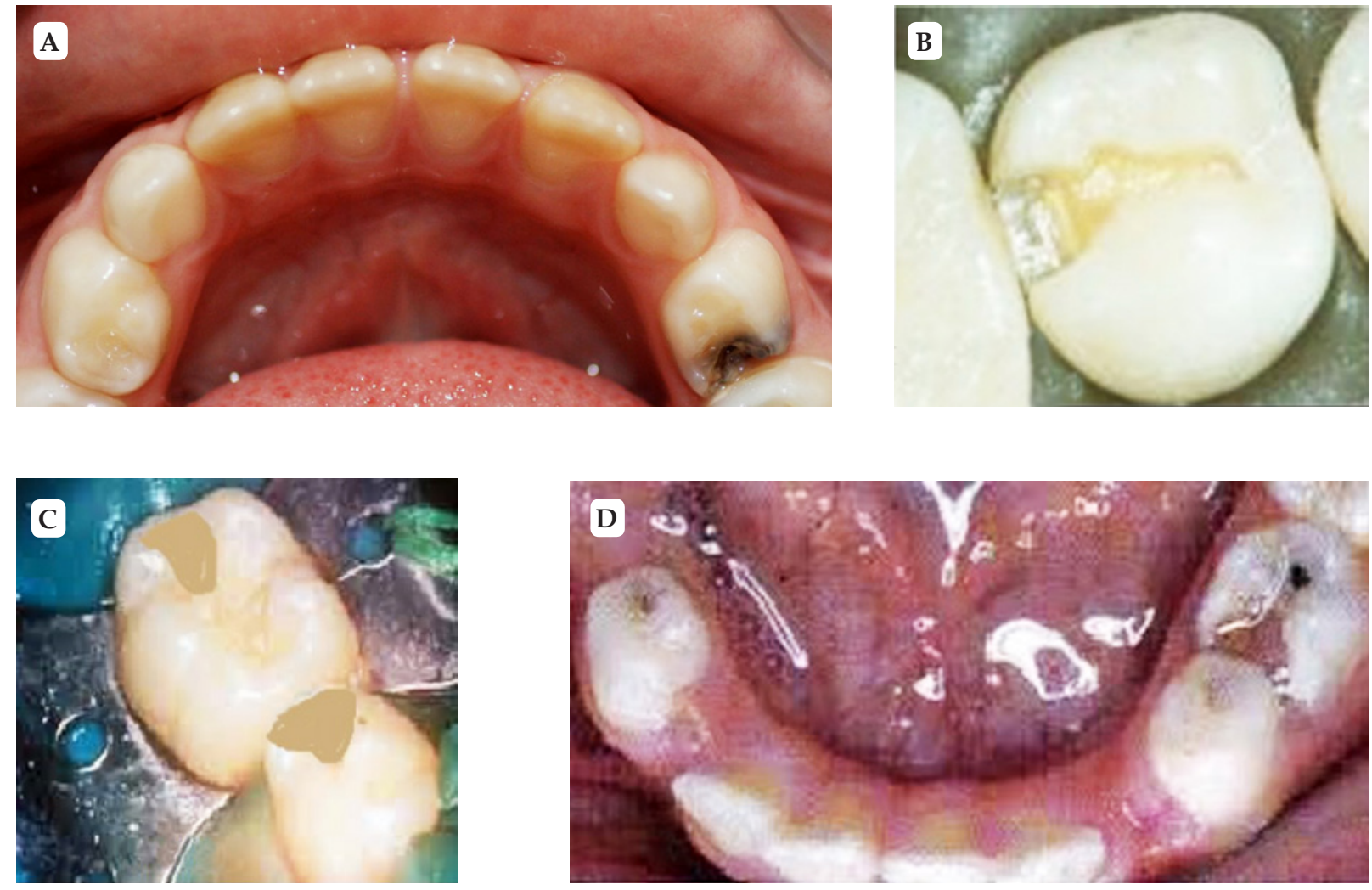

FIGURA 23

\section{Cavidades clase III}

Se localizan en dientes anteriores en las paredes, se realiza en las superficies proximales de los dientes anteriores, incisivos centrales, laterales y en caninos superiores e inferiores, en el tercio medio, Figura 24, que no abarquen el ángulo incisal. 

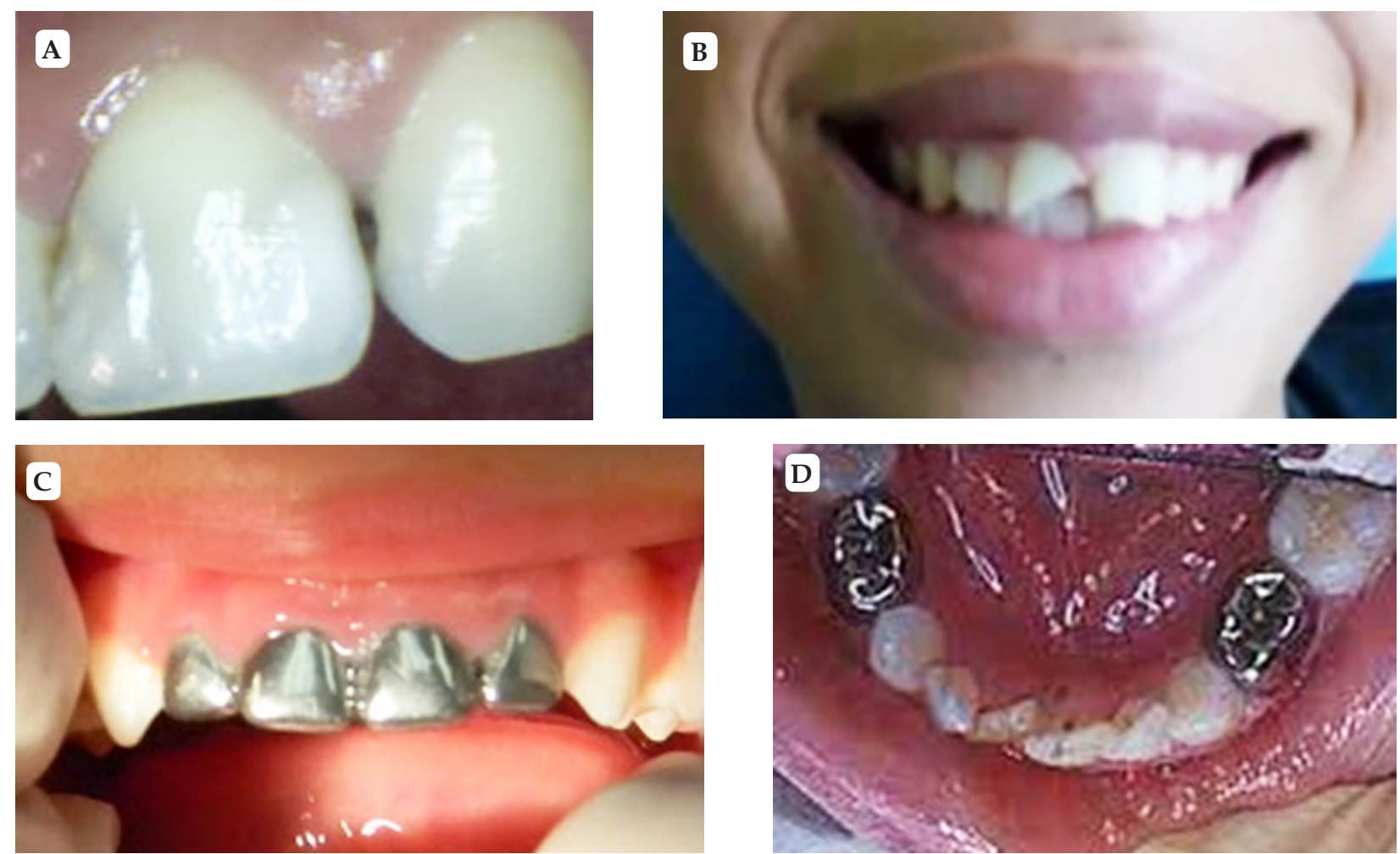

FIGURA 24

\section{Clase IV}

En las superficies proximales de los dientes anteriores, incisivos y caninos, abarcando el ángulo incisal, Figura 25. Éstas son causadas por traumatismos, sin embargo no se describirá por el espesor del esmalte en los dientes infantiles, en el caso de tener el diente muy destruido se recomienda, realizar una preparación de munón para colocar coronas de acero cromo. Las coronas de acero ofrecen las mejores ventajas como materiales de restauración, siempre que se coloquen correctamente: durables, económicas y funcionalmente satisfactorias.
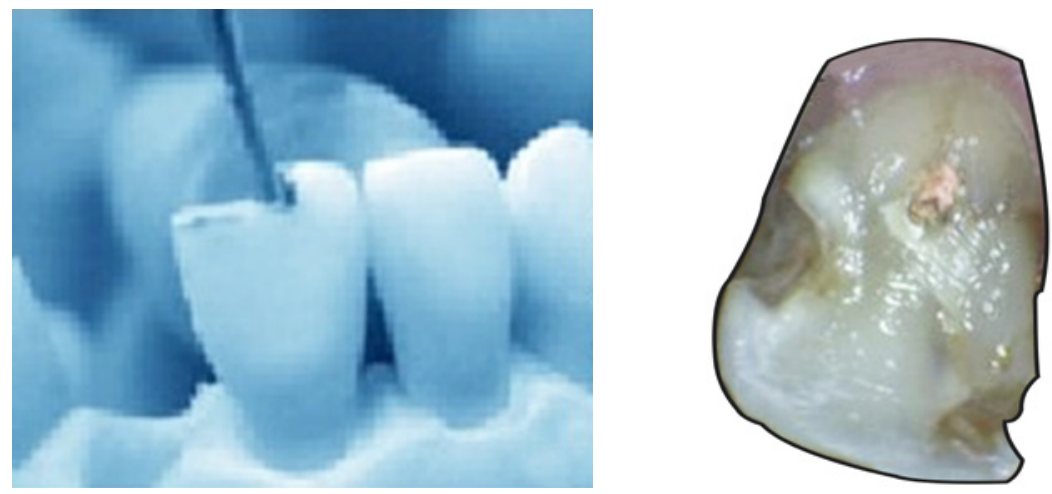

FIGURA 25 
Se conservan en la boca hasta la exfoliación, manteniendo un buen crecimiento y desarrollo de los maxilares con una dimensión vertical adecuada.

Sin embargo tienen un inconveniente, no son estéticas, lo cual puede ser un obstáculo en el momento de plantear el tratamiento al paciente.

En la Figura 25 podemos observar una cuarta clase, pero la del lado izquierdo es una cavidad tipo Black en el central, las paredes son rectas y en la imagen derecha, el incisivo lateral con la retención Bronner.

\section{Clase V}

Se localizan en el tercio gingival de todos los dientes en las superficies vestibular o palatina en el caso de los dientes superiores y en el caso de los inferiores en las superficies vestibular y lingual. En la imagen podemos observar el diseño de la cavidad en la cara vestibular.

Cabe señalar que en las cavidades III, IV y V, infantiles, actualmente se utilizan como material de restauración las coronas de policarboxilato en caso de dientes anteriores muy destruidos y/o coronas de acero-cromo en dientes anteriores y posteriores, Figura 26a, b y c.
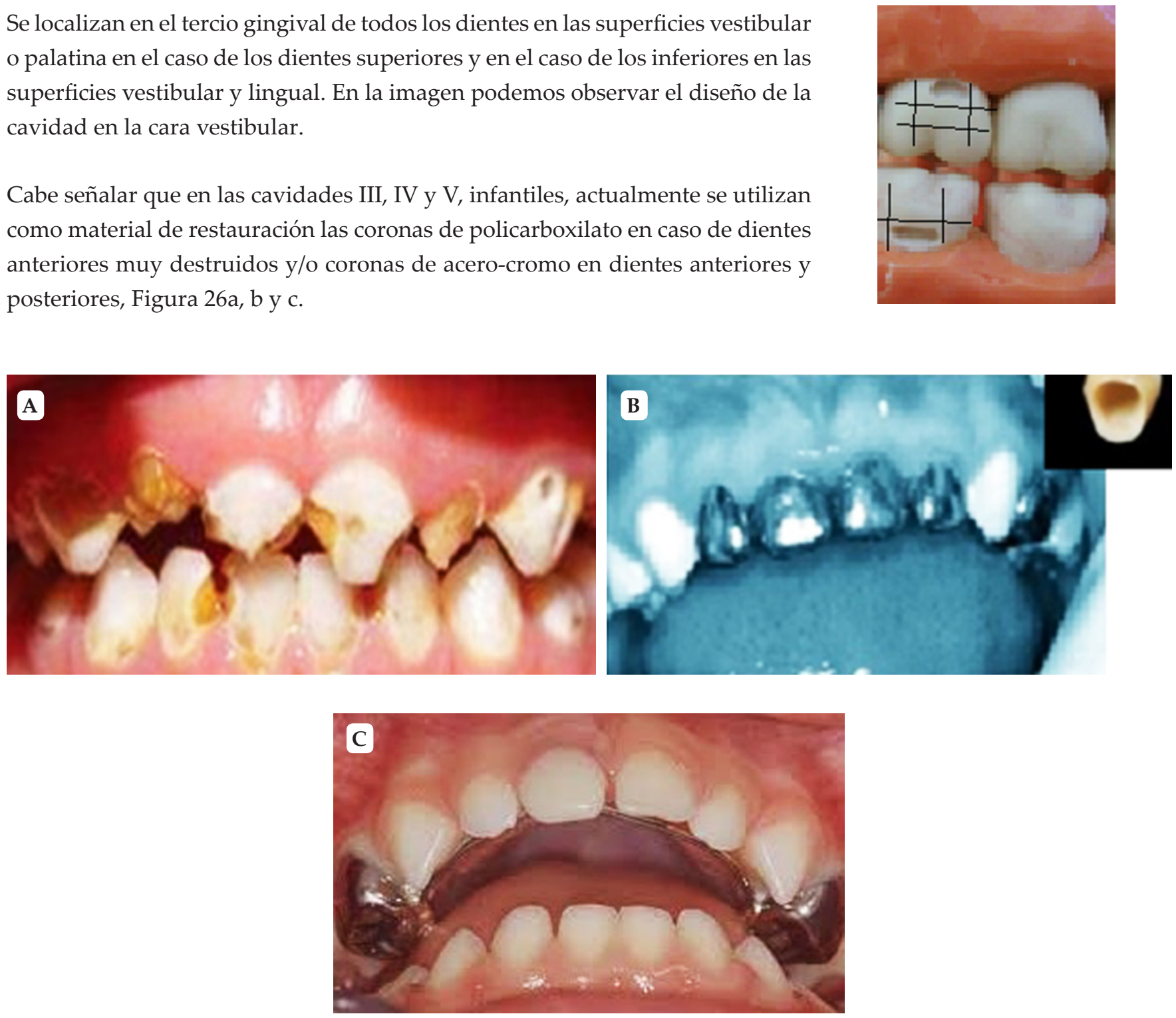

FIGURA 26 
Por otra parte es necesario recordar a Black, considerado como un pilar en la odontología, que en 1924, detalló la técnica de la preparación de cavidades y sentó ciertos principios a seguir, sus recomendaciones han resistido la prueba del tiempo y algunos todavía son aplicables, tanto para los dientes temporales como los permanentes, y responden a los siguientes principios:

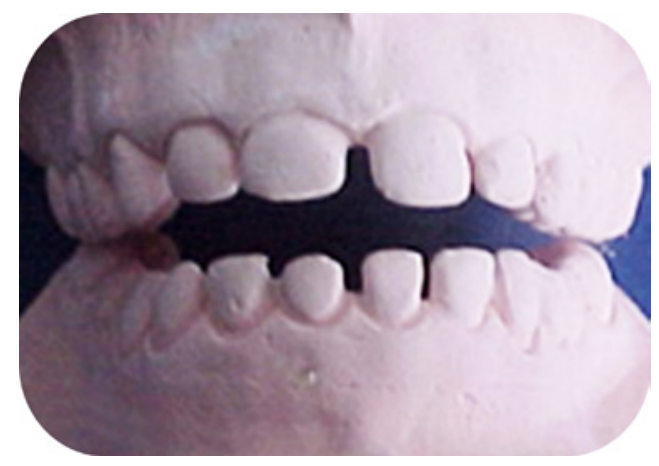

\section{Establecer su forma.}

3. Eliminar la caries.

4. Establecer la forma de resistencia y retención.

5. Pulido y limpieza de la cavidad.

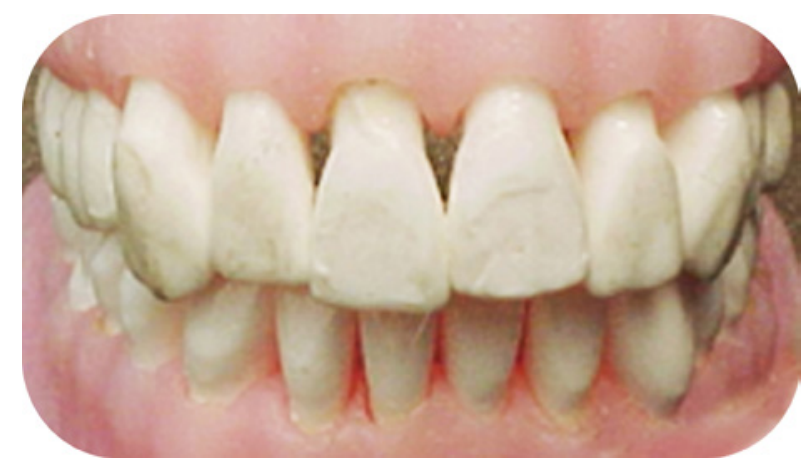

\section{Condiciones}

$\mathrm{E}$ s importante considerar que para la preparación de cavidades y obturaciones de los dientes de la primera dentición se realizarán las cavidades tipo Bronner, Figura 27, ya que ellas difieren en cuanto al tipo de retención que se debe manejar en las paredes de la superficie dentaria, en la cual se localiza la cavidad, comparando con las cavidades tipo Black, que son paredes paralelas al piso de la cavidad (las líneas color amarillo).
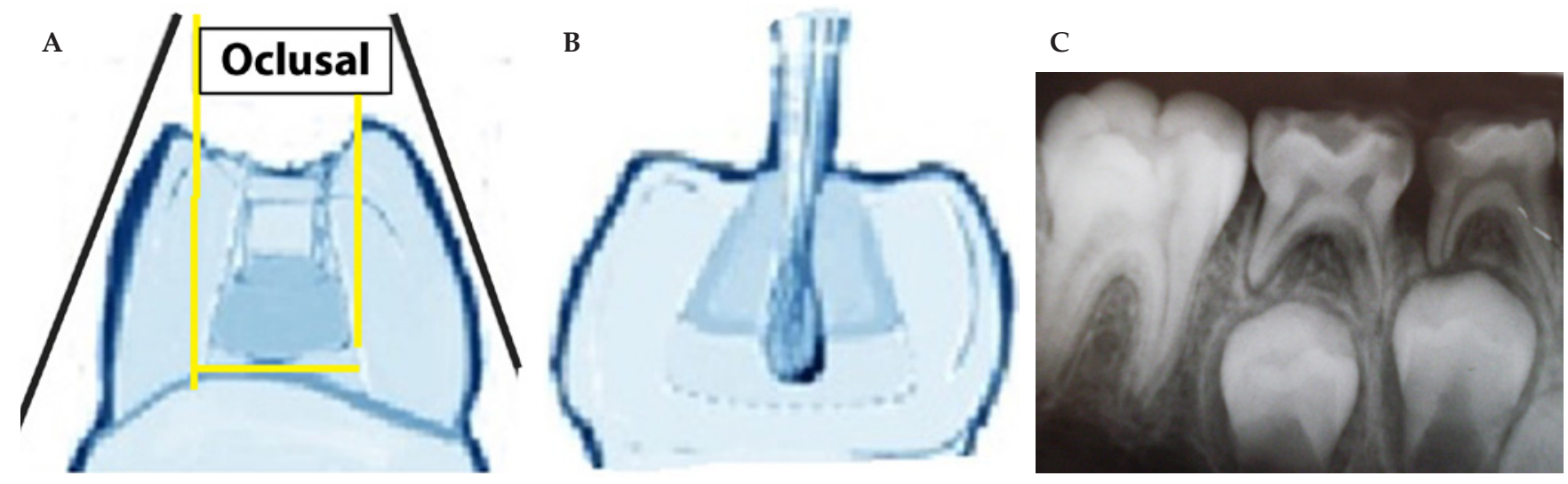

FIGURA 27 


\section{4 \\ Gurrola Martínez B \& Álvarez Bañuelos VJ}

Las diferencias que encontramos en las Bronner son las paredes convergentes hacia oclusal, determinadas por la anatomía de la pieza dentaria exterior, pisos cóncavos y ángulos redondeados.

En la vista de corte axial de la pieza dentaria, la cavidad, se inicia sin diente vecino que impida entrar por proximal. Se hará el acceso y se continua con el diseño por oclusal, Figura 27, cuando sea el caso, se basa en la utilización de fresas de pera, cono invertido para lograr la profundidad de los pisos, utilizando también las fresas de cono invertido, se debe evitar la comunicación pulpar, tomando una radiografía de control, Figura 27c.

En este tipo de preparación de cavidades y obturaciones en los dientes de primera dentición, se debe tener cuidado con los cuernos pulpares. Se puede observar los pisos cóncavos para librar los cuernos pulpares, así como los ángulos redondeados y la convergencia de las paredes hacia oclusal con la cavidad tipo Bronner, Figura 28.

Es también importante señalar la diferencia que existe con la cavidad tipo Black, donde las paredes y pisos planos, paredes paralelas, con ángulos de $90^{\circ}$, Figura 29. Como podemos ver en la imagen que en las cavidades Bronner el diseño de las paredes y el piso son cóncavos, en color amarillo.

Por lo que es importante en las cavidades Bronner efectuadas en pacientes infantiles recordar; que el piso se hace cóncavo con el propósito de no lastimar los cuernos pulpares, pues fácilmente se puede realizar una comunicación pulpar y causar una iatrogenia, sino se tiene en mente esta característica fisiológica de la dentición infantil. Cabe señalar que en pacientes adultos el piso se hace recto porque la cámara pulpar es de menor tamaño.

Es condición previa absoluta la completa remoción de todo tejido cariado, esto se hace ya sea con fresa redonda de bola o con excavadores bien afilados. Deberá hacerse cuidadosamente ya que puede ser un sitio cercano a la cámara pulpar, Figura 30.

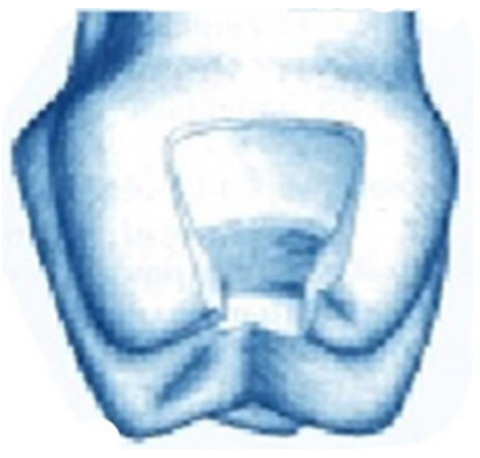

FIGURA 28

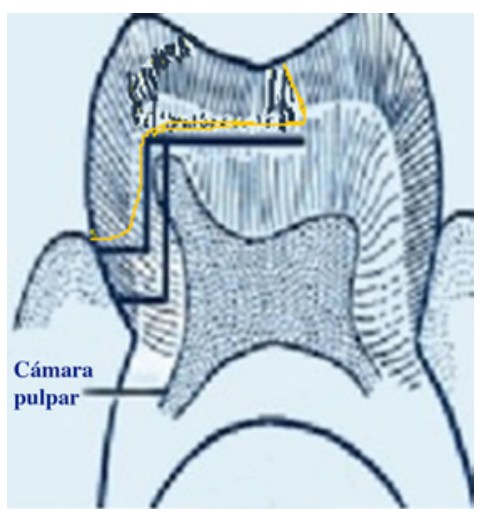

FIGURA 29

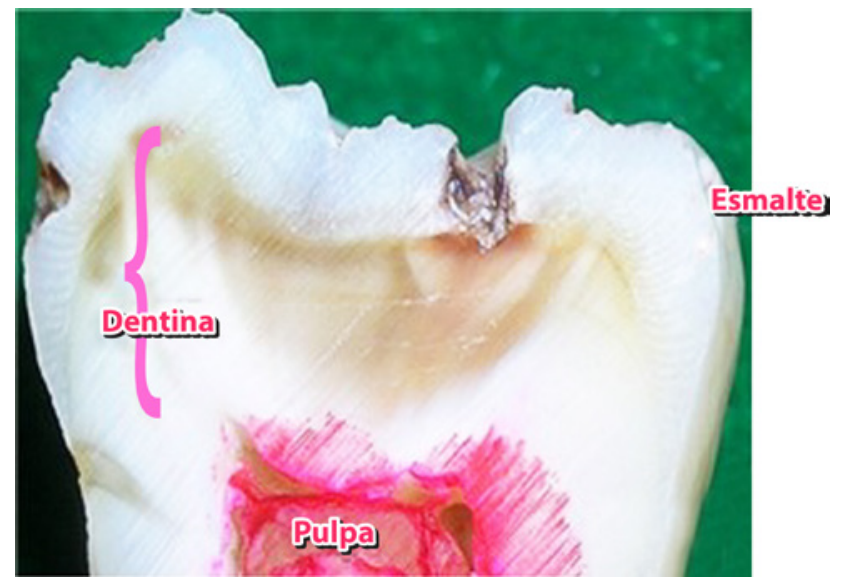

FIGURA 30 
Autores como Welk tienen conceptos básicos para el diseño de preparaciones de cavidad a la luz de los conocimientos y tecnología actuales, ${ }^{24}$ el principio de Black, extensión por prevención, ya no es muy actual considerando los avances en los nuevos materiales dentales y adelantos técnicos en el instrumental en los últimos años. Los materiales utilizados actualmente son resinas que no requieren de retención mecánica, son de tipo Epoxy fotopolimerizables. Por otro lado, Mount señala las zonas afectadas por la caries, ${ }^{21}$ las cuales considera se deberán de rehabilitar con materiales de relleno estético, considerando el tamaño de la lesión cariosa. Cuadro 3.

\begin{tabular}{|c|c|c|c|c|c|}
\hline \multirow{2}{*}{$\begin{array}{c}\text { Tamaño } \\
\text { Zona }\end{array}$} & $\begin{array}{c}\text { No } \\
\text { cavitada }\end{array}$ & \multicolumn{1}{c}{$\begin{array}{c}\text { Tamaño 1 } \\
\text { (Mínimo) }\end{array}$} & $\begin{array}{c}\text { Tamaño 2 } \\
\text { (Moderado) }\end{array}$ & $\begin{array}{c}\text { Tamaño 3 } \\
\text { (Grande) }\end{array}$ & $\begin{array}{c}\text { Tamaño 4 } \\
\text { (Extenso) }\end{array}$ \\
\hline $\begin{array}{c}\text { Zona 1 } \\
\text { (Fosas y fisuras) }\end{array}$ & 1.0 & 1.1 & 1.2 & 1.3 & 1.4 \\
\hline $\begin{array}{c}\text { Zona 2 } \\
\text { (Proximal) }\end{array}$ & 2.0 & 2.1 & 2.2 & 2.3 & 2.4 \\
\hline $\begin{array}{c}\text { Zona 3 } \\
\text { (Cervical) }\end{array}$ & 3.0 & 3.1 & 3.2 & 3.3 & 3.4 \\
\hline
\end{tabular}

CUADRO 3.

Mount GJ et al. Int Dent J. 2006; 56:82-91.

Por otra parte para evitar pulpitis secundarias o necrosis pulpares debajo de obturaciones de dientes primarios, debe quedar entre el piso cavitario y la pulpa una capa de dentina radiológicamente visible, de 0.3 a $0.5 \mathrm{~mm}$ de espesor.

En las imágenes radiográficas se puede observar el proceso carioso afectando la dentina, Figuras 31 y 32.

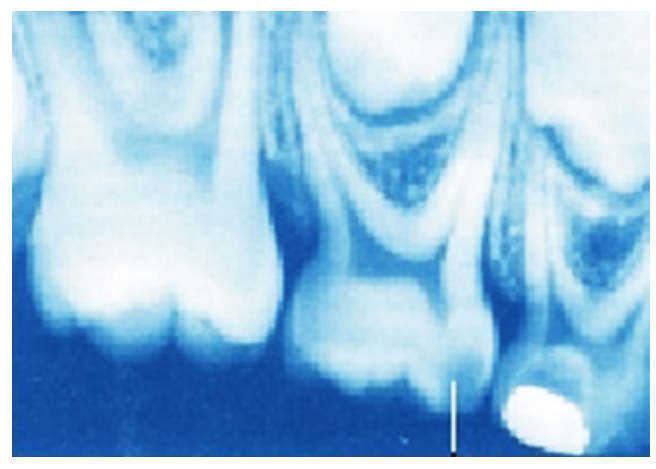

FIGURA 31

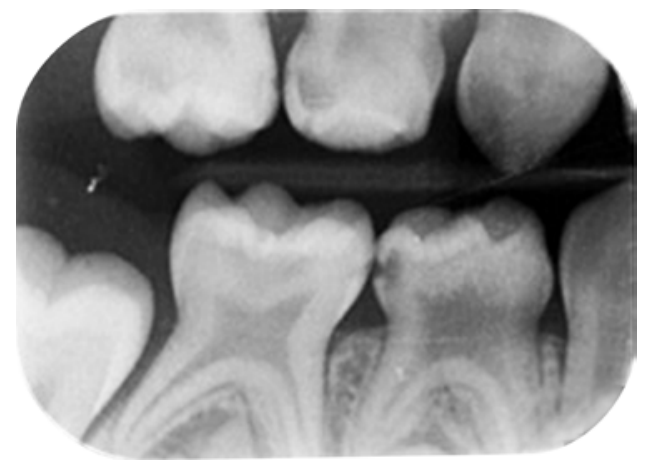

FIGURA 32 


\section{Pasos a seguir en la preparación de cavidades}

$\mathrm{S}$ e debe seguir la forma de la anatomía de la pieza dentaria para no eliminar tejido sano de más, pensando siempre en dejar esmalte con soporte dentinario, para evitar que se fracturen las paredes de la cavidad, eliminar todo el tejido carioso, hasta llegar al área de dentina sana. La preparación de estas cavidades exige la eliminación quirúrgica de la destrucción provocada por el proceso carioso, lo cual debe incluir el esmalte descalcificado y debilitado, así como la dentina defectuosa, Figuras 33, 34 y 35.

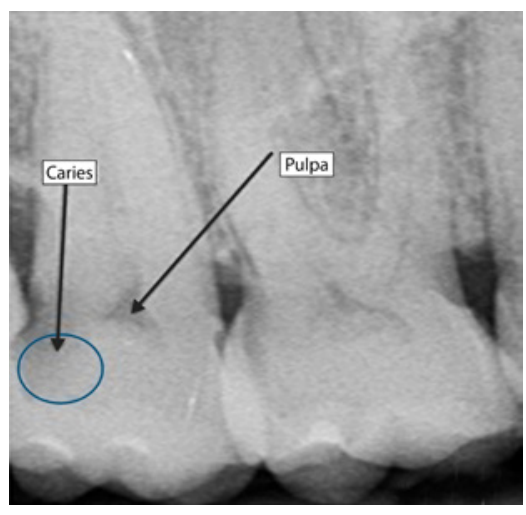

FIGURA 33

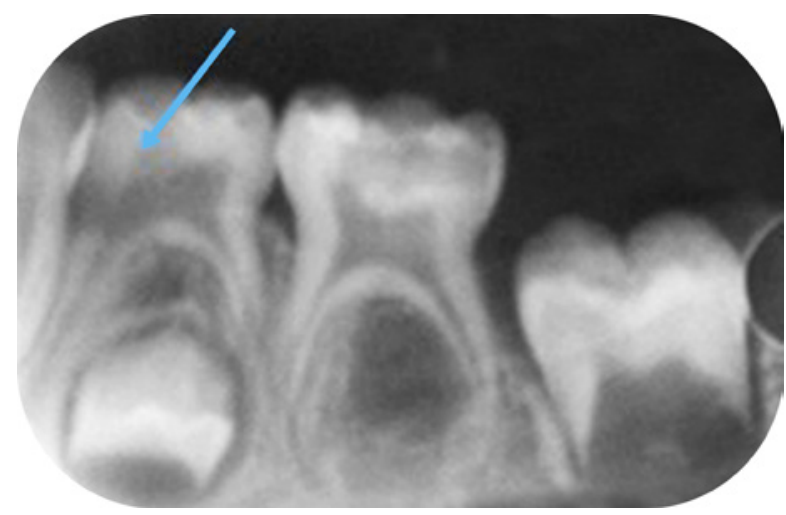

FIGURA 34

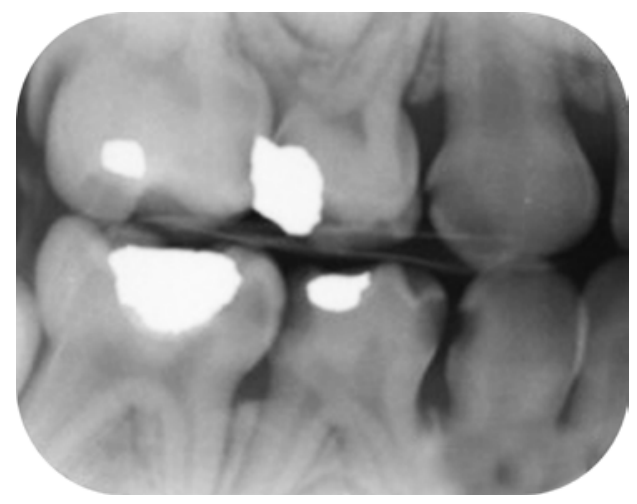

FIGURA 35

El proceso carioso se manifiesta de color diferente al resto de la superficie dentaria se torna más oscuro, el brillo del esmalte se pierde, se ve blanco gisoso, mate, se inicia la mancha blanca, Figura 36. 


\section{Cavidades para dentición infantil}
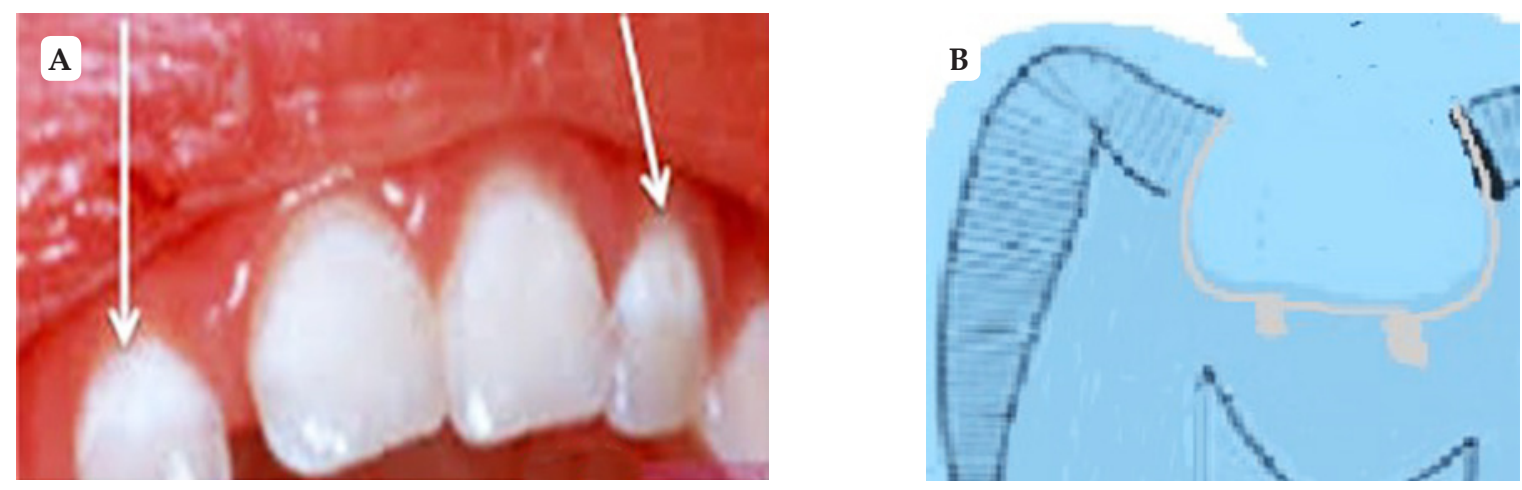

FIGURA 36

En la imagen se observa el tono, del esmalte que se tornó blancuzco, en la zona gingival, es opaco, tenemos diferente tonalidad.

Eliminar todo el tejido carioso, hasta llegar al área de dentina sana. En la imagen del lado izquierdo se puede apreciar, diferentes profundidades en el piso pulpar, en tono gris, debido a la caries, no emparejar el piso, sólo eliminar los puntos cariosos.

La preparación de estas cavidades exige la eliminación quirúrgica de la destrucción provocada por el proceso carioso, lo cual debe incluir el esmalte descalcificado y debilitado, así como la dentina defectuosa, Figura 37, y en la Figura $37 \mathrm{~b}$, tenemos diferente profundidad en el piso pulpar.
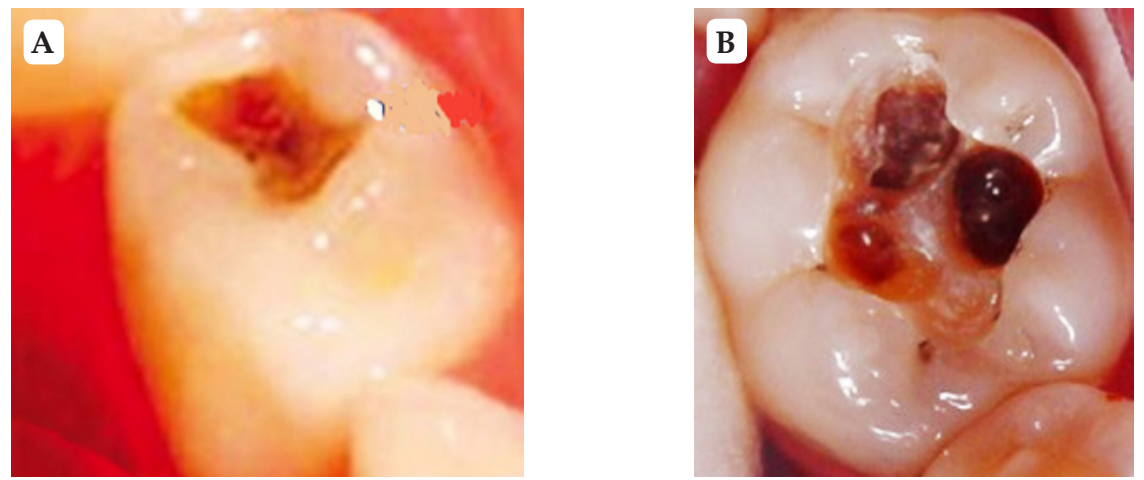

FIGURA 37

Tomar en cuenta la zona o área de acceso, si se trata de cavidades donde se tenga que hacer una cavidad en la zona proximal, como las cavidades mesial o distal de la Figura 38. Se dificulta la preparación de la cavidad por la presencia de la pieza continua.

Para lo cual se debe coloca una banda matriz, de metal o de celuloide en la pieza en la que estamos trabajando, con el fin de proteger a la pieza vecina. Cuando sólo se decide entrar a trabajar por la cara oclusal no, es necesario, Figura 38. 


\section{Gurrola Martínez B \& Álvarez Bañuelos VJ}
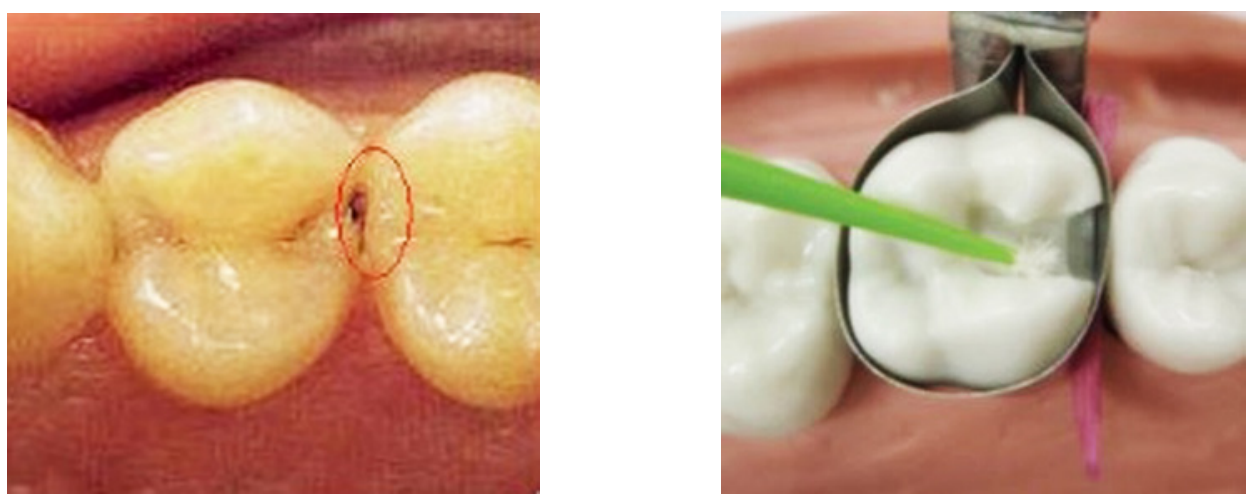

FIGURA 38

Para el tallado de una cavidad oclusal, el odontólogo debe imaginar siempre la preparación terminada, tomando en cuenta la relación con las otras piezas dentarias, la anatomía de la pieza, la posición, el tamaño, la cavidad y el material con que va a ser restaurada.

Recordando que estas cavidades las podemos realizar en la superficie oclusal de piezas posteriores como el primero y segundo molar inferiores así como en los superiores. No olvidar que pueden incluirse o extenderse el diseño de estas cavidades a los surcos y fisuras, con grandes afectaciones.

Para conseguir la retención y forma de resistencia, es necesario seguir la anatomía de los surcos redondeando los ángulos, esto se logra utilizando fresas de carburo del número con la forma cilíndrica, troncocónica, periforme, o numeración: 330, 331, 332, Figura 39.
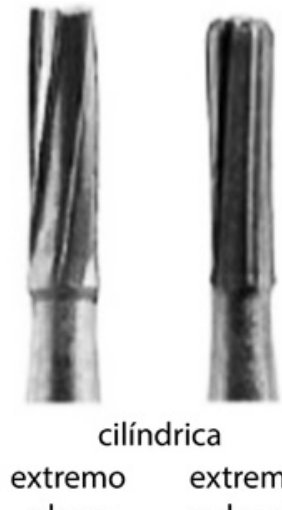

cilíndrica extremo

redondo

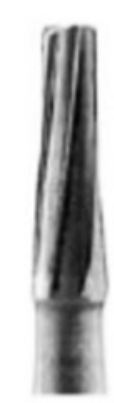

troncocónica

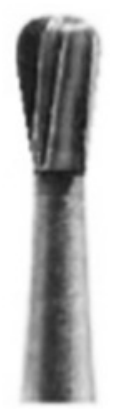

piriforme

FIGURA 39

Utilizamos para la apertura de la cavidad fresas de diamante, encontrándose en el mercado de diferentes calibres y tamaños, chica, mediana y gruesa. Una vez terminado el delineado de la cavidad, se usan fresas de diamante para eliminar los prismas libres del esmalte, ésta se coloca entrando por oclusal en posición perpendicular a la superficie y se desliza por el surco fundamental. 
Sin tocar el piso pulpar que deberá ser cóncavo para salvar los cuernos pulpares de los dientes infantiles y en caso de dientes permanentes el piso será plano, para el cual se utilizan las fresas de cono invertido. Cabe señalar que existen en el mercado fresas actualmente están las llamadas inteligentes, Figura 40, son Smart-Bur II de SS White permite algo único: determinar con precisión de la eliminación de caries.

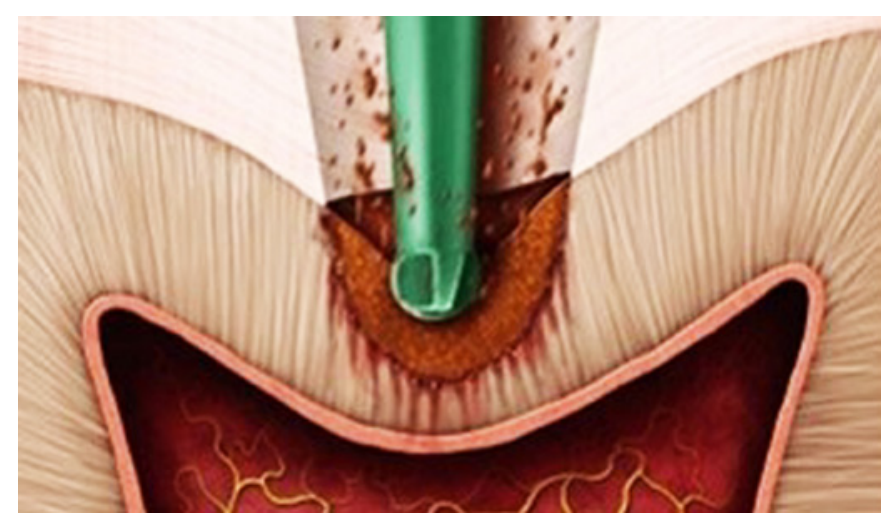

FIGURA 40

Este sistema de fresa dental inteligente a base de polímero, desarrollado para eliminar dentina cariada sin dañar la estructura del diente sano, está diseñado para distinguir la dentina sana de la dentina cariada basándose en la dureza de la dentina sana, Figura 41.

A

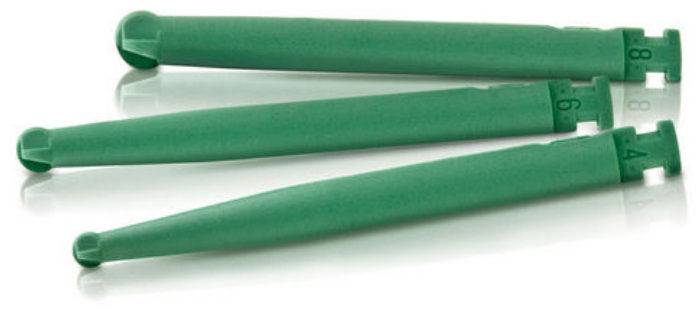

\section{B}

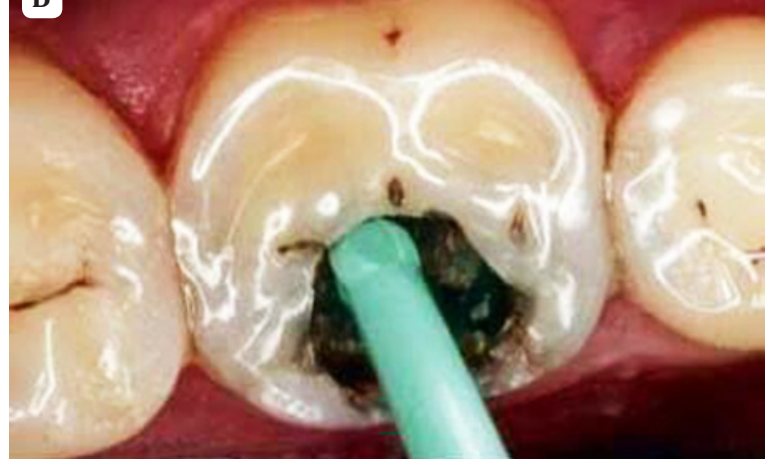

FIGURA 41

La superficie cortante, hecha de polímero de grado medio, tiene una dureza inferior al esmalte sano y la dentina, pero mayor que la dentina cariada. Este aspecto único permite utilizar la fresa selectivamente para eliminar la estructura dental cariada sin dañar la sana.

En algunos casos, incluso se puede remover la caries sin usar anestesia local en pacientes de Clase I y Clase V. La fresa de polímero de grado médico Smart Bur II, utilizada como pieza de mano de baja rotación a hasta 4000 


\section{0 Gurrola Martínez B \& Álvarez Bañuelos VJ}

rpm de velocidad, permite un corte auto limitante que preserva la dentina. La investigación demuestra que, en comparación con las de carburo metálico y cerámica, la fresa de polímero es realmente segura para la dentina sana.

La fresa Smart Bur II permite la preservación de la estructura dental sana y evita una exposición pulpar innecesaria. Figura 41a. No causa trauma en los túbulos dentinarios, lo que en muchos casos, la naturaleza mínimamente invasiva de corte de este instrumento de polímero.

\section{Diseño de la cavidad clase I}

Se recomienda seguir el diseño de segmentos de círculo para realizarlo en la cara oclusal, a continuación se $\checkmark$ presentan diferentes diseños que se pueden realizar en las piezas infantiles para las primeras clases.

Cavidades clase I. En las caras palatinas de los dientes anteriores y en la oclusal de los molares, Figuras 42,43 y 44 .

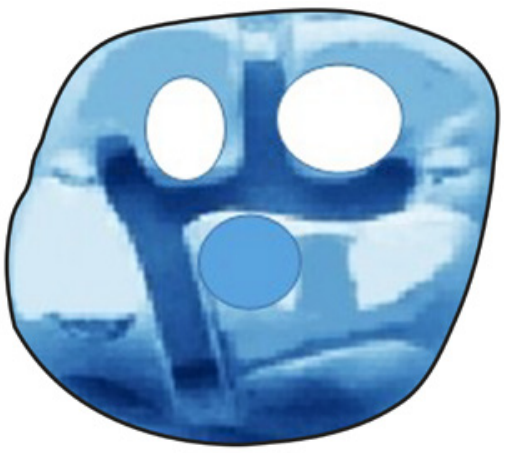

FIGURA 42

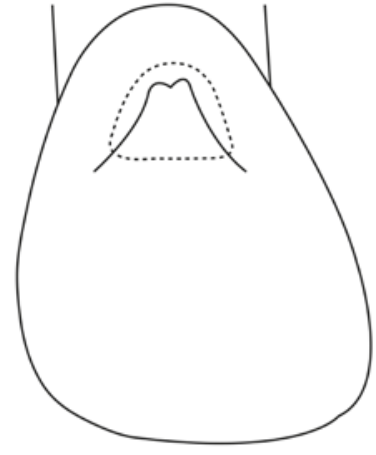

FIGURA 43

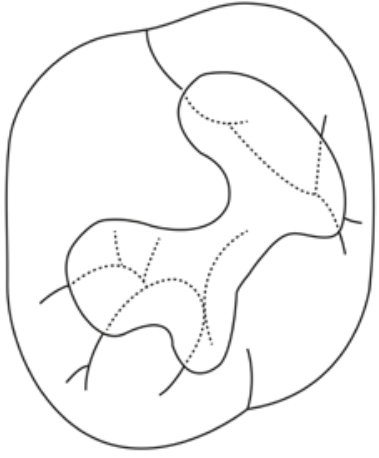

FIGURA 44

El diseño de la cavidad en los dientes anteriores infantiles es en forma triangulada por la cara palatina en el cíngulo o talón del diente de la pieza dental anterior, ya sea en los incisivos centrales o laterales, Figuras 45 y 46.

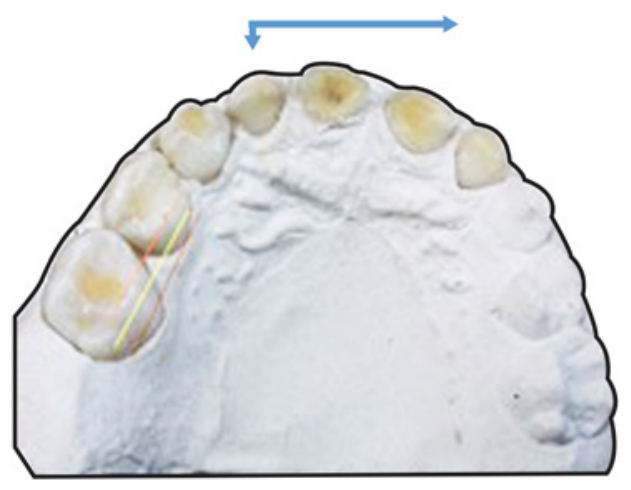

FIGURA 45
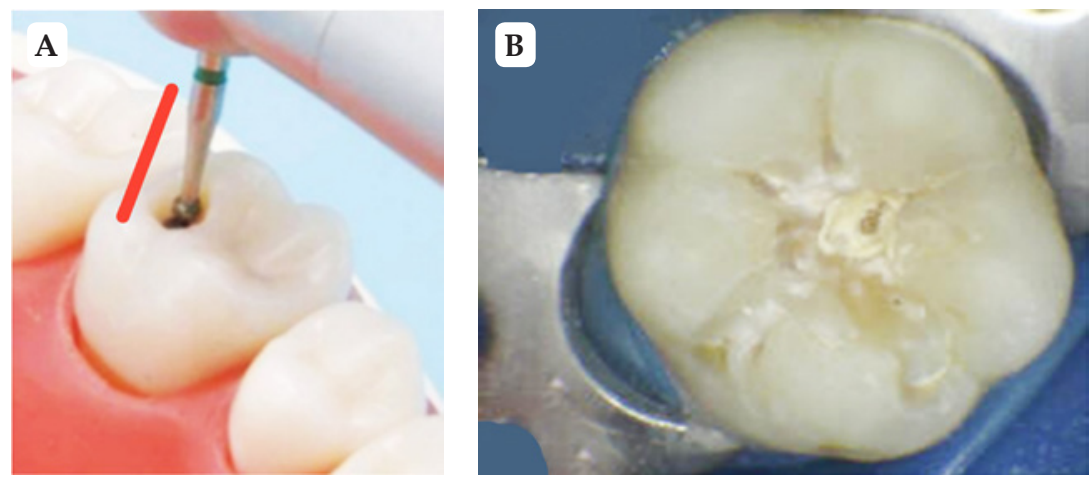

FIGURA 46 
Para conseguir la retención y forma de resistencia, es necesario seguir la anatomía de los surcos, esto se logra utilizando las fresas de diamante, sobre el esmalte y cambiando por las de carburo para trabajar en dentina.

La inclinación de la fresa siempre deberá ir de acuerdo a la pared externa del diente y teniendo cuidado de no inclinarlo demasiado, pues esto puede ocasionar la fractura de la pared, al igual en los surcos accesorios de los molares, Figuras 46 y 47, en el dibujo vemos el surco accesorio y en la imagen de la derecha las cavidades terminadas.
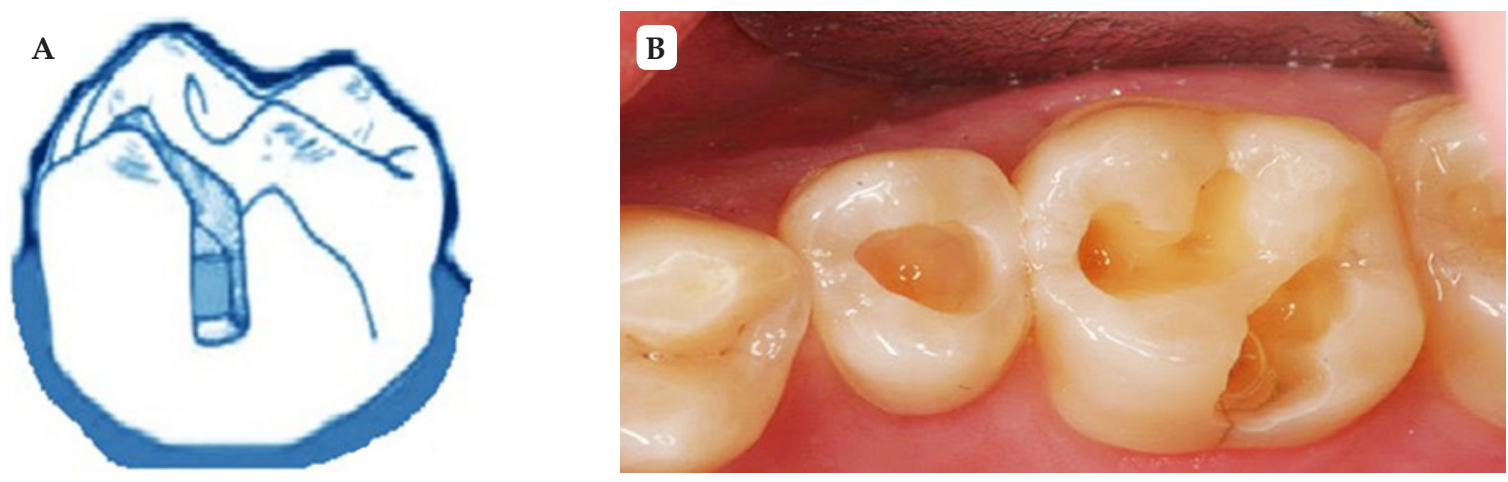

FIGURA 47

\section{Ejercicio: Cavidades clase I}

Instrucciones: lee cuidadosamente selecciona un número y colócalo en el paréntesis de la izquierda.

1. Identifica y coloca el número que le corresponda de acuerdo a la clasificación de cavidades Black y localización de la cavidad de la pieza dentaria.

a) Cavidades de clase I ( )

b) Cavidad de clase I simple ( )

c) Cavidad de clase I compuesta ( )

d) Cavidad de clase I compleja ( )
1. Se encuentran en dientes anteriores en la cara palatina y posteriores en la cara oclusal.

2. Implica una sola pared.

3. Involucra dos caras oclusal y vestibular.

4. Involucra tres superficies: ocluso, vestíbulo, palatino. 


\section{2 \\ Gurrola Martínez B \& Álvarez Bañuelos VJ}

5. De acuerdo a la clasificación de cavidades ¿qué tipo le asignaría al primer molar permanente en la Figura A?

6. De acuerdo a la clasificación de cavidades ¿qué tipo le asignaría al primer molar permanente en la Figura B?

¿Y al segundo molar en la misma imagen (B)?

7. De acuerdo a la clasificación de cavidades ¿qué tipo le asignaría a los molares en la Figuras C y D?
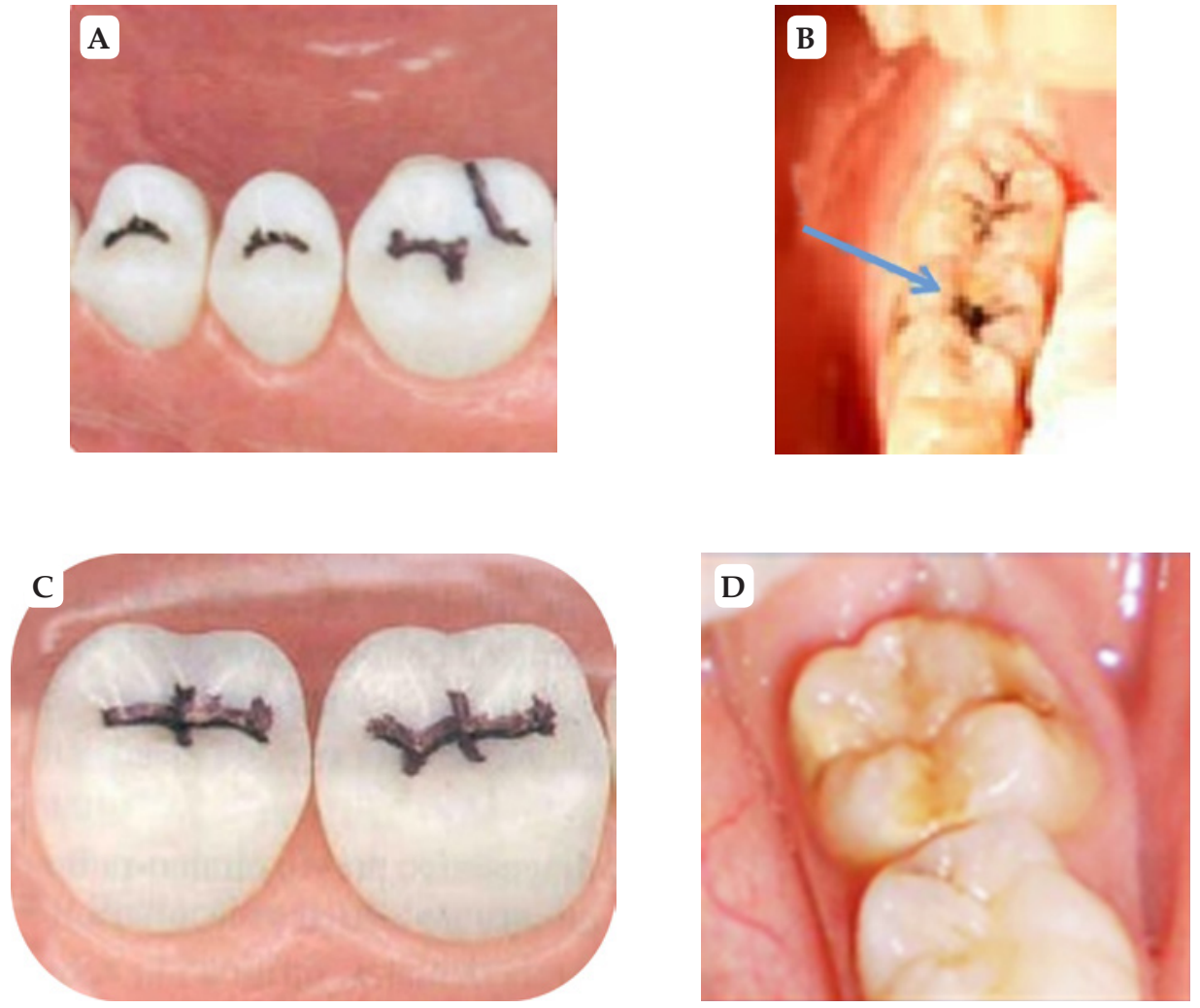

8. Menciona que tipo de cavidad tiene el diente 46 de acuerdo a la imagen del tipodonto inferior.

9. Menciona que tipo de cavidad tiene el diente 85 de acuerdo a la imagen del tipodonto inferior. 
10. Menciona que tipo de cavidad tiene el diente 84 de acuerdo a la imagen del tipodonto inferior.

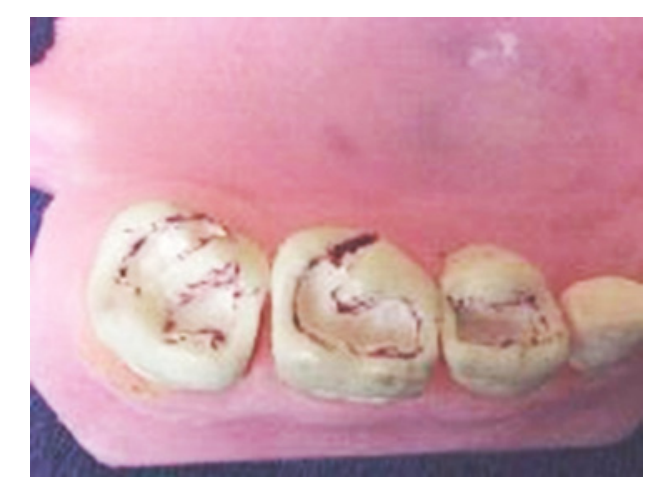

\section{Cavidades clase II}

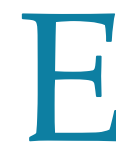

s una cavidad difícil de preparar en las piezas infantiles, porque por una parte requiere el cuidado de la pulpa y por otra de no lesionar la pared de la pieza continua. Son cavidades que en caso de existir un proceso carioso muy amplio se opta por otro tipo de restauración como las coronas totales, en la Figura 48, se ve en los molares infantiles la zona más oscura en las paredes proximales, lo que nos indica la presencia del proceso carioso.

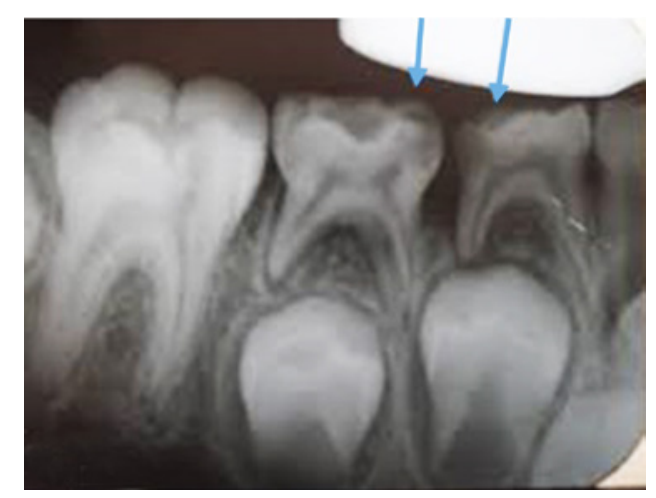

FIGURA 48

En la imagen, se muestra el diseño para retirar la caries de la pared mesio-oclusal o disto-oclusal de ser posible con un diseño separado, o se prepara con un anclaje oclusal, la caja principal es en la pared proximal, conservando en algunos casos el puente de esmalte central, Figuras 49a y 49b. 


\section{$44 \quad$ Gurrola Martínez B \& Álvarez Bañuelos VJ}
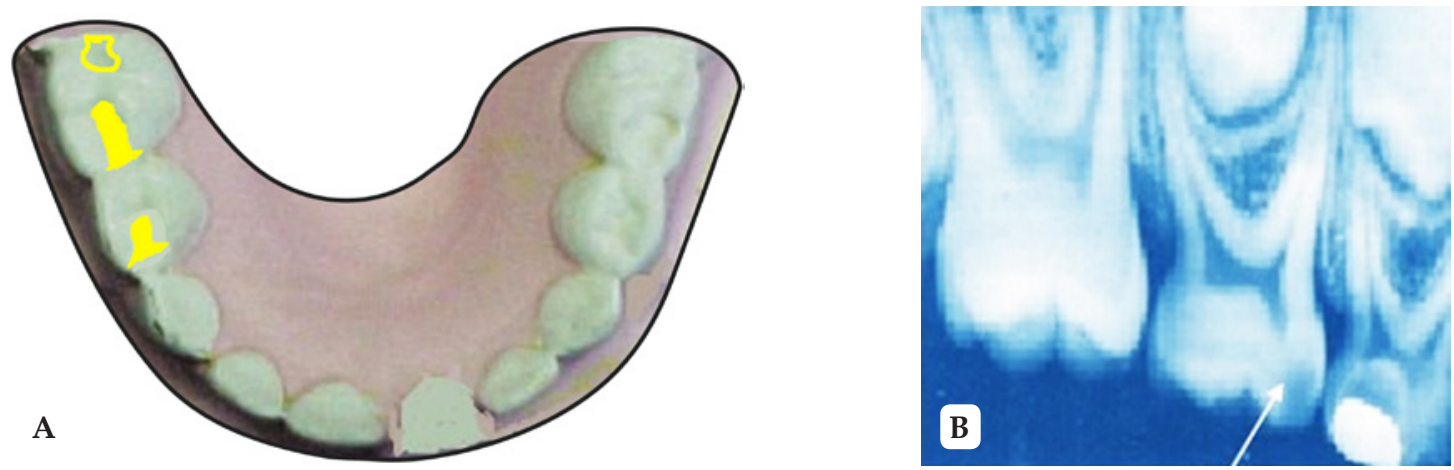

FIGURA 49

Por otra parte también es necesario considerar como se restaurará la cavidad clase II. Su indicación será que se puede colocar una amalgama, para lo cual es muy importante considerar el margen del ángulo cavo superficial, el cual debe estar sin bisel y ubicado fuera de las zonas que soportan las cargas; los ángulos internos deben redondearse ligeramente.

Cuando se prepara una forma de cola milano en los segundos molares primarios, su amplitud vestíbulo lingual debe ser mayor que la del istmo, este debe medir un tercio del ancho intercuspídeo, y las paredes deben converger un poco en dirección oclusal, Figura 50.

Los ángulos línea interna serán redondeados para aliviar las tensiones de la masticación, también proporciona un elemento mecánico de retención, los bordes de la caja proximal deben extenderse hasta la superficie que va más abajo del surco interproximal (SI), Figura 51.

Con una fresa 330 se hará el ángulo axiopulpar ampliamente redondeado evitando así fracturas de la amalgama. Todos los prismas del esmalte sin soporte deberán ser removidos con instrumento de mano (cincel). La preparación en los pacientes estará limpia y sin restos.

\section{Retención}

El área de contacto se libera y la forma de anclaje se hará con las paredes convergentes hacia oclusal como lo muestra la imagen. La inclinación de las paredes es de acuerdo a la superficie externa da la pieza dental, la cual no se hará muy pronunciada si se exagera se corre el riesgo de fracturar la pared del esmalte, Figura 52 vista proximal.

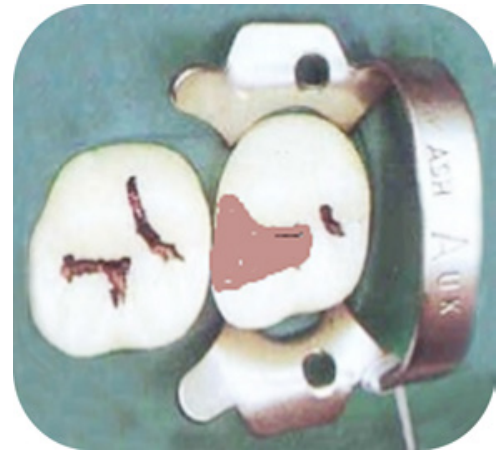

FIGURA 50

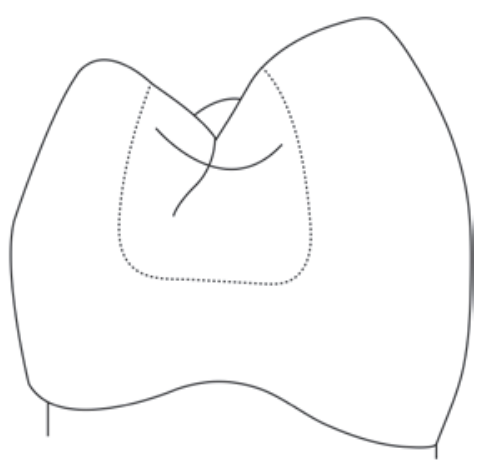

FIGURA 51 


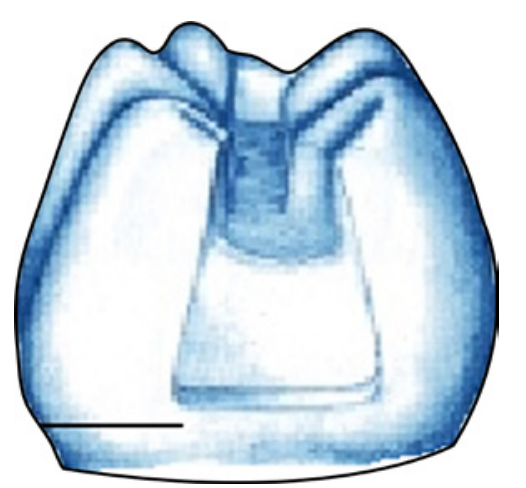

FIGURA 52

El ancho de la cavidad en la pared oclusal es menor que la amplitud que se logra en la pared pulpar, Figura 53 vista oclusal.
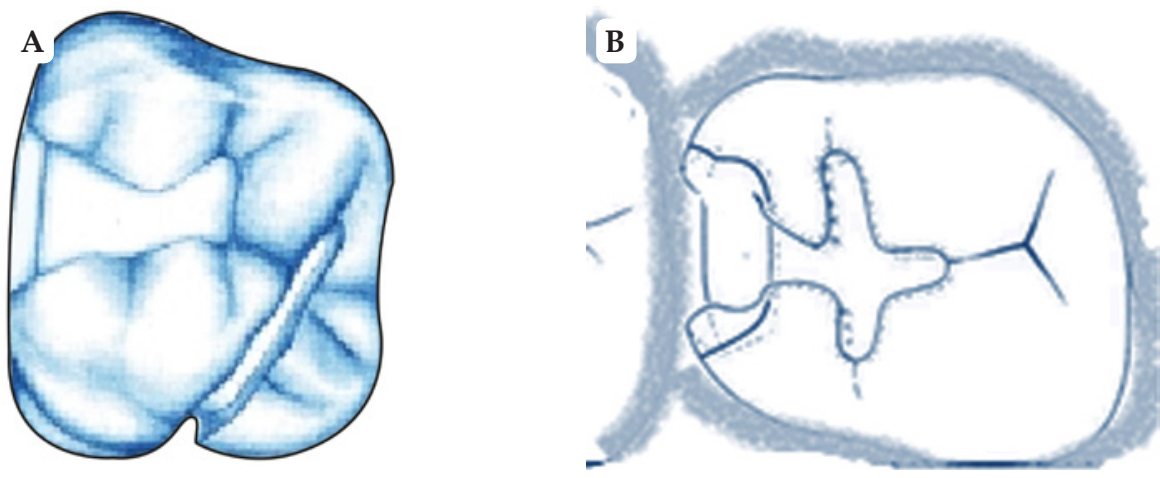

FIGURA 53

Es necesario preparar primero la caja proximal cuando el proceso carioso ya está demasiado obvio y se continúa con la caja accesoria, Figura 54a, se hace con una fresa 330, realizando la acción de péndulo, convergiendo la línea vestibular con la palatina, hacia la pared proximal, y se obtendrá una cavidad con la retención hacia oclusal.

Para evitar fracturas de las paredes proximales se redondean los ángulos (corresponde al biselado) de las paredes axio-pulpar, Figura 54b.
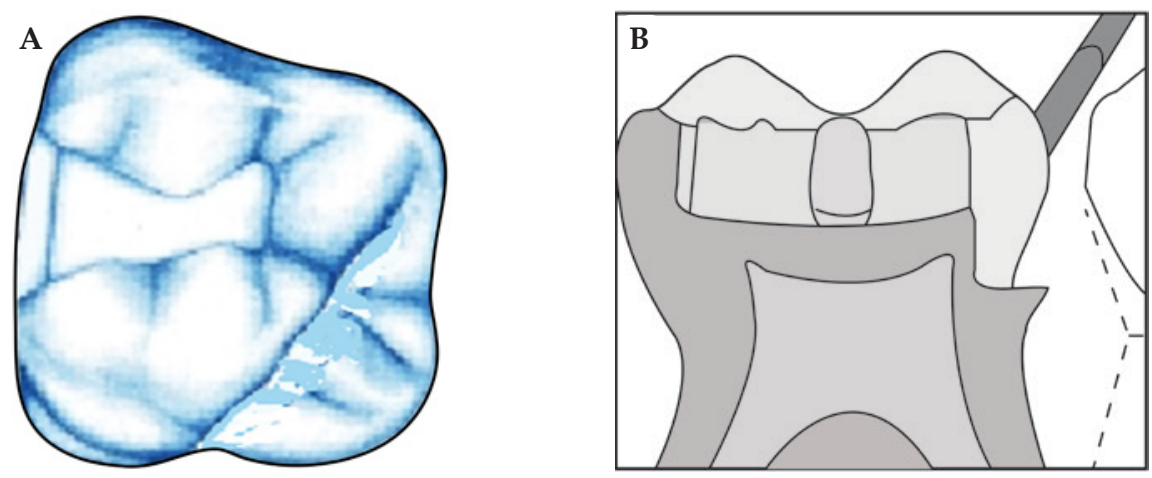

FIGURA 54 


\section{6 \\ Gurrola Martínez B \& Álvarez Bañuelos VJ}

En la Figura 55 se muestra la forma en que debe de quedar, al hacer el escalón en la caja proximal, claro que esto dependerá de la forma de la caries en esta área, de la conformación cavitaria de caja proximal si es única, o está unida a la superficie oclusal. Y al tipo de material con el que se restaura, considerando entonces técnicas adhesivas.

Cuando existe una caja proximal única, cuando no está presente el diente vecino, en estos casos no se realizará la caja oclusal como hemos descrito anteriormente, sino que se comienza la apertura por la fosa adyacente al reborde marginal de la pared afectada, Figura 5c.

El diseño de la caja proximal es el descrito anteriormente pero sólo en mesial o distal. Conformación cavitaria de caja proximal única. La retención de la restauración la propone la convergencia de las paredes vestibular y lingual hacia oclusal y la realización de unas pequeñas ranuras en los ángulos axiopulpares. Esta preparación se propone tanto para amalgama de plata en lesiones pequeñas o para técnicas de restauración adhesivas, Figura 55e.

La conformación cavitaria para técnicas adhesivas, en ellas no se realiza la caja oclusal como hemos descrito anteriormente, sino que se comienza la apertura por la fosa adyacente al reborde marginal de la pared afectada.

El diseño de la caja proximal es el descrito anteriormente pero sólo en mesial o distal. En estas cavidades se realiza la extensión mínima necesaria para la limpieza de la caries y su posterior obturación.

La retención de la restauración la propone la convergencia de las paredes vestibular y lingual hacia oclusal y el redondeado interno de todo el contorno de la preparación, clase MOD como se ve en la Figuras 55e y 55f. Finalmente en el paciente se procede al lavado y secado de la cavidad.
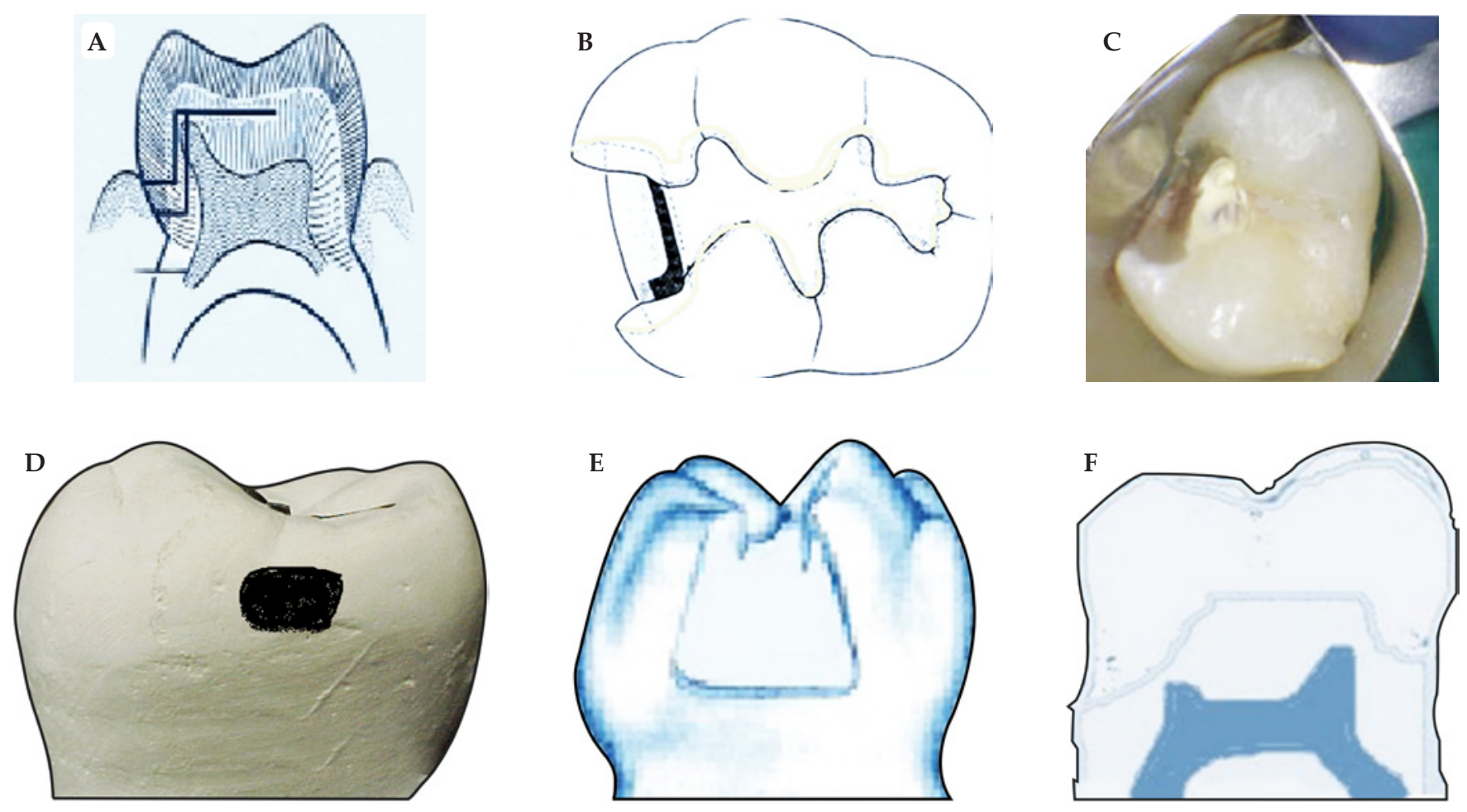

FIGURA 55 
Se recomienda evitar los siguientes errores al preparar una cavidad:

a) Extensión demasiado reducida en la zona oclusal.

b) Realizar cortes innecesarios de las cúspides.

c) Paso de la cavidad oclusal a la proximal preparado demasiado ancho, más de un tercio de la distancia de las cúspides.

d) Las paredes proximales no deben ser muy divergentes, hacer proyección de la convergencia hacia proximal.

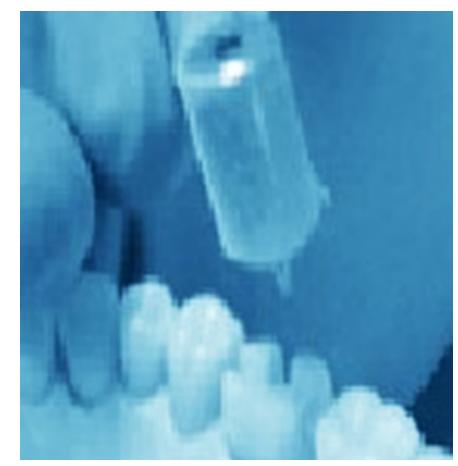

e) No se liberan las áreas de contacto entre las piezas en las que se realizan cavidades.

f) No se realiza el redondeado de la pared axio-pulpar.

g) Si es muy grande la destrucción por la caries, se deberá preferir colocar una corona de acero cromo.

\section{Ejercicio: Cavidades clase II}

Instrucciones: lee cuidadosamente selecciona un número y colócalo en el paréntesis de la izquierda.

1. Identifica y coloca el número que le corresponda de acuerdo a la clasificación y localización de la cavidad de la pieza dentaria.

a) Cavidad clase II Simple ( )

b) Cavidad clase II Compuesta ( )

c) Cavidad clase II Compleja ( )
1. Se localizan en dientes posteriores en la caras proximales.

2. En dientes posteriores abarcan dos caras, una proximal y la oclusal DO-MO.

3. En dientes posteriores abarcan tres caras las proximales y la oclusal MOD. 


\section{8 \\ Gurrola Martínez B \& Álvarez Bañuelos VJ}

De acuerdo a las imágenes inferiores coloca la clase de cavidad que corresponda:

2. Señala que cavidad es la que se observa en la imagen del primer molar superior.

3. Menciona que restauración está indicada realizar para el primer molar superior en la superficie oclusal disto vestibular que se observa en la imagen.

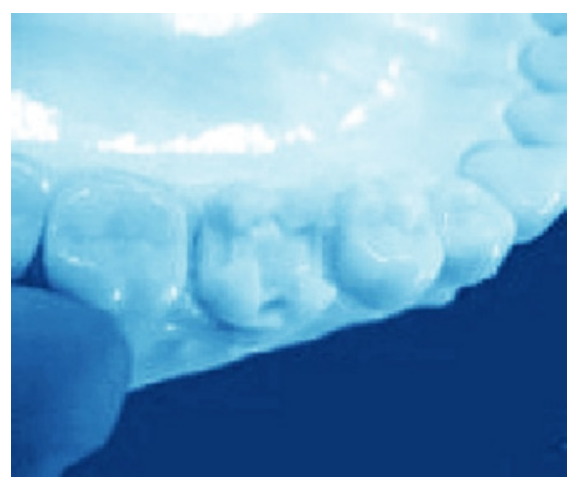

4. Indica que caras está afectando la caries en primer molar.

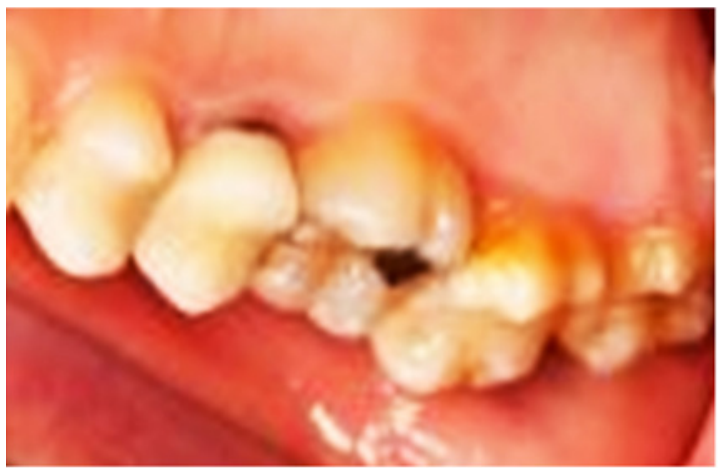

5. Indica que tipo de cavidad se realizara en el primer molar y en el segundo molar

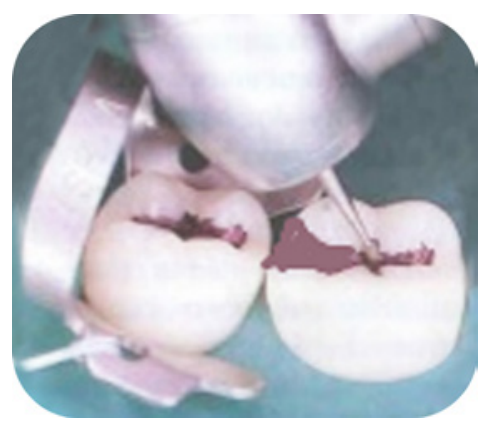

6. Señala con una flecha, en el dibujo del lado derecho, los siguientes ángulos y las paredes donde se localizan:

a) Pared axio pulpar.

b) La pared vestibular.

c) La palatina.

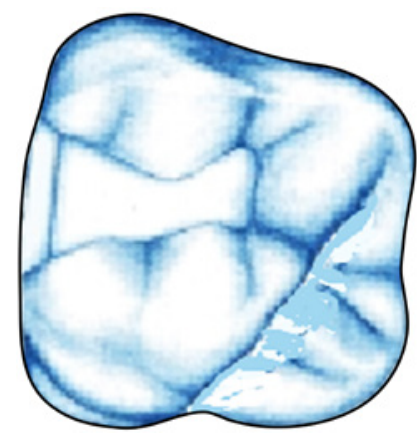


7. Señala con una flecha, en el dibujo inferior del lado derecho, las siguientes paredes donde localizas:

a) El surco accesorio.

b) La pared vestibular.

c) La palatina.

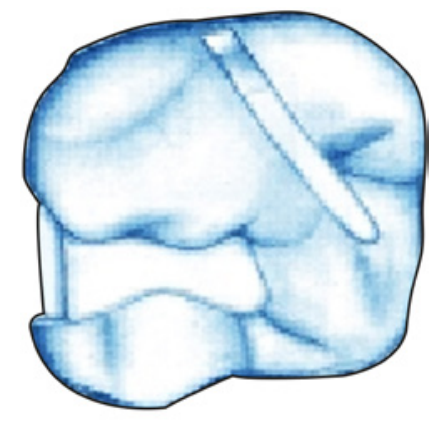

8. Menciona que harías en el caso de que la caries esté en la superficie oclusal y proximal para proteger las paredes del diente contiguo, el que tiene la corona de acero cromo.

Y como iniciarías la cavidad clase II, del molar con diente continuo.

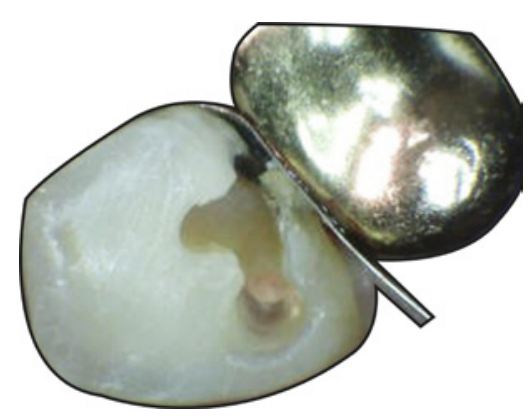

\section{Cavidades clase III}

$\mathrm{D}$ urante años la búsqueda de materiales de restauración estéticos ha sido tan añejo como la misma historia de la odontología, esto con la intención de restaurar lo mejor posible la apariencia de los dientes anteriores, en este sentido los materiales desarrollados con éste fin deben ser adhesivos, igualarla forma y color del diente de una manera permanente, ser compatible con los restos de los tejidos dentarios, que sean de fácil manejo, Figura 56.
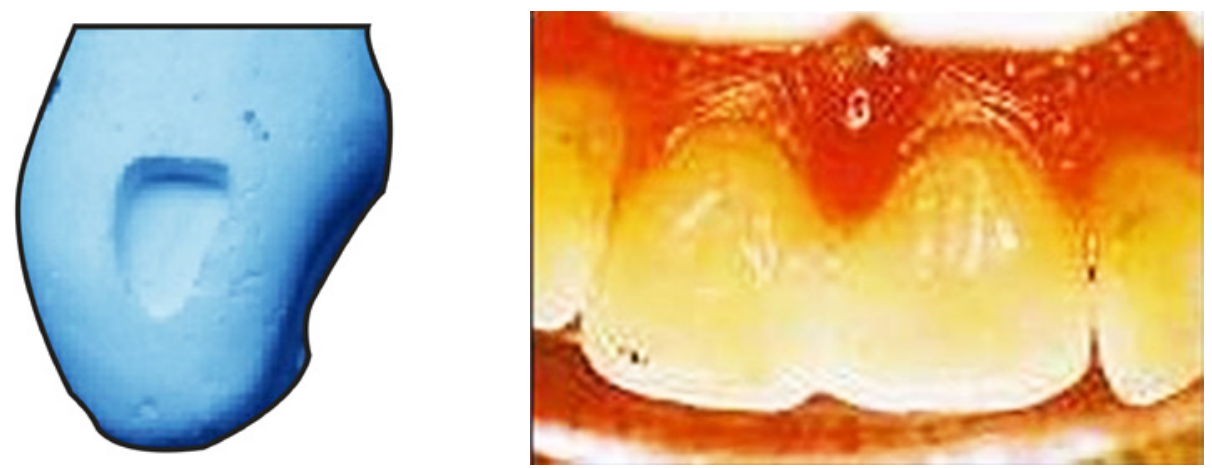

FIGURA 56 


\section{0 Gurrola Martínez B \& Álvarez Bañuelos VJ}

Antes de proceder a la apertura de la cavidad debe tomarse en cuenta la dirección al acceso de la misma, ya que se pueden encontrar los siguientes casos: posición de los dientes en la arcada, Figura 57.

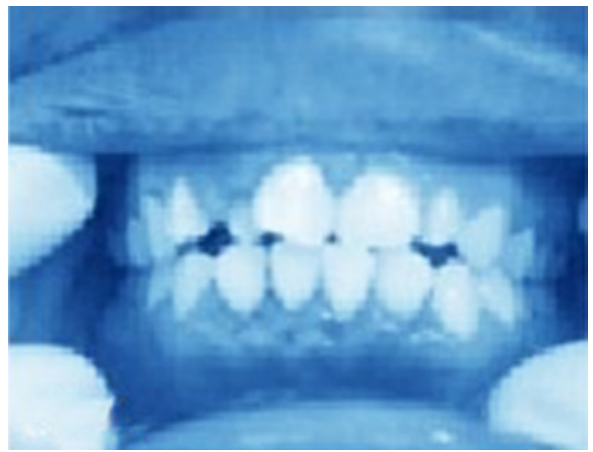

FIGURA 57

Por otra parte, cuando existen espacios de desarrollo fisiológico y está presente la lesión incipiente, o no existe el diente continuo, se pueden preparar directa y fácilmente, Figuras 58a, b y c.
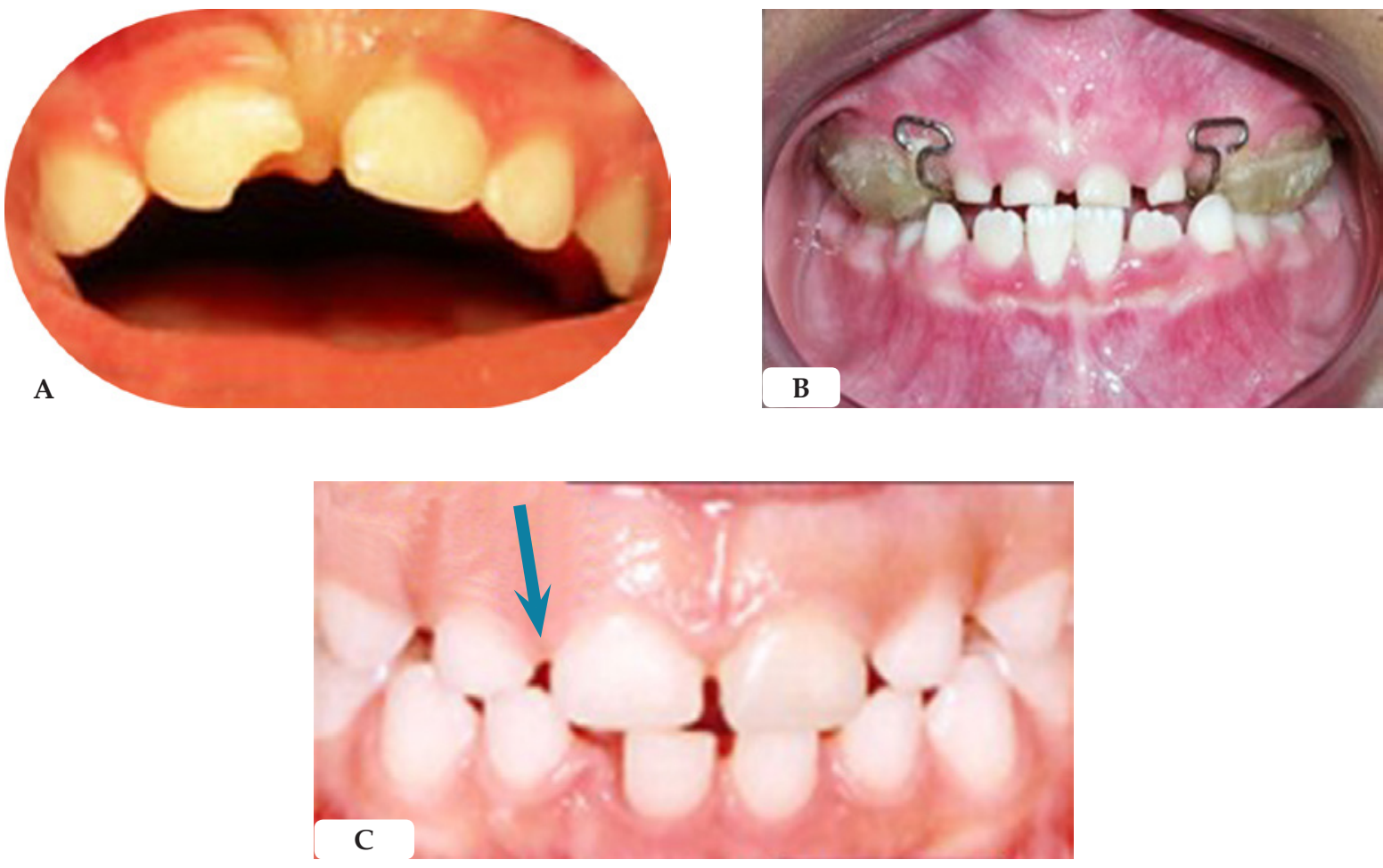

FIGURA 58

En numerosas ocasiones reemplazaremos una restauración defectuosa la cual deberá ser abordada desde la pared palatina o en el mejor de los casos iniciamos sobre la pared labial para concluir con la pared proximal, Figura 59. 

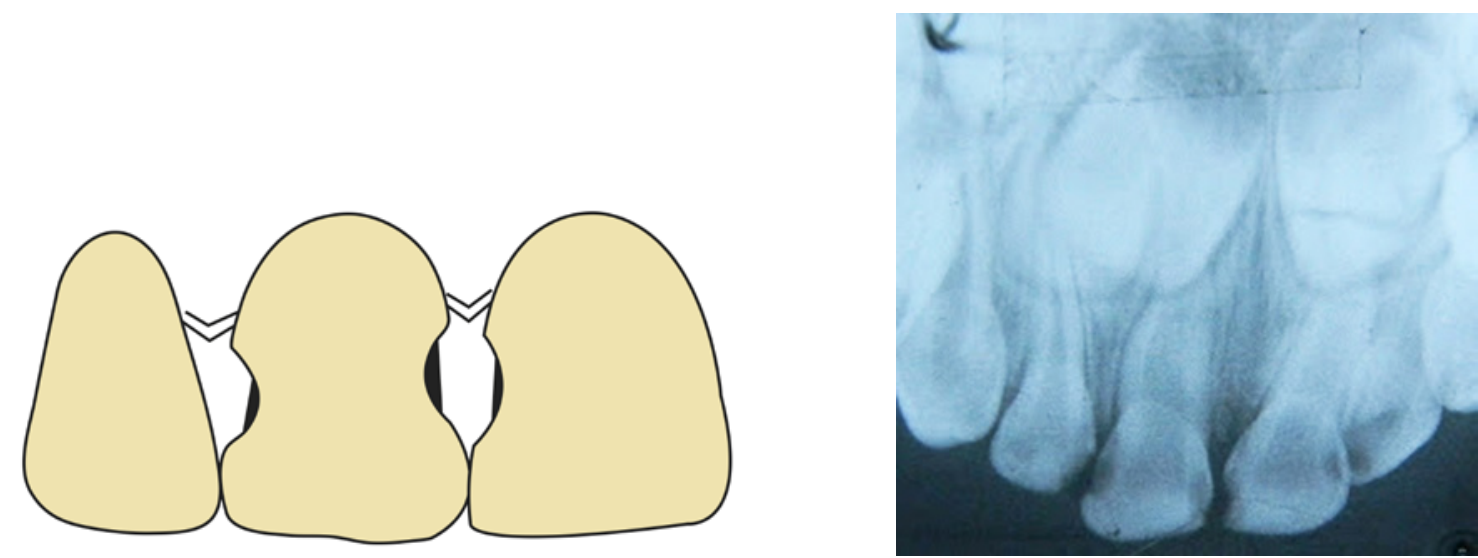

FIGURA 59

Es necesario recordar que son caries que se encuentran en la pared proximal de los dientes anteriores abarcando el tercio medio.

En las siguientes fotografías se puede observar, en el incisivo central superior izquierdo, el diseño del proceso carioso en la pared mesial, del tercio medio y la lesión inicial en la pared mesio distal de los centrales, Figura 60.
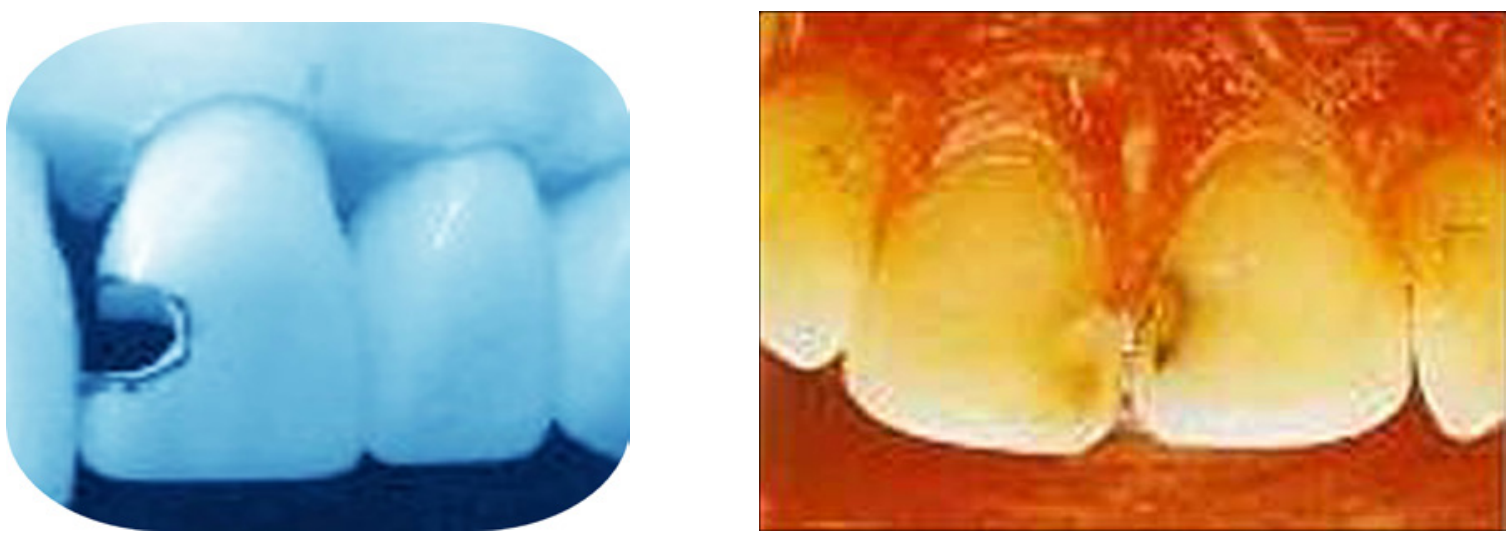

FIGURA 60

\section{Retención}

La retención principal de esta cavidad se logra mediante el seguimiento del contorno que tiene el proceso carioso y, además, por lo regular se busca una retención adicional.

La cavidad de clase tres comúnmente tiene una forma de " $\mathrm{C}$ " por la superficie proximal vestibular y la mayoría de las veces involucran la superficie palatina. Cuando es así, en palatino es donde se realiza la retención adicional llamada cola de Milano, como se puede observar en el diente de yeso, Figura 61. Pero cabe hacer notar, que los incisivos centrales ya tienen con la caries, un diseño previo, el cual se deberá respetar para no hacer más grande la cavidad. 


\section{Gurrola Martínez B \& Álvarez Bañuelos VJ}
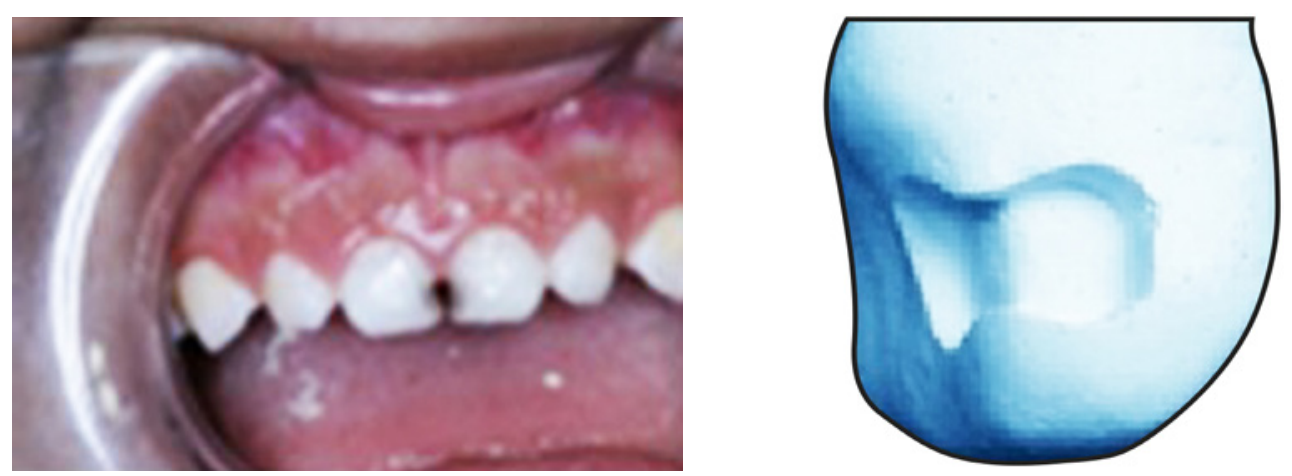

FIGURA 61

Además podemos reforzar la cavidad, para la retención adicional, haciendo en la pared palatina de la cavidad, una cola de milano, lo cual se logra por medio del ácido grabador que se utiliza en las resinas, que es el material de elección, para este tipo de restauración, dada su estética, Figura 62.
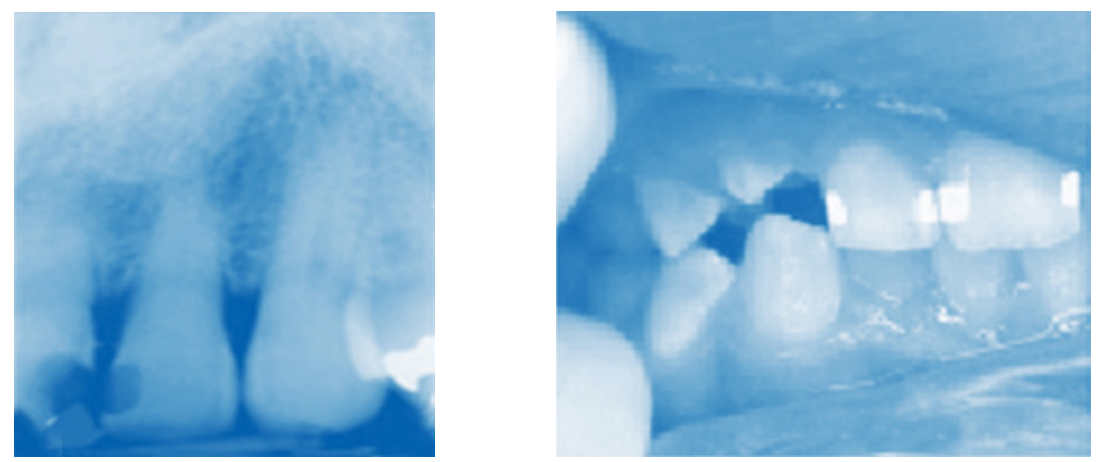

\section{FIGURA 62}

Se debe profundizar por la cara proximal hasta acceder a la lesión, teniendo en cuenta que no es necesario eliminar el punto de contacto.

A continuación, se realizará un bisel de 0.5 a $1 \mathrm{~mm}$ de extensión, a 45ํㅜ en todo el margen cavo superficial, con una fresa diamantada a lo largo de todo el esmalte que rodea la cavidad (ángulo cavo superficial biselado), para aumentar la retención. Colocar una matriz de acetato y acunarla debidamente, Figuras 63b y 63c.

Se recomienda la utilización del dique de hule para todo tipo de preparación de cavidad ya que los materiales de restauración que se emplean no son compatibles con la humedad, Figura 63d. 

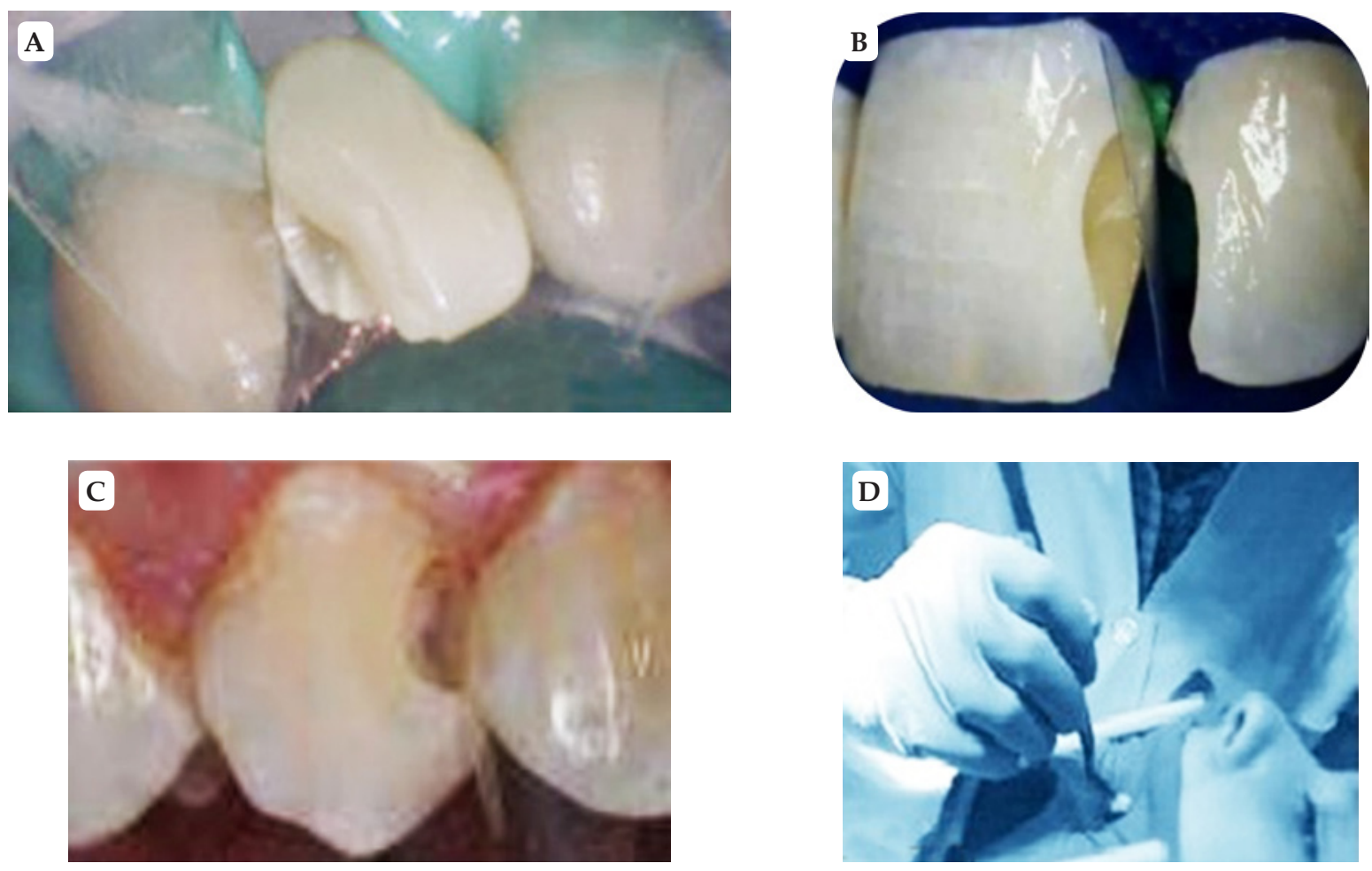

FIGURA 63

\section{Ejercicio: Cavidades clase III}

Instrucciones: lee cuidadosamente selecciona un número y colócalo en el paréntesis de la izquierda.

1. Identifica y coloca el número que le corresponda de acuerdo a la clasificación y localización de la cavidad de la pieza dentaria.

a) Cavidad clase III ( )

b) Cavidad clase III simple ( )

c) Cavidad clase III compuesta ( )

d) Cavidad clase III compleja ( )
1. Se localizan en dientes anteriores en el tercio medio de las caras proximales.

2. En una sola superficie.

3. Abarcan superficies vestíbulo mesial o disto-palatino.

4. Abarcan superficies mesial-vestibular-palatino 


\section{Gurrola Martínez B \& Álvarez Bañuelos VJ}

2. Identifica en la siguiente imagen si se trata de una cavidad simple, compuesta o compleja.

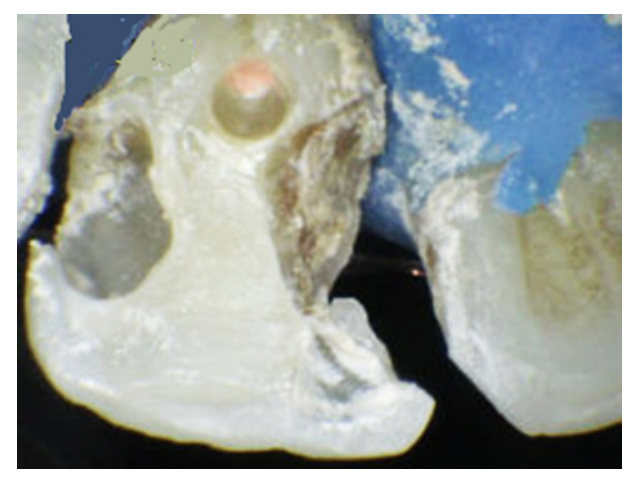

\section{Cavidades clase IV}
abe destacar que este tipo de cavidades clase IV no se realiza en niños, pero de ser necesarias se realizan cuando la caries es muy avanzada y ha debilitado en forma importante el ángulo incisal. O debido o un accidente que ha destruido el ángulo incisal.

Debido a su localización es un área difícil de reconstruir, por lo que sólo se recomienda en este caso la colocación de un pin o poste para reforzar la colocación de resinas, Figura 64a.

Recuerda que en los pacientes infantiles los cuernos pulpares son muy grandes. Por lo que se recomienda utilizar en estos casos coronas de celuloide, o policarbonato, o en su defecto coronas de acero cromo, Figuras 64c, d, e.
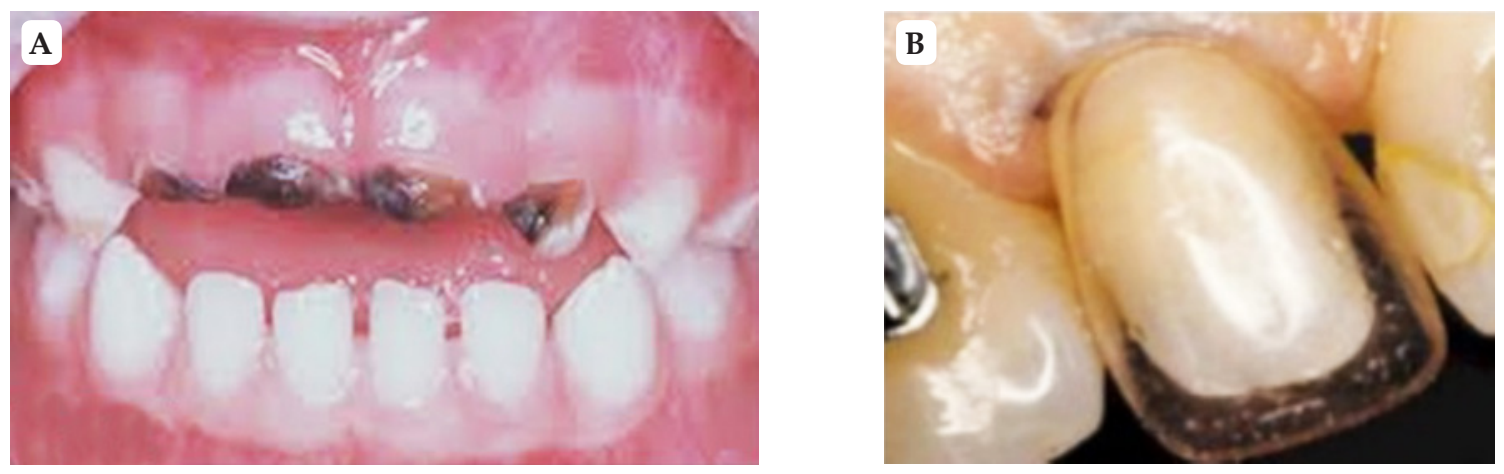

FIGURA 64 

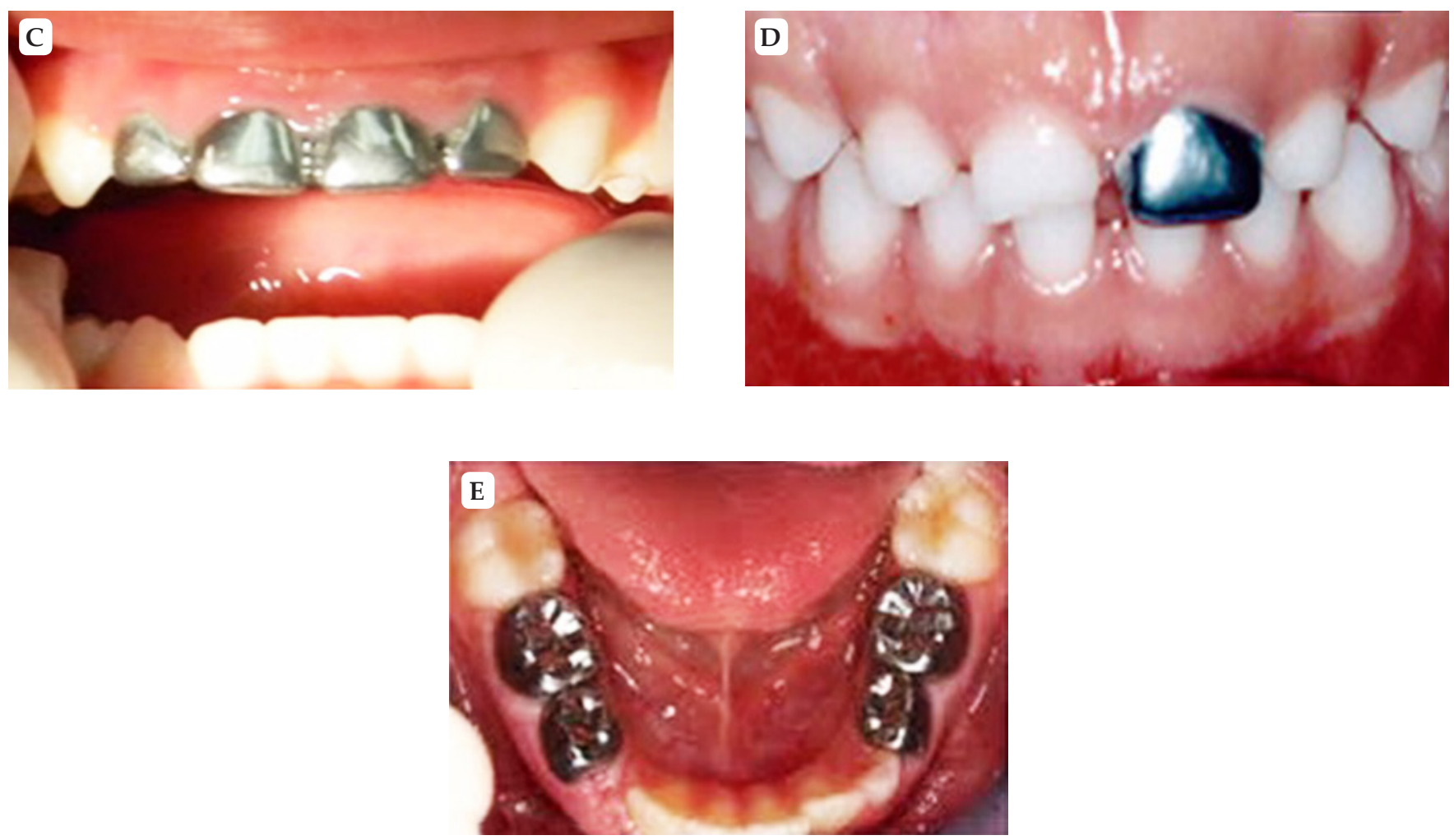

FIGURA 64

\section{Ejercicio: Cavidades clase IV}

Instrucciones: lee cuidadosamente selecciona un número y colócalo en el paréntesis de la izquierda.

Menciona el tipo de restauración que realizarías en el caso de los dos segundos molares superiores que se observan en la siguiente imagen.

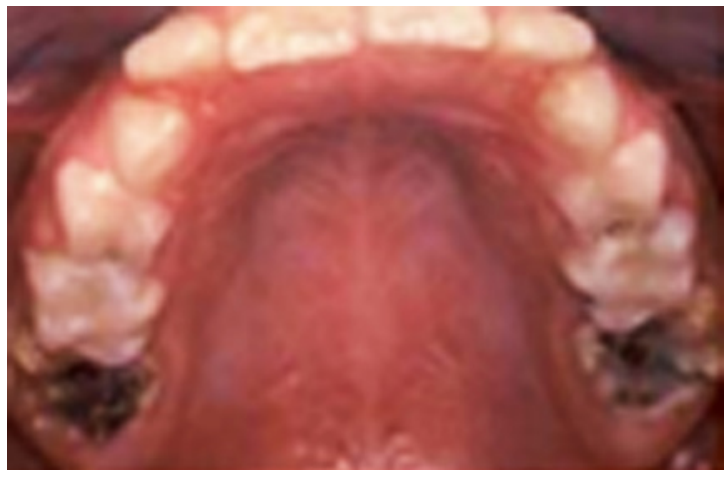




\section{6 Gurrola Martínez B \& Álvarez Bañuelos VJ}

En esta caries del primer molar por su amplitud que tipo de restauración indicarías:

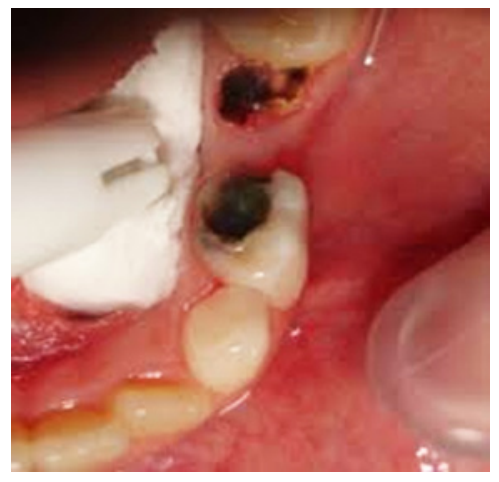

\section{Cavidades clase V}

e encuentran ubicadas las caries en el tercio gingival o cervical de las caras bucales o labiales y linguales de 1 todas las piezas dentarias. La sensibilidad está caracterizada en esta zona por la apertura de los túbulos del esmalte, influye la temperatura, la presión osmótica y los estímulos químicos, Figura 65.

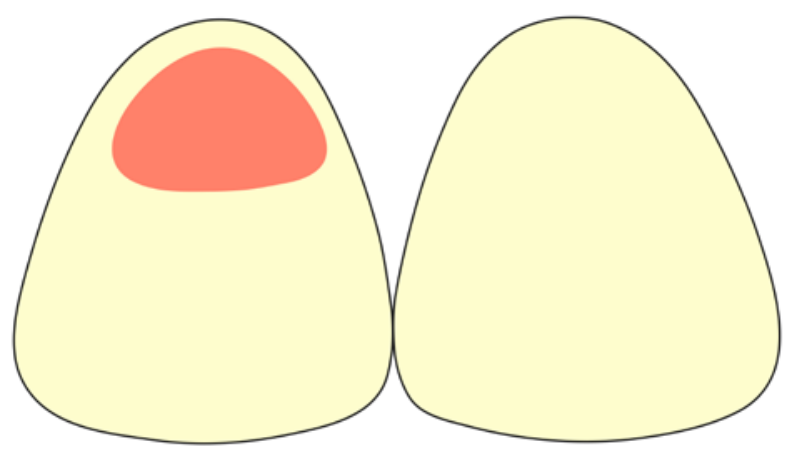

FIGURA 65

La forma de la cavidad estará limitada a la forma de la caries y a zonas descalcificadas adyacentes. Su forma de diseño puede ser trabajada en diferentes maneras:

Como riñón o en forma de media luna, o en forma de ocho acostado, corbata, con los bordes también redondeados, en los dientes posteriores se pueden observar dos cavidades, Figura 66. 


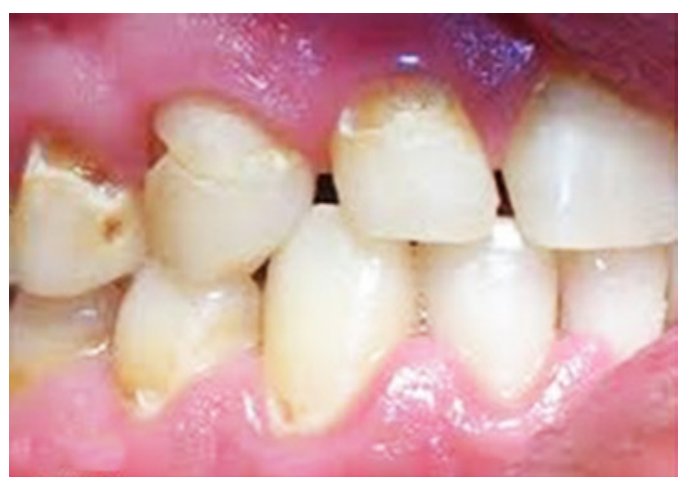

FIGURA 66

En alguna ocasiones podrán extenderse por abajo del borde libre de la encía. Se sigue utilizando la fresa 330 o pera o la 335 de cono invertido para profundizar la cavidad, teniendo cuidado con la cámara pulpar, Figura 67 vista vestibular y Figura 68 corte axial.
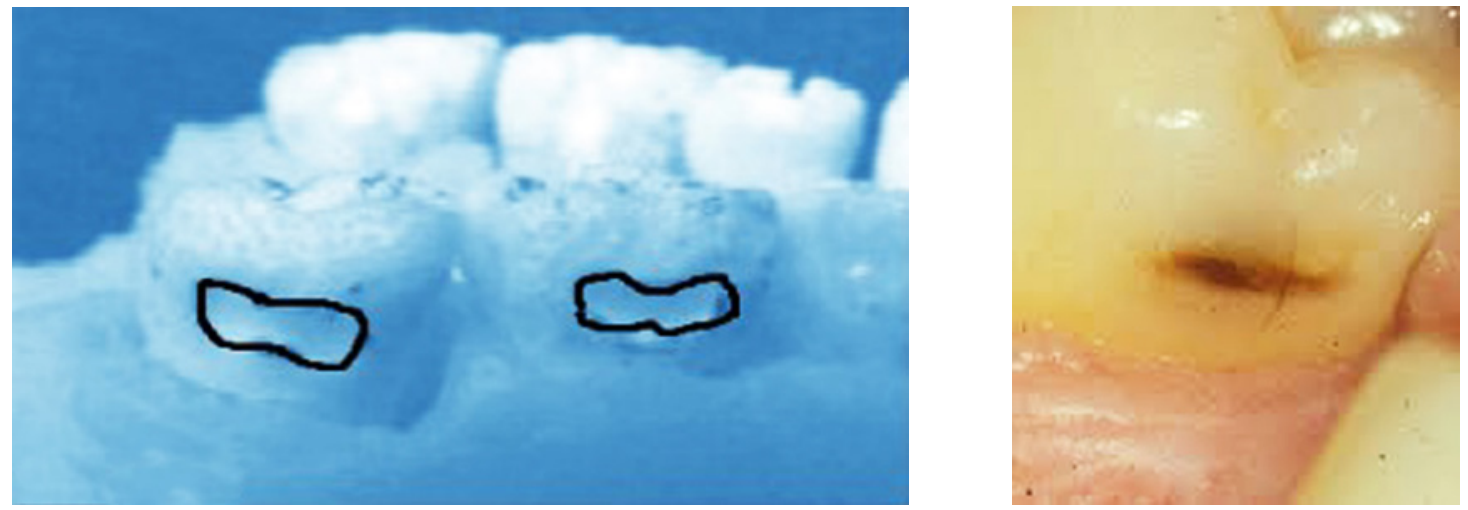

FIGURA 67

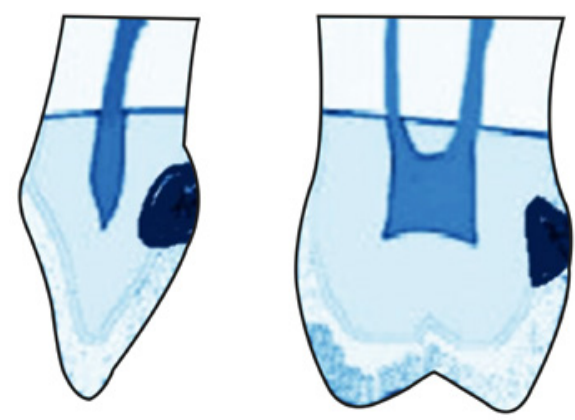

FIGURA 68

Forma de contorno se determina dependiendo de la forma de la cavidad ya hecha por la caries, dándole una forma de media luna, por abajo del borde libre de la encía marginal, la fresa de carburo \#245 penetra $1.5 \mathrm{~mm}$. Inclinando la fresa en angulación de 45 grados a la superficie vestibular. 


\section{8 \\ Gurrola Martínez B \& Álvarez Bañuelos VJ}

Perpendicular a la superficie externa del diente, Figura 69.
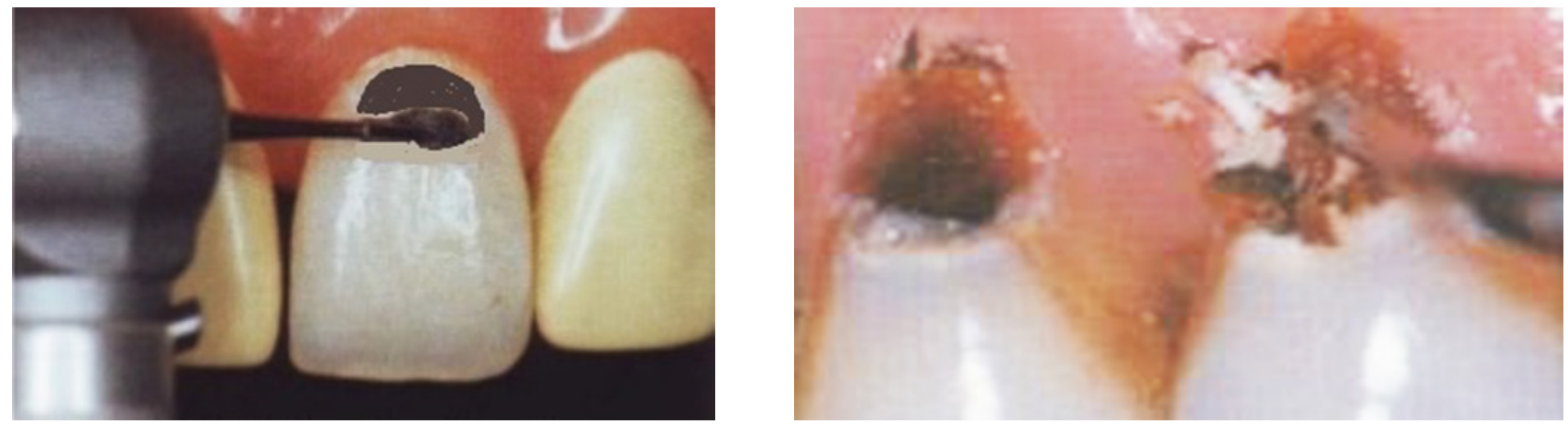

\section{FIGURA 69}

La forma de resistencia debe ser llevada en consideración al margen de la preparación a fin de que las paredes circundantes estén inclinadas hacia labial evitando que el esmalte se quede sin soporte dentinario, de esta forma, las paredes están convergentes hacia el labial, Figura 70.

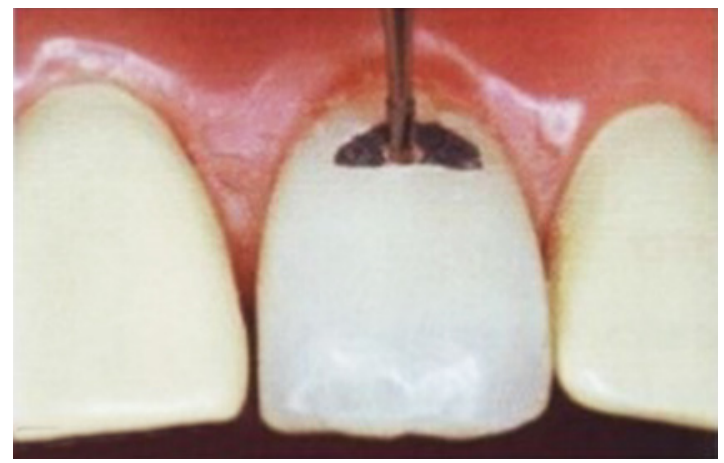

FIGURA 70

Forma de conveniencia, la pared axial convexa en todos los sentidos, considerando la forma biológica del diente, para evitar la remoción de dentina sana, misma que protege a la pulpa.

Esta forma también puede ser de trabe mecánica cuando no hay mucho tejido dentinario afectado, en ese caso se utiliza un grabador de esmalte y se coloca una resina.

A continuación se colocan las diferentes fresas de corte con las que se puede hacer estas cavidades tipo clase V: forma de cono invertido, rueda de carro y bola, Figura 71. Cuando están muy destruidas las superficies dentarias, como se ve en la imagen se recomienda colocar coronas. 

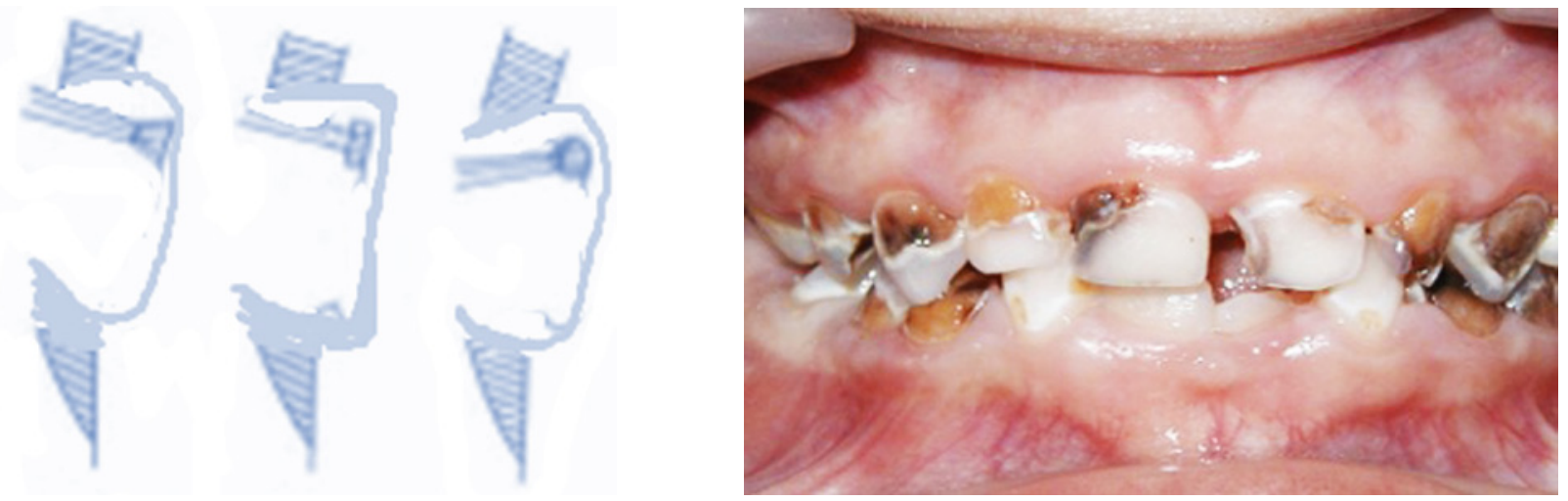

FIGURA 71

\section{Ejercicio: Cavidades clase V}

De las dos imágenes inferiores, marca con una cruz la que corresponda al diente infantil.
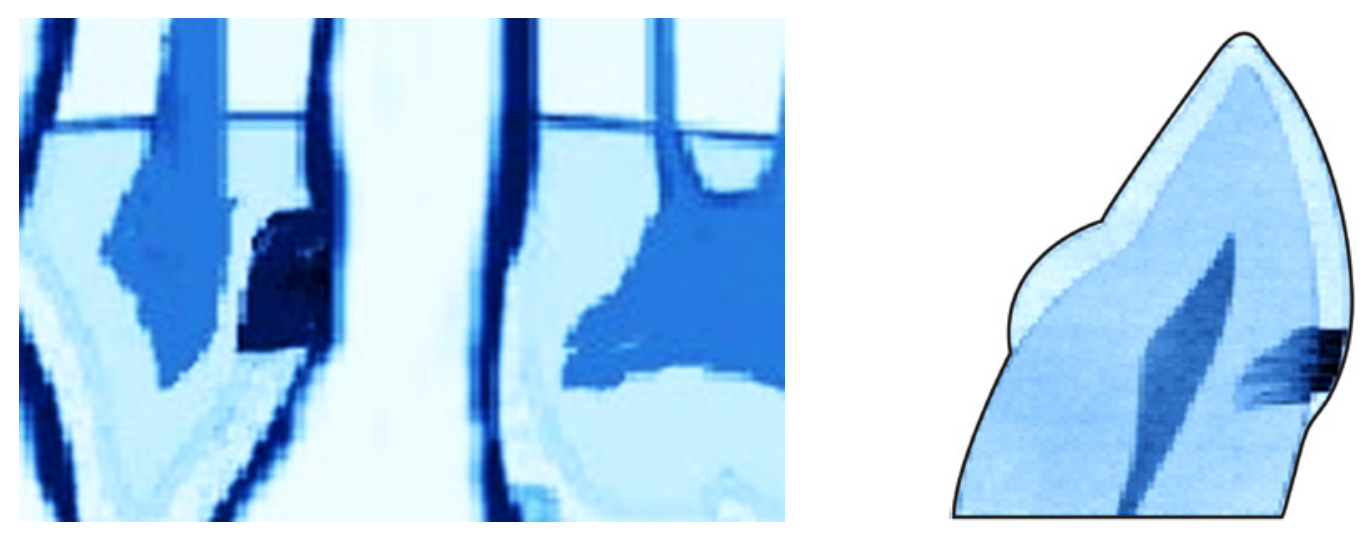


\section{Técnica de realización de la cavidad clase I}

P ara realizar la cavidad de clase I, iniciamos en la cara palatina, y se utiliza una fresa de diamante para abrir el esmalte de bola pequeña. Se mide más o menos $3.5 \mathrm{~mm}$ alrededor del surco donde se encuentra la caries, esto es de un milímetro y medio hacia afuera para realizar la apertura de la cavidad, Figura 72.
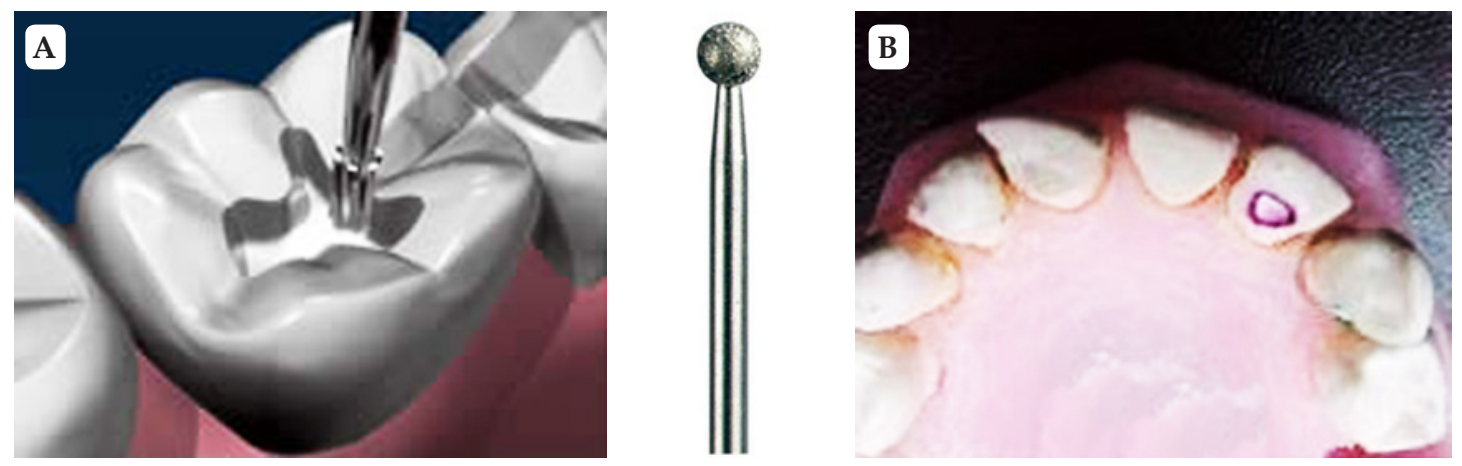

\section{FIGURA 72}

Como podemos ver en la cara palatina del incisivo lateral en la Figura 72b y en el dibujo del molar, la amplitud y la profundidad de la fresa con la inclinación de las paredes, con la convergencia hacia oclusal, Figura 73.
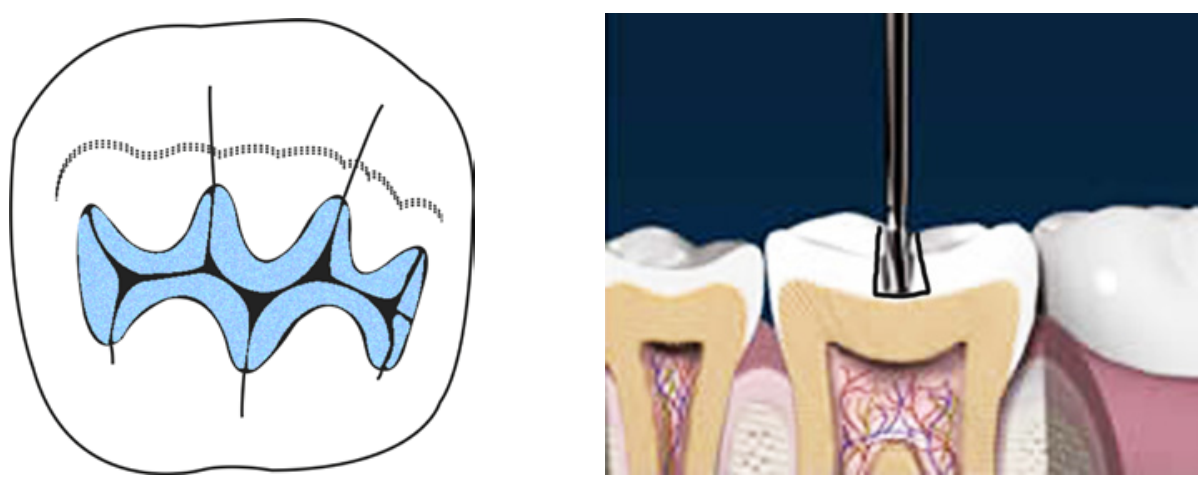

\section{FIGURA 73}

Se debe tener cuidado de no hacer muy grande la apertura, siempre inicia de menor a mayor, ya que de esto dependerá la inclinación de la fresa en el fondo de la cavidad, Figura 74.

Sigue la profundidad del proceso carioso. Se coloca la fresa, en la cara oclusal y con movimientos de vaivén, de vestibular a palatino, logrando la convergencia hacia oclusal, Figura 75, se va haciendo la cavidad y eliminando la caries. 


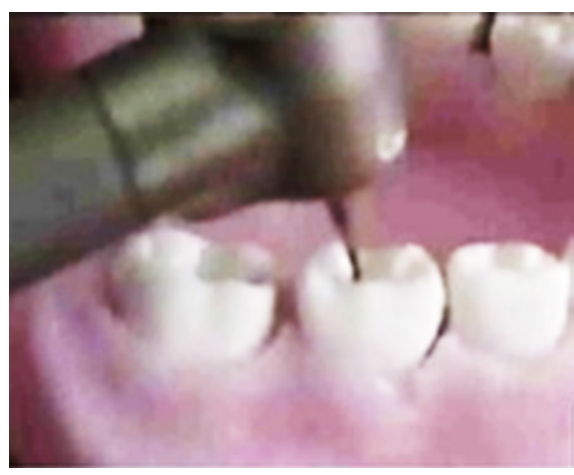

FIGURA 74

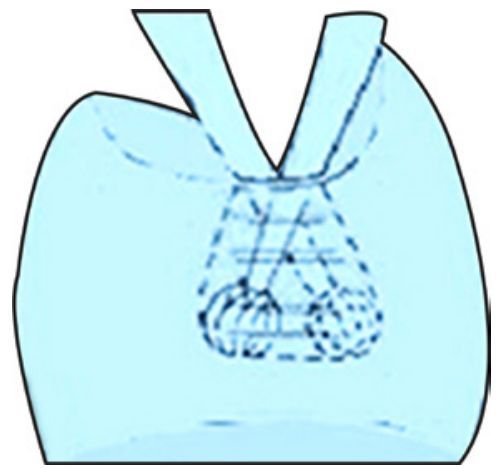

FIGURA 75

Diferentes diseños de clase I, se pueden realizar en los dientes infantiles, depende del proceso carioso y de la anatomía de la cara oclusal, Figura 76. Con la fresa 330 (de pera), generalmente con alta velocidad y refrigeración, con la pieza de alta velocidad y agua, penetrar en la fosa careada y extender la preparación por todos los surcos principales hasta zonas de esmalte listo. Profundidad adecuada: $1^{\circ}$ molar temporal: $1.00-1.20 \mathrm{~mm}, 2^{\circ}$ molar temporal: 1.20-1.50 mm, Figuras 77a y b.

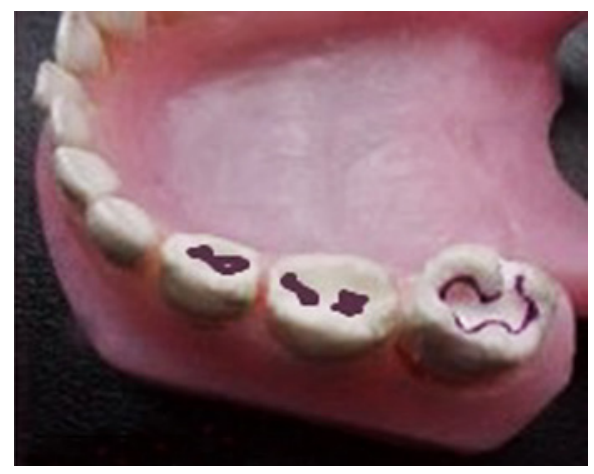

FIGURA 76
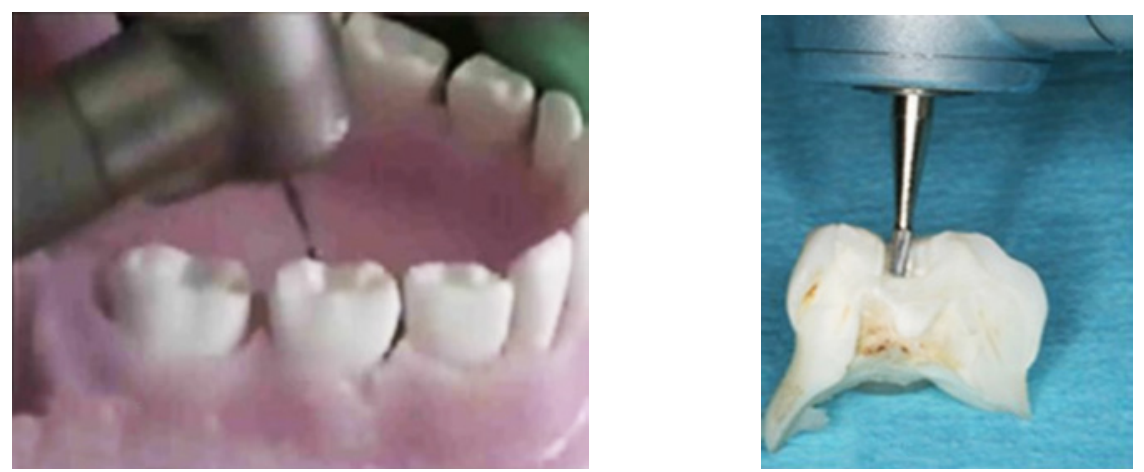

FIGURA 77 


\section{2 Gurrola Martínez B \& Álvarez Bañuelos VJ}

La profundidad adecuada permitirá situar el suelo de la preparación ligeramente $(0,5 \mathrm{~mm})$ por debajo de la unión amelo dentinaria sin llegar a producir una exposición pulpar.

La parte activa de la fresa $330(1,5 \mathrm{~mm})$ puede ser usada como guía, en la amplitud de surco, Figura 78.

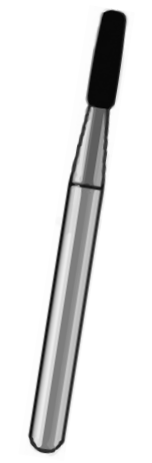

FIGURA 78

Las paredes son convergentes a oclusal, lo que nos dará la inclinación es la colocación de la misma fresa. Esto es piso amplio que no se alcanza a ver por oclusal, la unión de la pared con el piso.

El ángulo cavo superficial es a 90º esta convergencia da la retención a las paredes, Figuras 79 y 80.

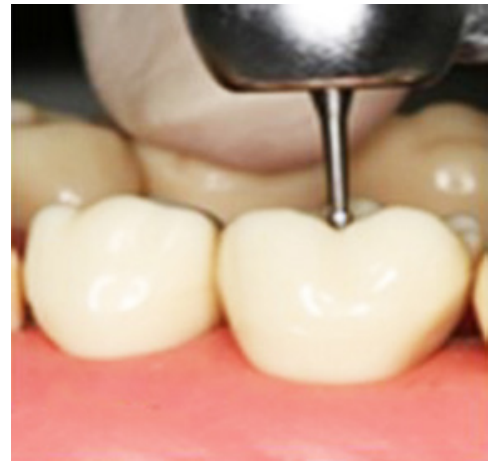

FIGURA 79

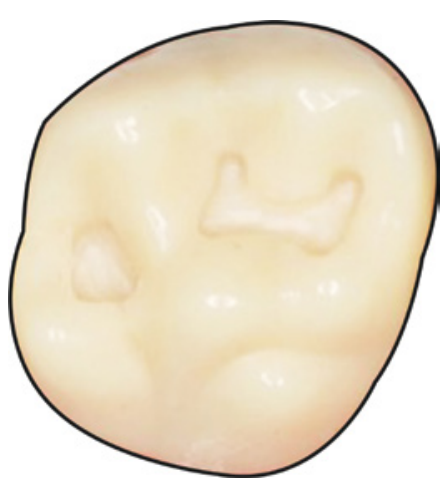

FIGURA 80

Extender la preparación por las fisuras vestibulares y linguales acabando en superficies lisas.

La estructura dentaria que quede entre la superficie vestibular y la extensión por las fisuras será de 1,5 mm, aproximadamente, Figuras 81, 82,83. 


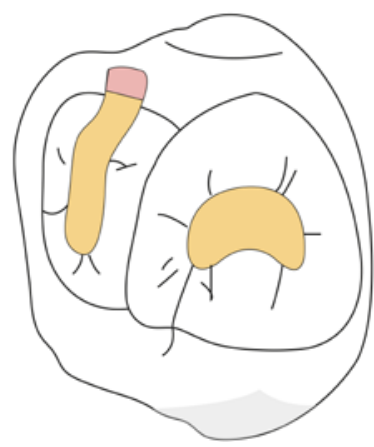

FIGURA 81

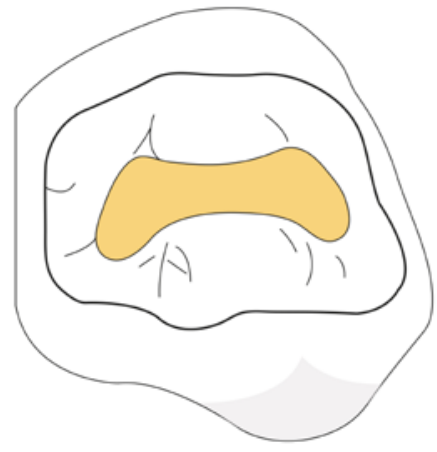

FIGURA 82

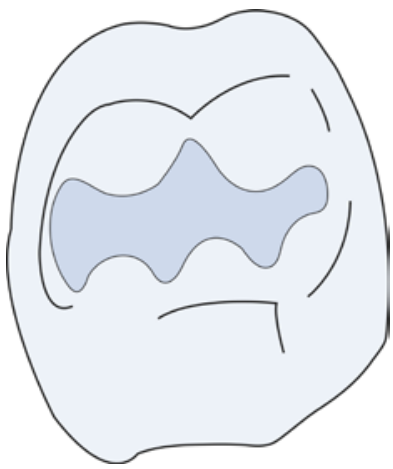

FIGURA 83

Para hacer las paredes proximales mantener la fresa paralela o ligeramente divergente respecto al eje axial del diente para no debilitar la cresta marginal, que no deberá ser menor de 1,25 mm, Figura 84. Evitar debilitar las cúspides y mantener una continua y suave curva en el trazado de la cavidad. La anchura del istmo deberá ser aproximadamente de $1.50 \mathrm{~mm}$ (doble de diámetro de la fresa 330).

La pared pulpar deberá ligeramente cóncava (en sentido mesiodistal) hacia oclusal, con su parte más profunda en el centro de la cavidad. Todos los ángulos internos han de ser redondeados. Al igual los márgenes y paredes serán acabados y suavizados. No invadiremos las crestas oblicuas, la preparación estará limpia y sin restos, Figura 85.

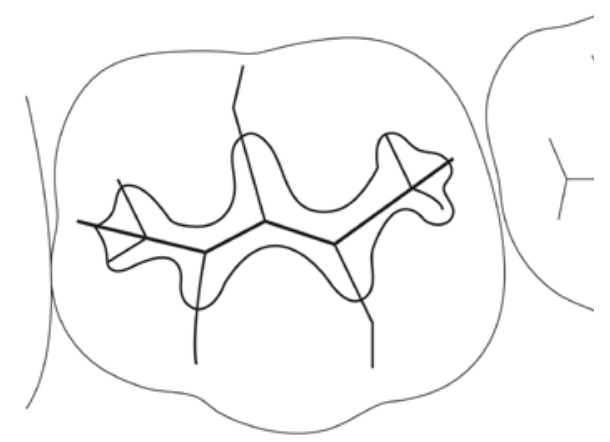

FIGURA 84

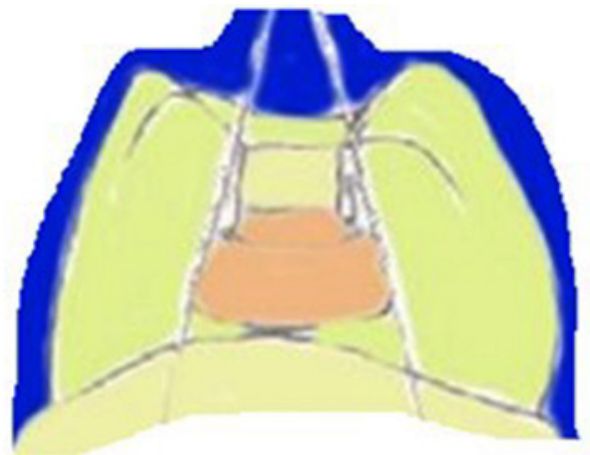

\section{8}

Cuando se va a colocar un composite (material adhesivo) sólo se requiere eliminar el esmalte y la dentina cariados y no debe hacerse extensión profiláctica, ya que tras la obturación se cubrirá con sellado de fisuras aquellas zonas libres de caries. El ángulo cavo superficial debe ser biselado, aproximadamente en una extensión de $0.5-1 \mathrm{~mm}$, Figura 86.

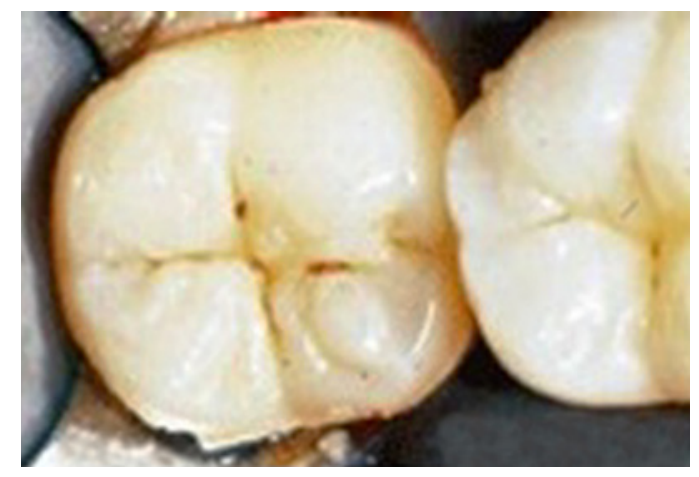

FIGURA 86 


\section{4 \\ Gurrola Martínez B \& Álvarez Bañuelos VJ}

Ya Bronner, citado por Chaple y Maldonado, ${ }^{24,25,26}$ desde (1931) establece que "el área entre el contacto proximal y el reborde marginal no es sitio de aparición ni desarrollo de la caries, y en consecuencia no necesita extensión por prevención", por tanto, un cajón proximal estrecho era factible, Figuras 87 y 88.

En cualquier preparación cavitaria se debe remover la menor cantidad de tejido sano, y cuidar los cuernos pulpares.

En el caso de existir diferentes puntos de caries en el piso pulpar, se deberá de profundizar como se observa en las Figuras $88 \mathrm{~b}$ y c, sólo en ese punto para evitar eliminar más tejido.

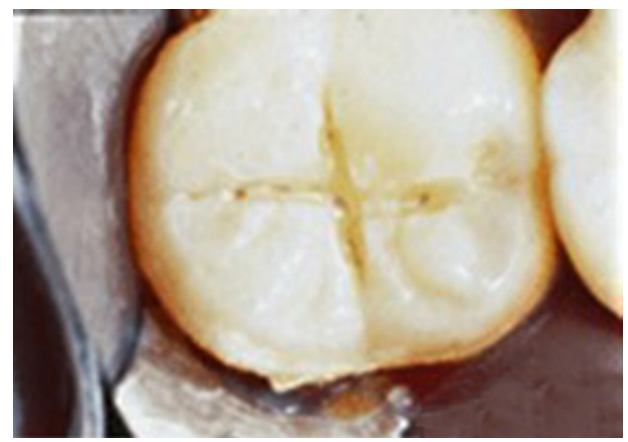

FIGURA 87
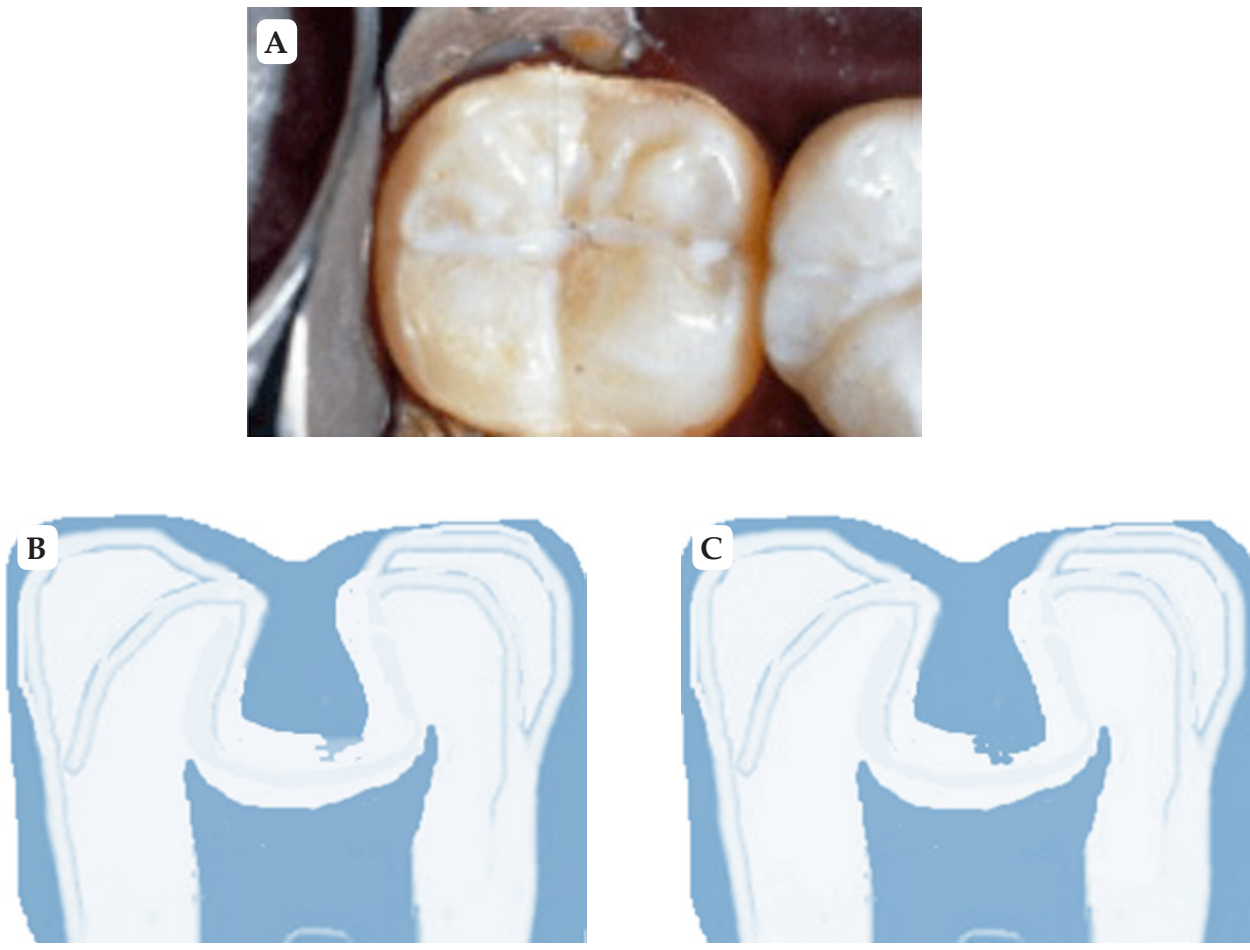

FIGURA 88 


\section{Técnica de realización de la cavidad clase II}

\section{Para amalgama}

\section{E} 1 diseño cavitario de una Clase II, de Black, requería de la creación de una cola de milano adyacente al reborde marginal de la pared proximal no cariada y los márgenes de las paredes vestibular y lingual del cajón proximal fuera del contacto con el diente vecino, en lo que llamó "área de inmunidad a la caries". Eran cavidades muy amplias. ${ }^{22}$

Recuerda siempre que para poder hacer el diseño de la cavidad Bronner siempre se deberá tener en cuenta en el paciente, la anatomía dentaria; altura cúspidea, profundidad de los surcos: observación de la curvatura y la forma de las caras y superficies libres y proximales. Y se recomienda hacer una

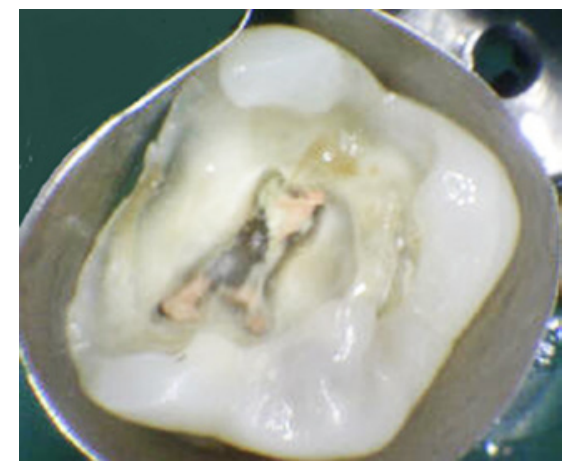
prueba de vitalidad, análisis oclusal y de fuerzas, análisis de la relación del área de contacto, así como la evaluación periodontal.

Ahora la preparación de la caja proximal, Bronner, la cavidad es menos invasiva, con la convergencia hacia oclusal de las paredes, vista desde la pared axial Figura 89. La liberación de los contactos proximales con el diente vecino se realizará con las técnicas que aseguren la menor remoción de tejido sano.
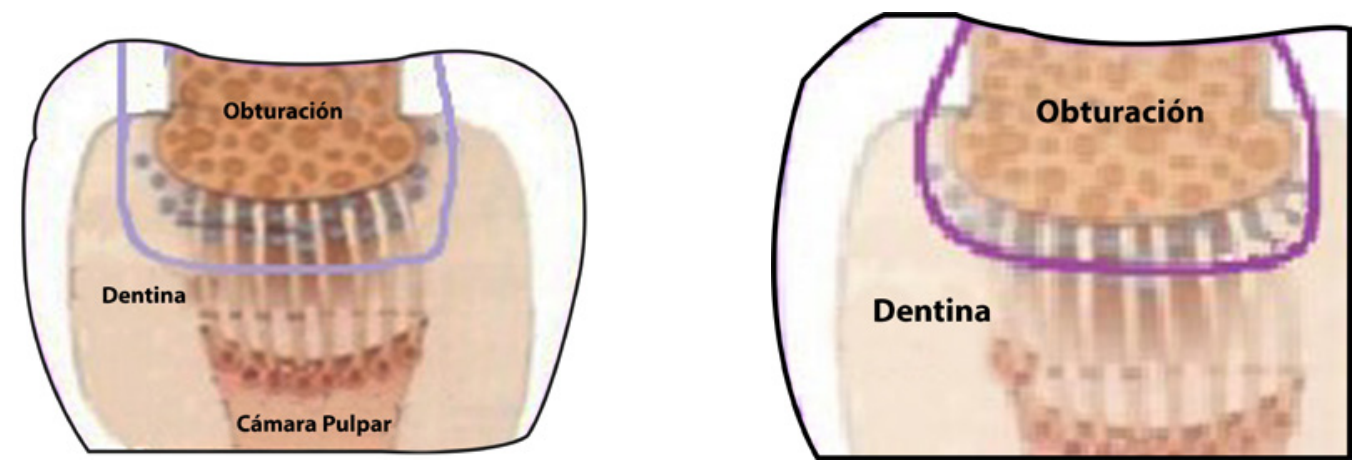

FIGURA 89

El diseño de las cavidades infantiles, en oclusal cuidar desde el istmo hasta la pared proximal, los cuales deberán ser suaves y ligeramente curvado.

El istmo deberá ser de 1/4 - 1/3 de la distancia intercuspídea, $1^{\mathrm{o}}$ molar temporal: $1.00-1.25 \mathrm{~mm}$, 2o molar temporal: $1.25-1.50$ mm, Figura 90.

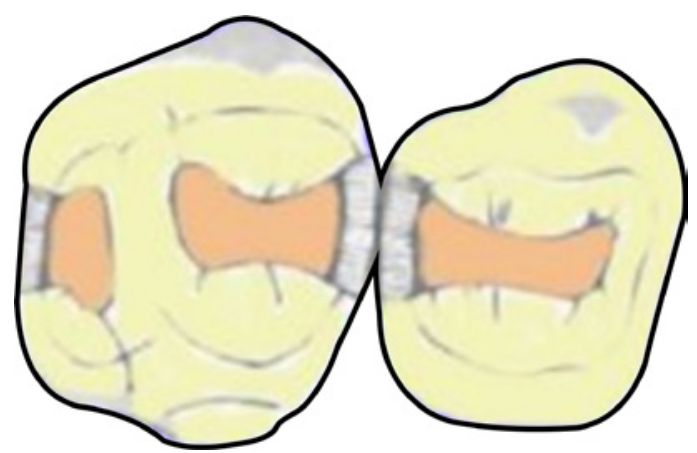

FIGURA 90 


\section{6 \\ Gurrola Martínez B \& Álvarez Bañuelos VJ}

Con un movimiento pendular de la fresa, se coloca en el piso, se mueve, hacia vestibular y lingual, a nivel de la unión amelodentinaria y en dirección gingival, estableceremos la anchura y profundidad de la caja proximal, la fina pared proximal, que queda puede ser removida, en ocasiones con una cucharilla muy pequeña, sin dañar el diente adyacente, Figura 91.

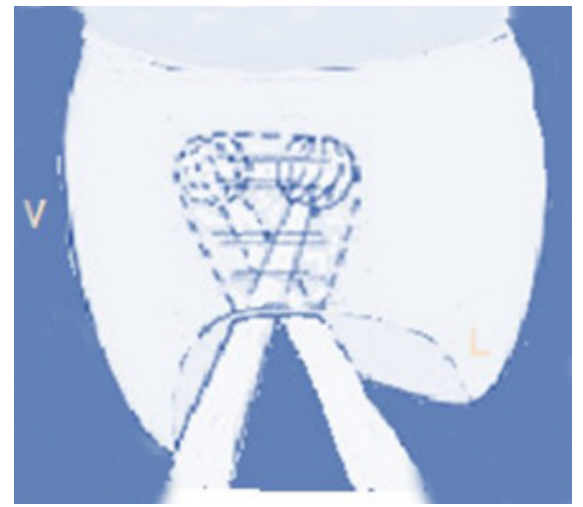

FIGURA 91

Las cavidades Bronner, el diseño base se hace siguiendo la forma de la caries, con la fresa de pequeña de pera, la forma de las paredes proximales vestibular y lingual de nuestra preparación se hacen convergentes hacia oclusal, Figura 92.
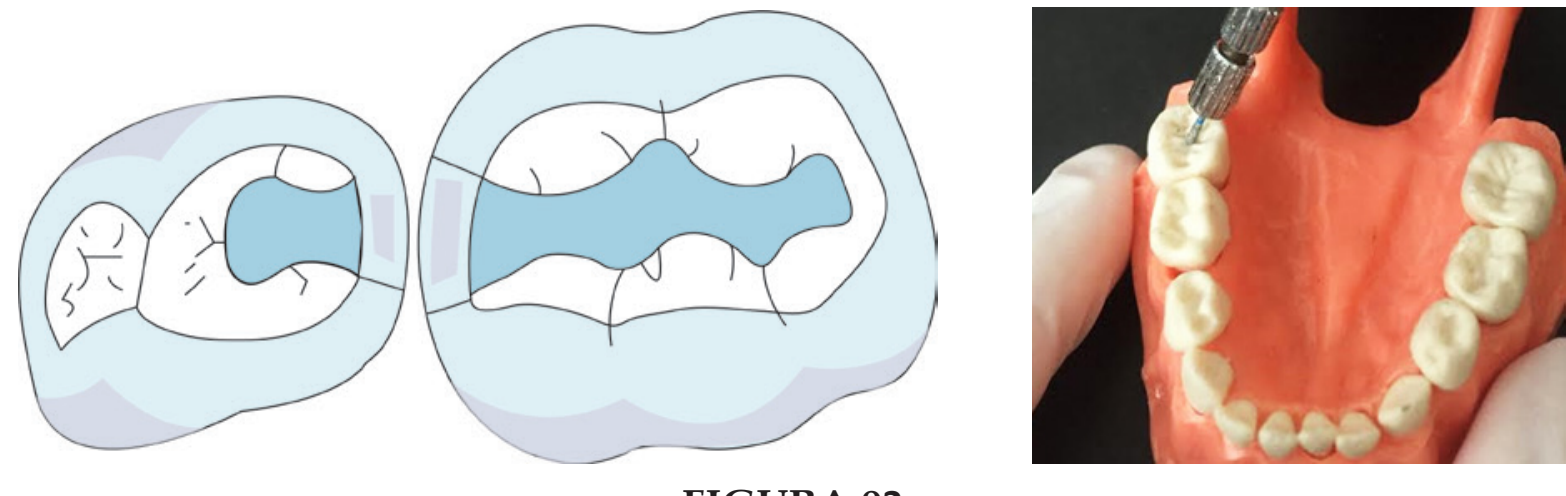

FIGURA 92

La pared gingival en su punto más bajo se extiende justo por encima de la encía. El contorno de la pared axial debe ser paralelo a la superficie externa del diente y no más profunda aproximadamente de: $1 \mathrm{~mm}$ en el $1^{\circ}$ molar y 1.2 mm en el 2o molar temporal, Figuras 93 y 94. 


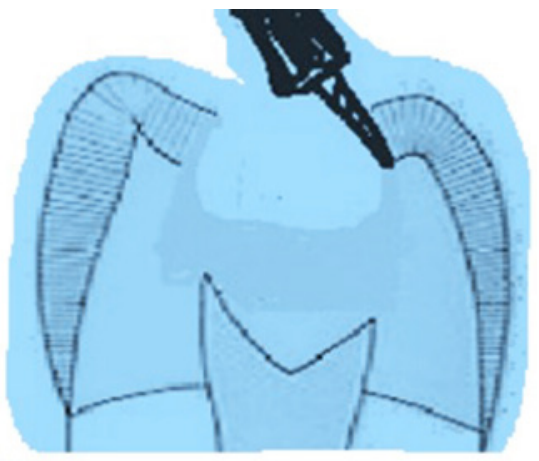

FIGURA 93

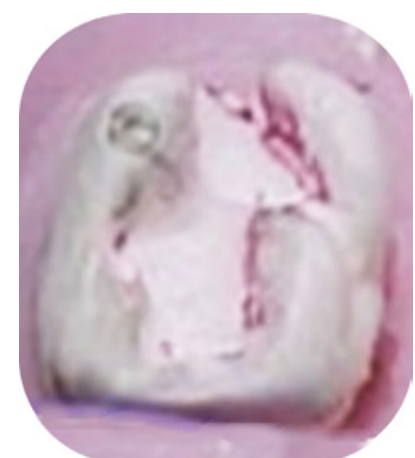

FIGURA 94

De este modo se mantiene una distancia desde la pulpa y se asegura un adecuado grosor de la amalgama, ensanchar de vestibular a lingual de manera conservadora, Figura 95.
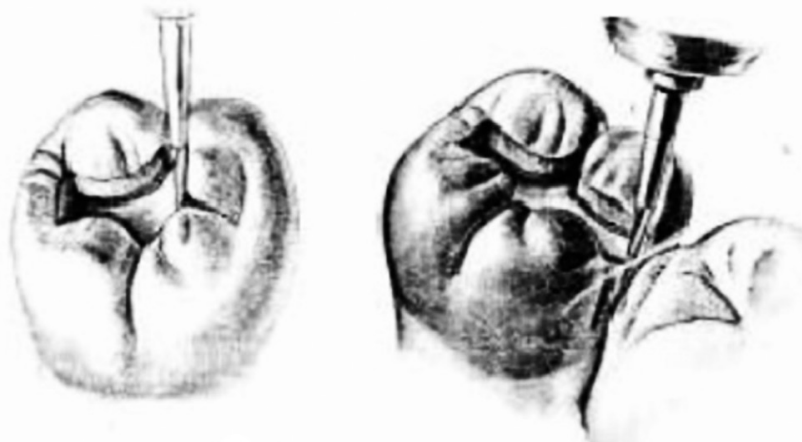

FIGURA 95

Por otra parte existen evidencias que avalan la utilización de selladores de puntos y fisuras; en consecuencia, estos son idóneos para sellar fisuras no cariadas limitando la restauración de amalgama a aquellas fisuras, donde la caries invadió a la dentina.

La verdadera prevención considera la eliminación quirúrgica de la caries, exclusivamente en las áreas de caries activa y que radiográficamente indique que invadió a la dentina, Figura 96.

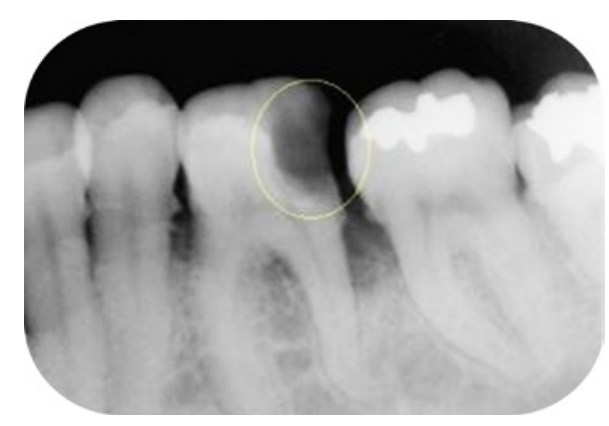

FIGURA 96 


\section{8 \\ Gurrola Martínez B \& Álvarez Bañuelos VJ}

Cuando se va a colocar material adhesivo como se ve en las imágenes inferiores, una vez terminada la cavidad, Figura 97, nos aseguramos de la retención mecánica del material con el grabado de esmalte, Figura 98.

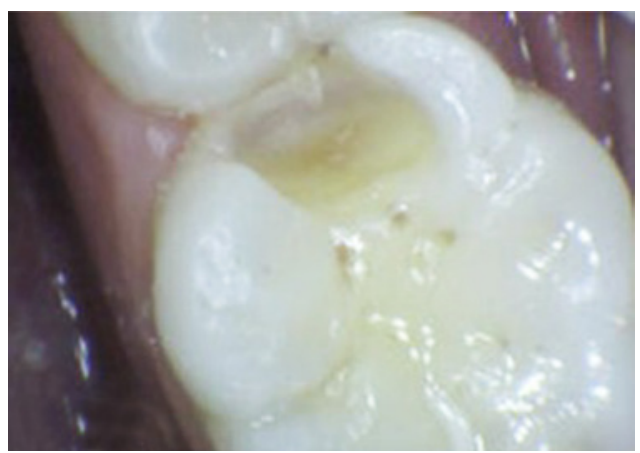

FIGURA 97

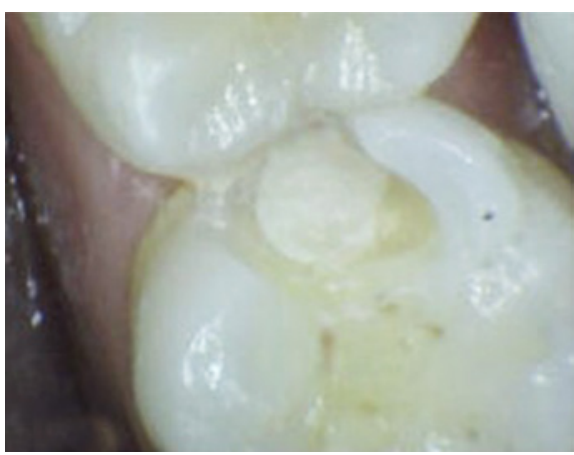

FIGURA 98

De esa forma el diseño cavitario de Black, paredes paralelas pisos planos, se limita a la eliminación de la dentina cariada y esmalte sin soporte, dejando mayor cantidad de tejido dentario.

El estado actual de la odontología operatoria considera como prevención la utilización de métodos que favorezcan al proceso de remineralización, el seguimiento de las lesiones sin cavidad y la mínima intervención de tipo quirúrgico tradicional.

En el caso del molar, la apertura se inició, con fresa de carburo por estar ya muy destruido el esmalte y se realizó la caja proximal en forma retentiva, Figura 99, Bronner, liberando la caries, se puede ver la diferencia del piso pulpar, no tiene profundidad igual, para evitar eliminar más tejido sano.
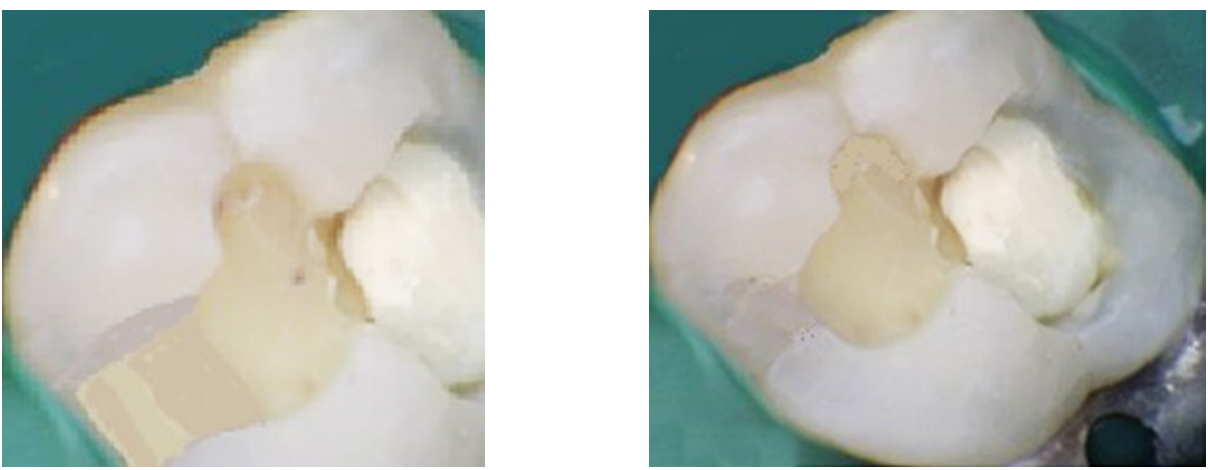

\section{FIGURA 99}

En el caso de las piezas dentarias sean inferiores, para lograr la convergencia, ángulos redondeados, el ángulo axio vestibular se hizo con la fresa troncocónica de carburo 1170, de pera, cono invertido, Figura 100, la pared axila ubicada $0.5 \mathrm{~mm}$ dentro del límite amelodentinario. En las Figuras 101 a podemos ver el diseño de la cavidad, la cavidad, que será restaurada con amalgama y en la Figura 102 cavidades muy amplias mesio ocluso distal. 
Para realizar las cavidades clase II, necesitaremos colocar una banda matriz.
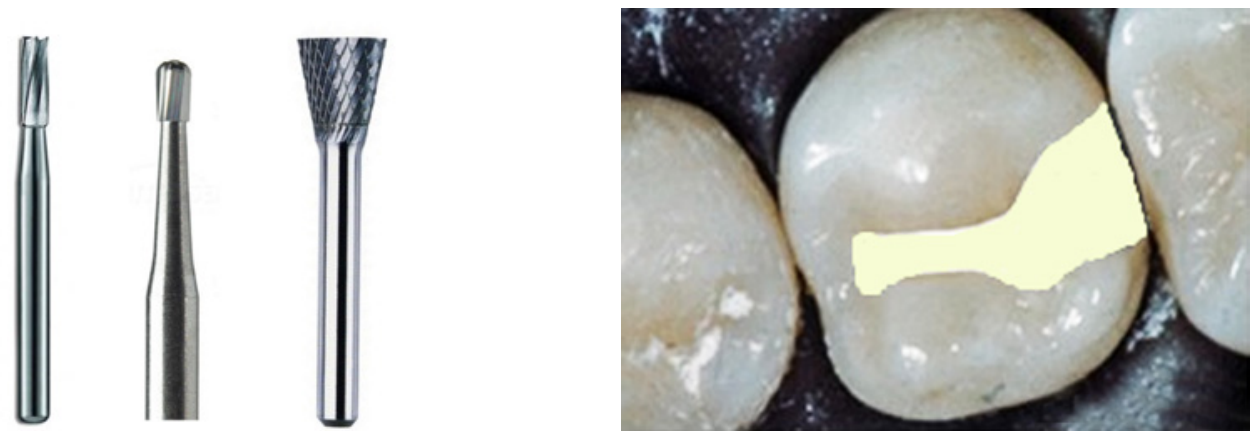

FIGURA 100
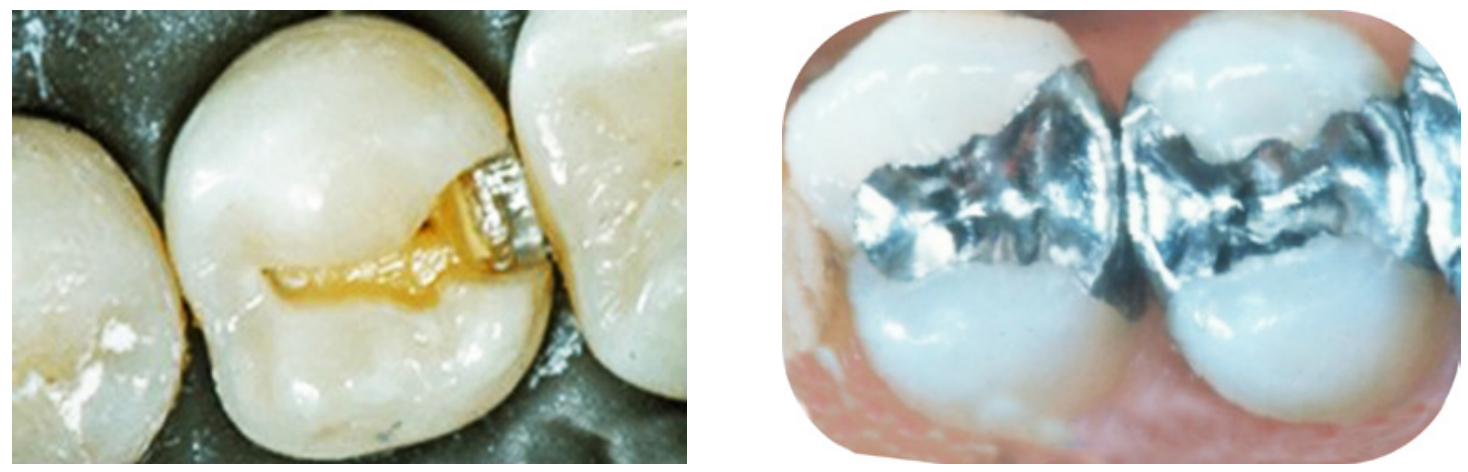

FIGURA 101
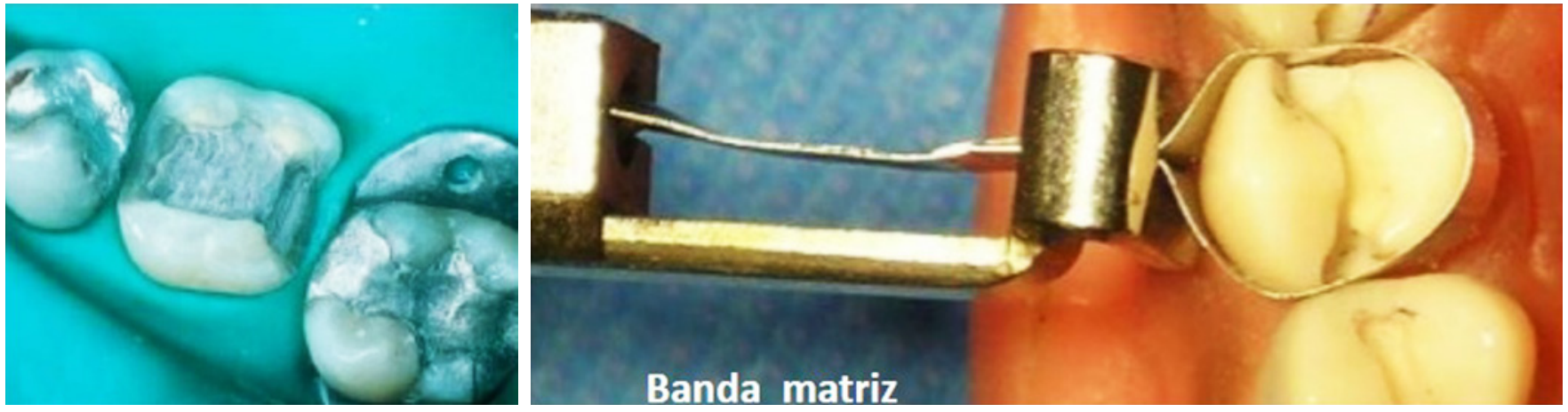

FIGURA 102 


\section{$70 \quad$ Gurrola Martínez B \& Álvarez Bañuelos VJ}

\section{Técnica de realización para cavidades clase III}

Localizadas en las superficies proximales de los dientes anteriores. Son de necesidad estética lo cual obliga al uso de las resinas compuestas se prefiere hacer el acceso por palatino o lingual, se deben diseñar y preparar siguiendo el diseño de la caries, Figuras 103 y 104.

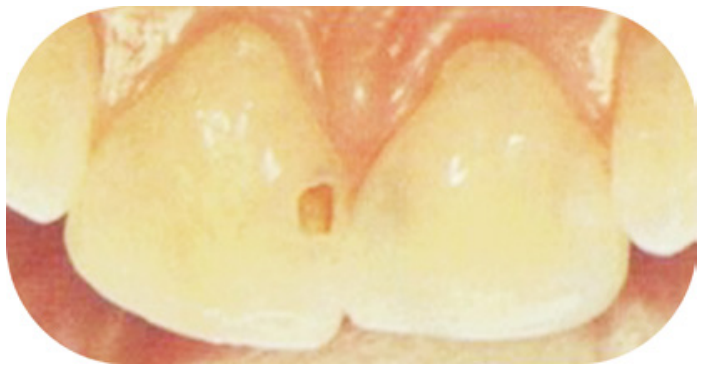

FIGURA 103

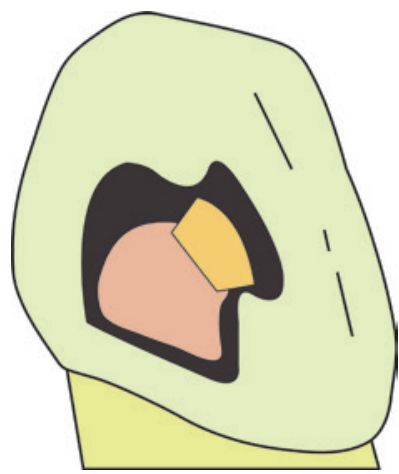

FIGURA 104

Cuando la lesión cariosa se extiende hasta vestibular se debe tener cuidado con el diente continuo, es necesario proteger con una banda matriz para, no lastimar la pared mesial del incisivo lateral, Figuras 105 y 106, la banda matriz puede ser de tira de celuloide o metálica.

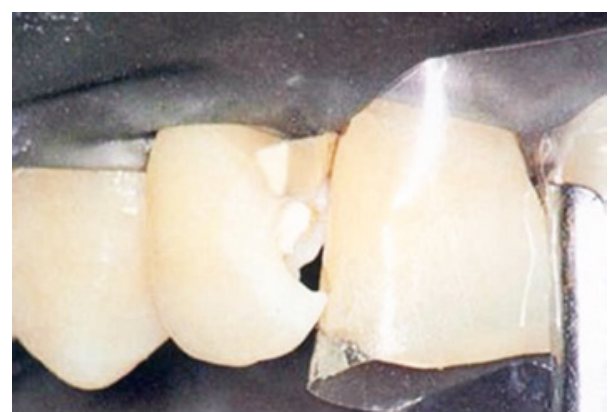

FIGURA 105

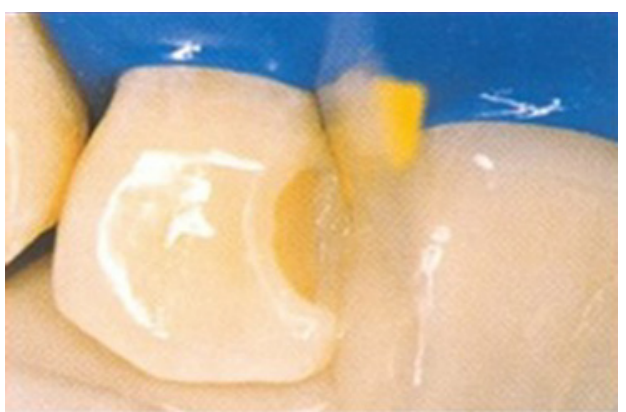

FIGURA 106

Se diagnostica clínicamente visualmente, por radiografía, o transiluminación. Por lo general no pasan el límite amelo dentinario. Se encuentran en el punto de contacto o ecuador del diente, Figura 107. 


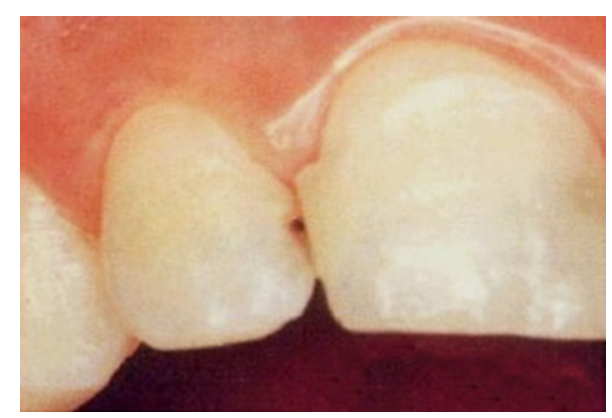

FIGURA 107

La forma de la cavidad es triangular con base gingival y vértice incisal, las paredes convergen hacia proximal, el piso es convexo, con ángulos redondeados, Figura 108. La forma de colocar la fresa es siguiendo la cara externa del diente, Figura 109, y para dar la retención inclinándola hacia apical y hacia incisal, Figura 110 y 111, se ve la profundidad de la fresa de bola.

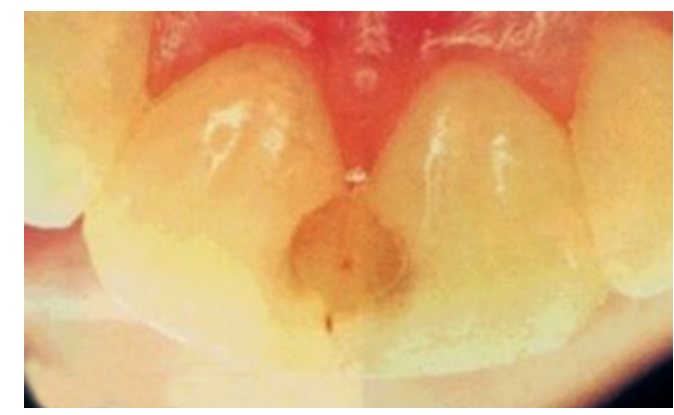

FIGURA 108

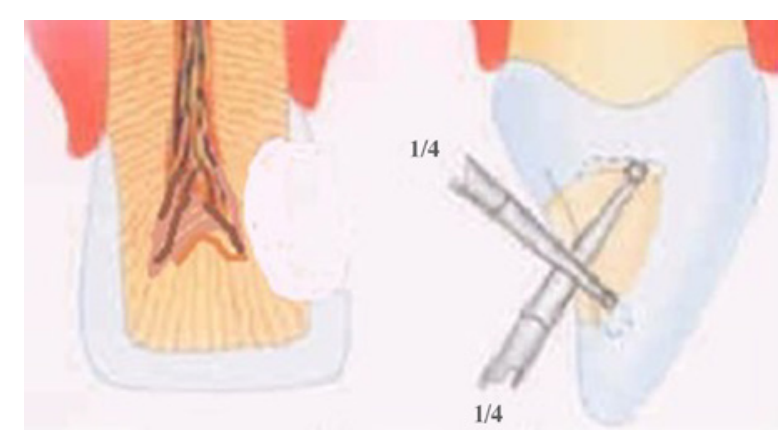

FIGURA 110

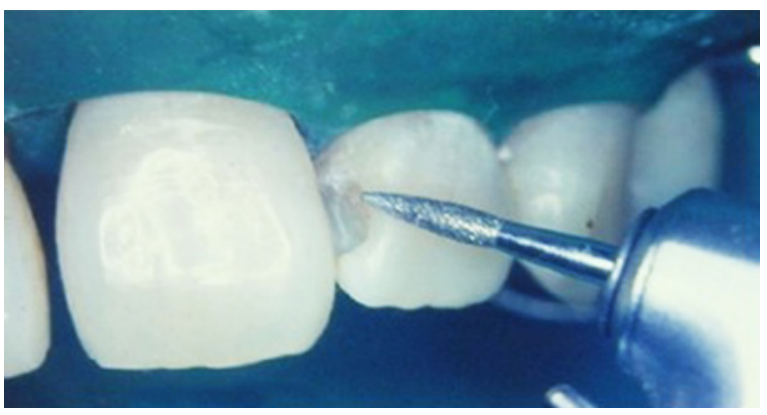

FIGURA 109

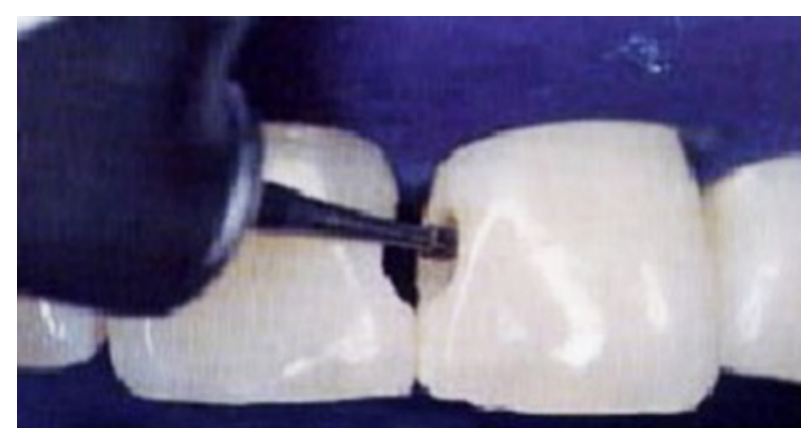

FIGURA 111

En las imágenes inferiores podemos observar las terceras clases obturadas, Figura 112, y las mismas que fueron removidas y se aprecia el diseño y el tamaño de las cavidades en la Figura 113, de forma traslúcida. 


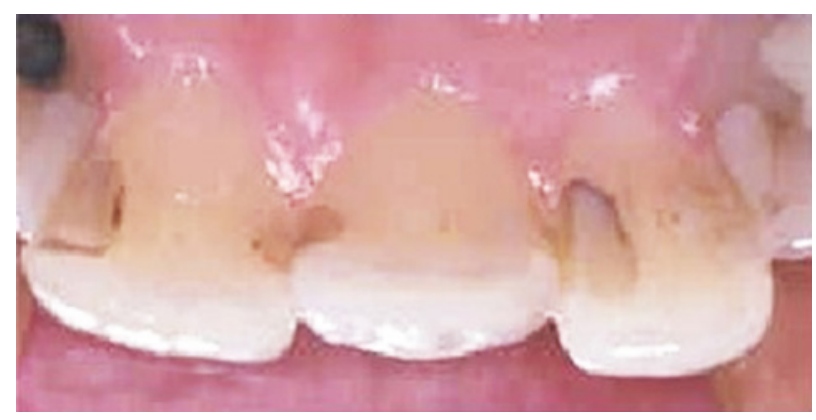

FIGURA 112

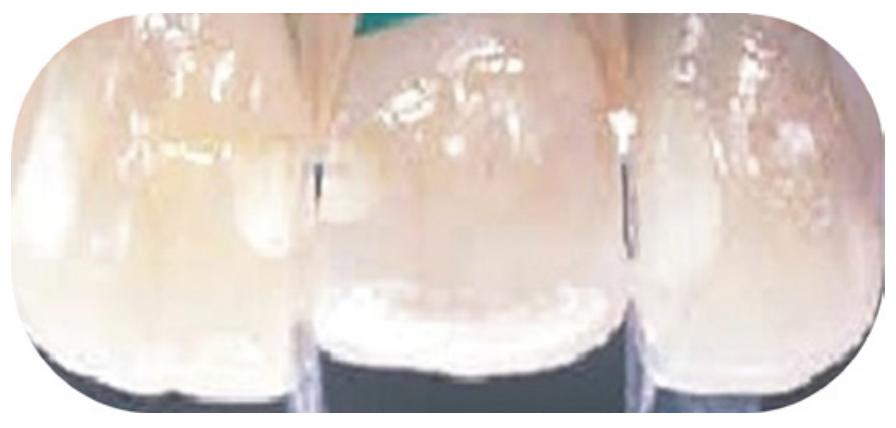

FIGURA 113

\section{Preparación de muñón}

Para las piezas dentarias muy destruidas ya sea por la presencia del proceso carioso, autores como Ortega ${ }^{27}$ señalan que: el diseño de la preparación será la preparación de muñón, Figura 114. Ya sea que en los dientes anteriores con clases III, se pueden colocar diferentes tipos de fundas: de policarbonato, de celuloide con resina o de acero cromo, Figura 115.

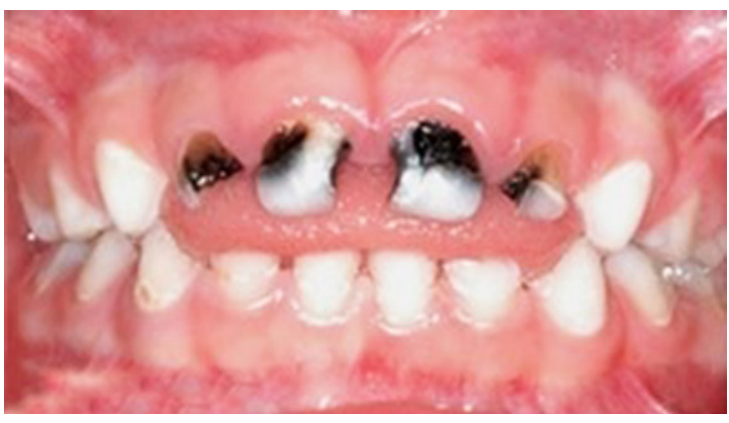

FIGURA 114

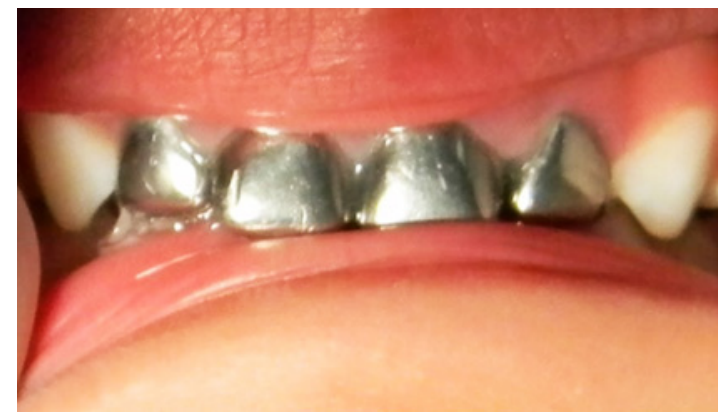

FIGURA 115

En dientes anteriores que tienen caries muy extensas y no se pueden realizar las cavidades de clase $\mathrm{V}$ se colocan las fundas de policarboxilato, Figuras 116, 117, 118a y 118b.

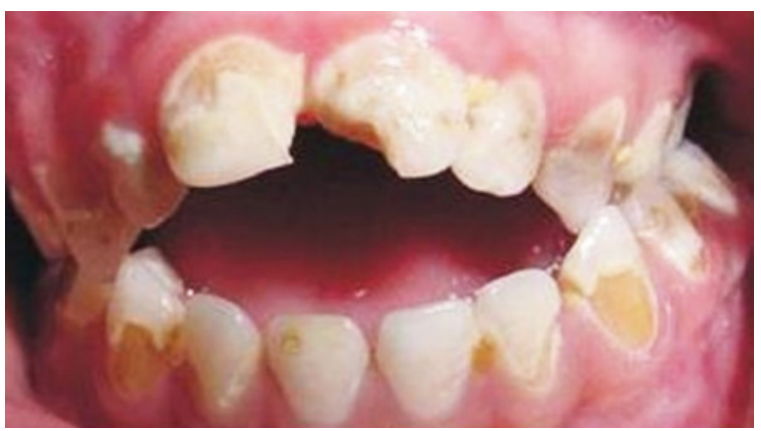

FIGURA 116

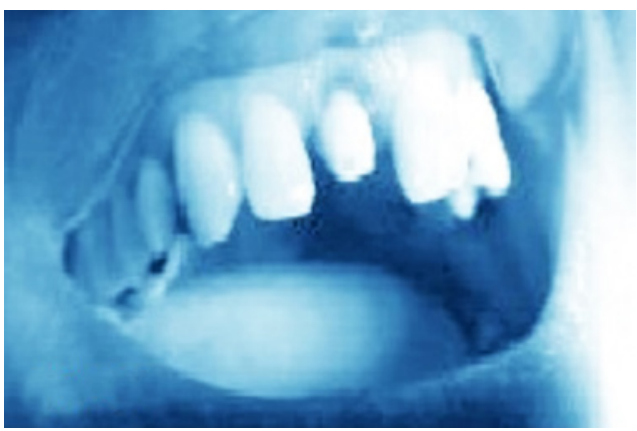

FIGURA 117 

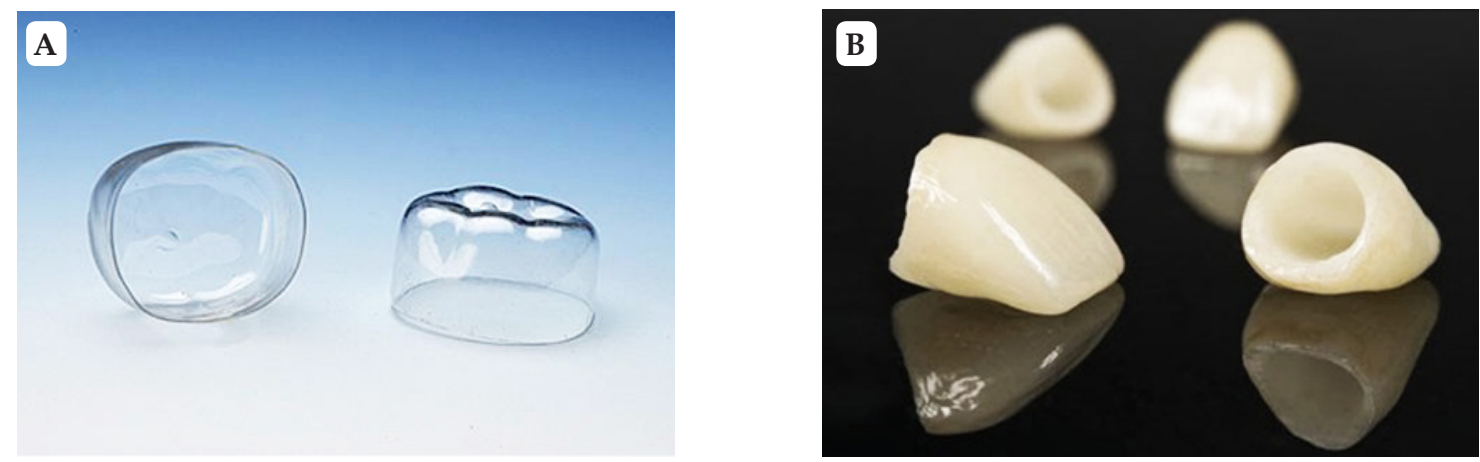

FIGURA 118

Preparación del diente. Previo a su tallado, tenga a la mano los modelos de estudio de su paciente para checar el tamaño que debe tener la corona de acero cromo, Figura 119.

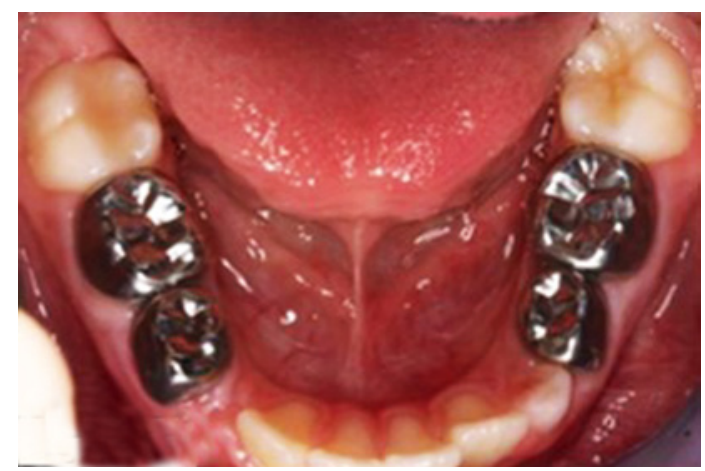

FIGURA 119

La secuencia clínica para el tallado del muñón de una pieza posterior es similar a la de una pieza anterior, salvo algunas diferencias:

1. Desgaste oclusal: se realiza con una fresa tronco-cónica, profundizando $1,5 \mathrm{~mm}$ en cúspides no funcionales y 2 mm en cúspides funcionales, Figura 120, siguiendo la anatomía dentaria. Además realice un bisel en esta última para darle el espesor correcto al material en esta área.

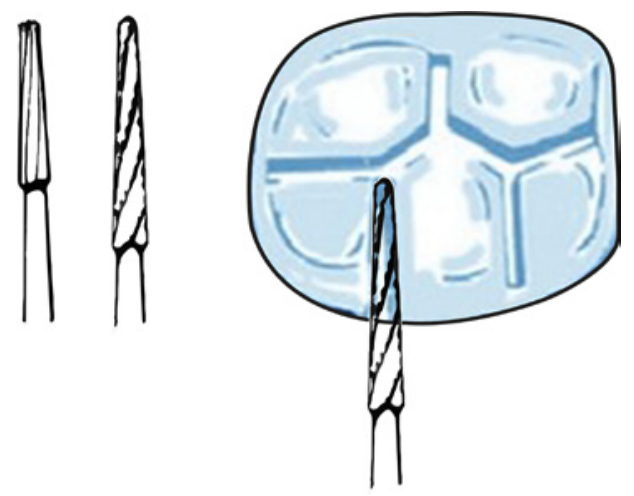

FIGURA 120 


\section{$74 \quad$ Gurrola Martínez B \& Álvarez Bañuelos VJ}

2. Desgaste pared vestibular: realice los surcos de orientación, tomando como medida de desgaste el espesor de la fresa en posición vertical aproximadamente, como se ve en la fotografía, con una profundidad de $1.5 \mathrm{~mm}$, y tomando en cuenta la inclinación de la cara del dientes (2/3 cervicales y $1 / 3$ oclusal), al igual que en el sector anterior, Figura 121.

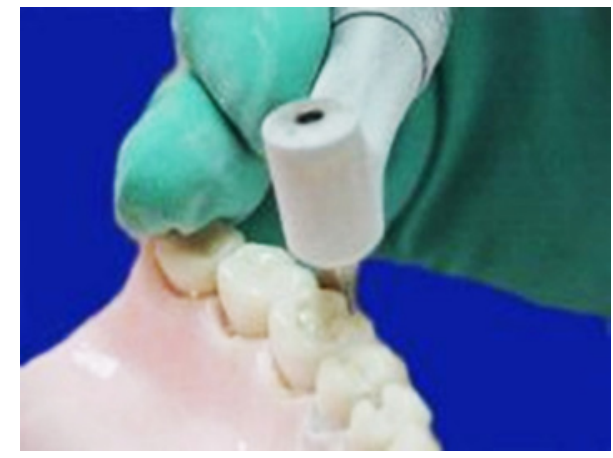

FIGURA 121

3. El desgaste pared palatina: se hace al igual que la cara vestibular, tomando en cuenta las inclinaciones de la pared, realizando surcos guías. El espesor recomendado es de $1 \mathrm{~mm}$.

4. Con una fresa de carburo troncocónica de 18 o 30 filos suavice y alise la superficie dentaria, Figuras 122. El primer paso para la preparación del diente en el cual se va a colocar una corona de acero cromo o de policarbonato deberá ser la administración del anestésico al paciente.
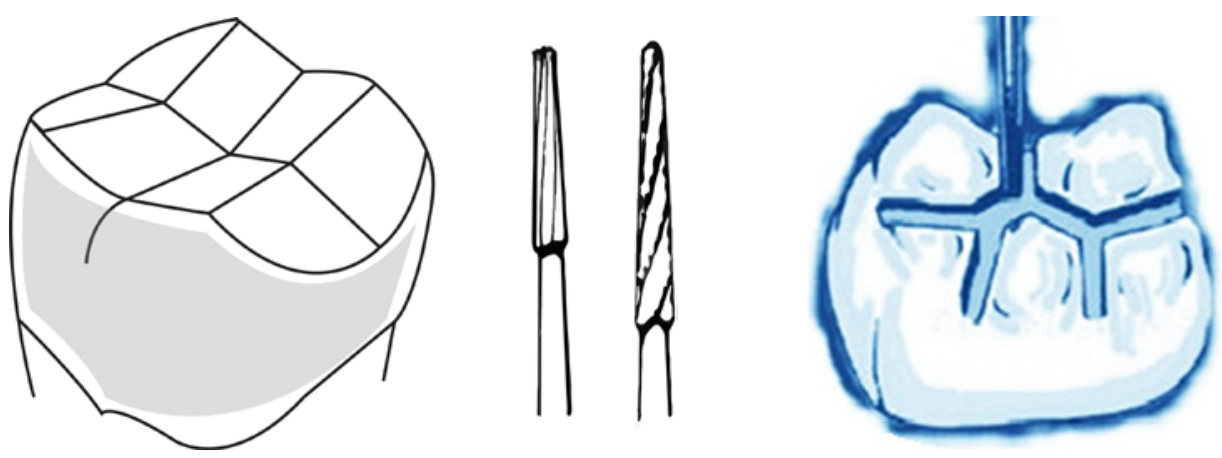

FIGURA 122

Por otra parte algunos autores como: Guilmore y Gillett, citados por Parula ${ }^{22}$, recomiendan la utilización de un disco de una sola luz para el corte de la pared proximal siempre y cuando se proteja al diente contiguo para evitar que se dañe realizar el recorte proximal. Se requiere de un corte distal aun cuando no exista diente contiguo.

Otros utilizan una fresa troncocónica o de fisura, para realizar los cortes, con fresas de fisura o punta de lápiz de diamante o de carburo número 169. L en las paredes mesial y distal tomando la forma vertical, con el cuidado de no formar un escalón falso en la pared, Figura 123. 


\section{Cavidades para dentición infantil 75}
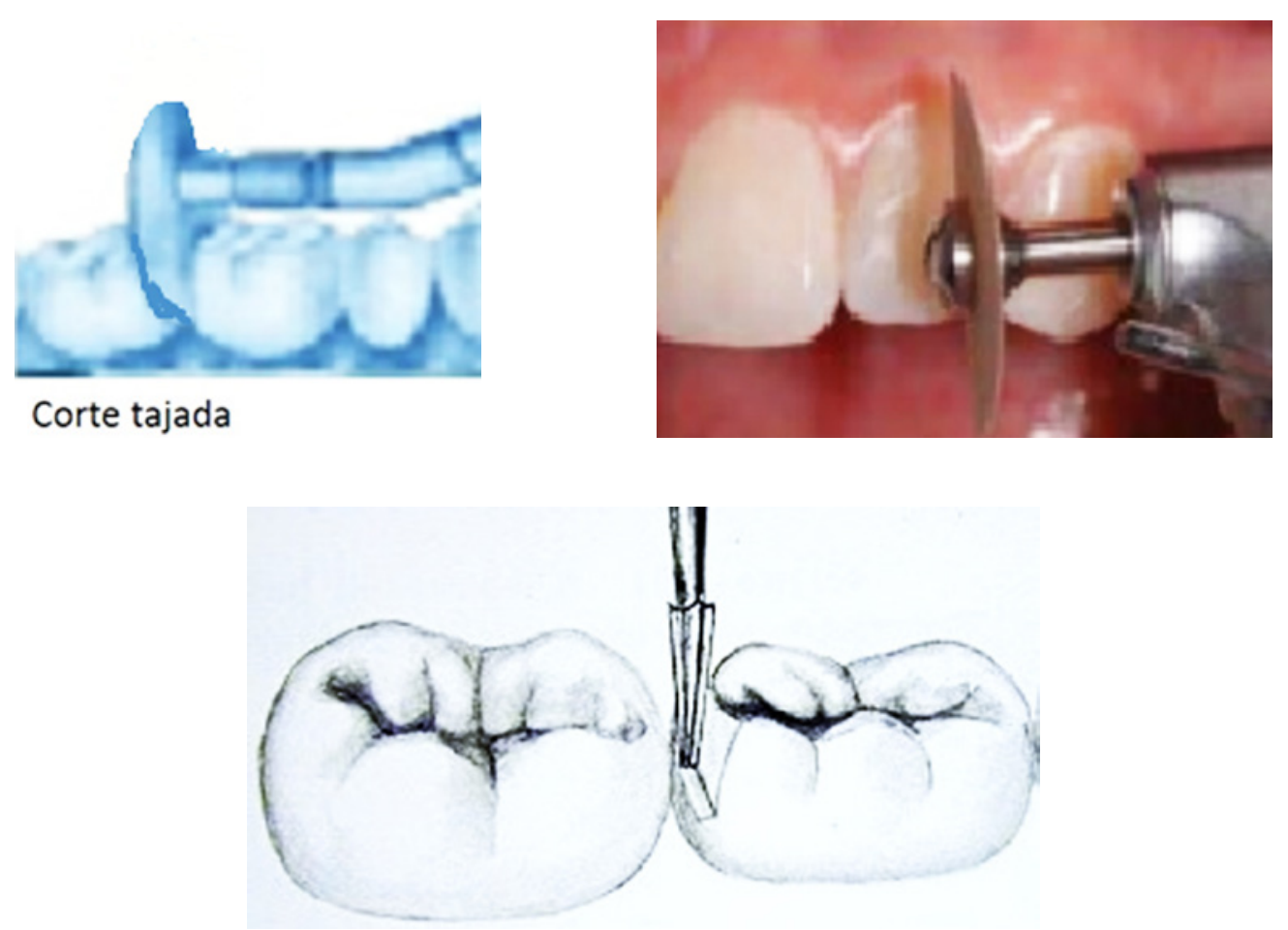

FIGURA 123

La colocación de la fresa cilíndrica o de punta de lápiz por la cara vestibular, es en forma recta sobre el surco accesorio, la profundidad la proporciona el grosor de la fresa, Figuras 124 y 125.

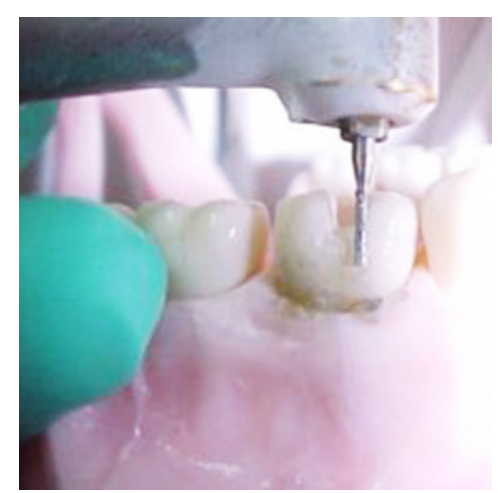

FIGURA 124

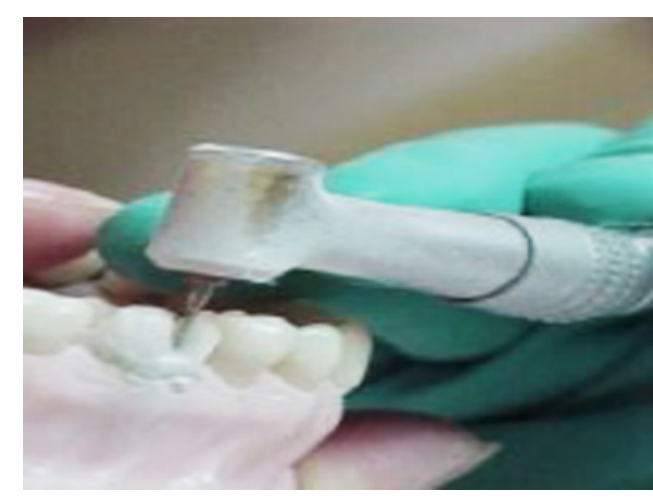

FIGURA 125 


\section{6 \\ Gurrola Martínez B \& Álvarez Bañuelos VJ}

\section{Reducción oclusal}

Reducción oclusal, este corte debe seguir la anatomía de la pieza dentaría en la superficie oclusal a una profundidad de 1.5 a $2 \mathrm{~mm}$ lo que permite suficiente espacio para la corona de metal. Autores como Kenneth ${ }^{28}$ y Escobar $^{29}$ recomiendan la realización inicial en los surcos de $1 \mathrm{~mm}$ de profundidad en la superficie oclusal, para contribuir a establecer la reducción correcta (Figuras 126b, c, d y e).

Para desgastar la altura de la cúspide del diente es indicado dividir la cara oclusal en secciones y empezar a desgastar cúspide por cúspide para tener una referencia y saber que cúspide ya fue rebajada, utilizando las fresas de carburo y de diamante, Figura 126c. En las imágenes se puede observar el desgaste de la pieza dentaría en color blanco y el contorno oscuro es la corona de acero, con la cual se va a sustituir el tejido perdido, Figuras 126d y e.
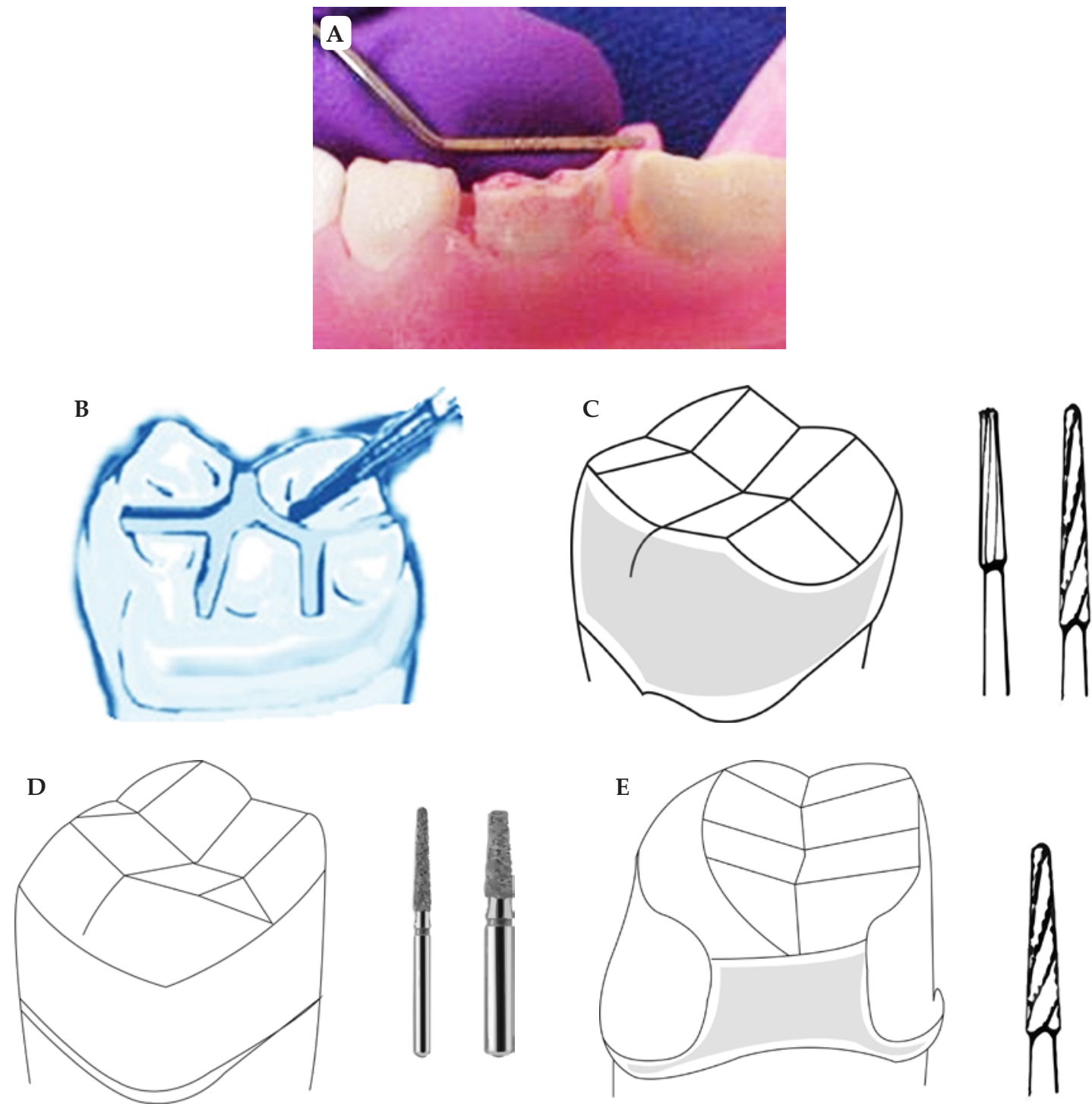

FIGURA 122 
Toda la preparación debe ser redondeada, de tal forma de que no existan bordes ajenos a la preparación. El desgaste de las caras bucal y lingual es mínimo. Se deberá tomar un modelo de estudio previo al desgaste de las paredes con el objetivo de medir la corona, Figura 127.

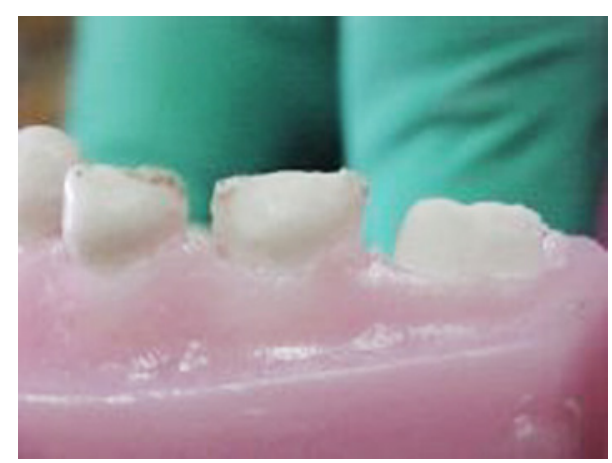

FIGURA 127

Selección de la corona, se mide con un calibrador o vernier en el modelo de estudio y se compra del tamaño exacto.

Adaptación, la finalidad es hacer que los bordes de la corona queden en el surco gingival y que reproduzca la morfología dentaría, como se ve en la Figura 128.

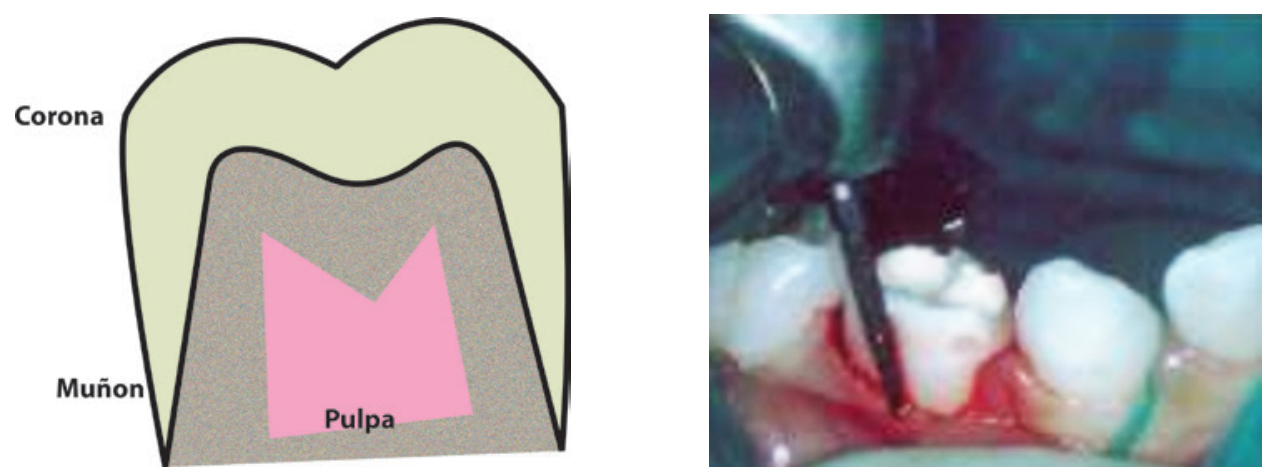

FIGURA 128

Todas las coronas prefabricadas precisan de adaptación y recortado.

Para calcular con certeza la reducción en el corte gingival se hará una marca en la corona a nivel del borde libre de la encía y se reducirá la corona con tijeras curvas, el borde de la corona recortado reducirá la altura ocluso gingival efectiva de ella. Toda la preparación debe estar cubierta por la corona, como se ve en la radiografía. 


\section{Gurrola Martínez B \& Álvarez Bañuelos VJ}
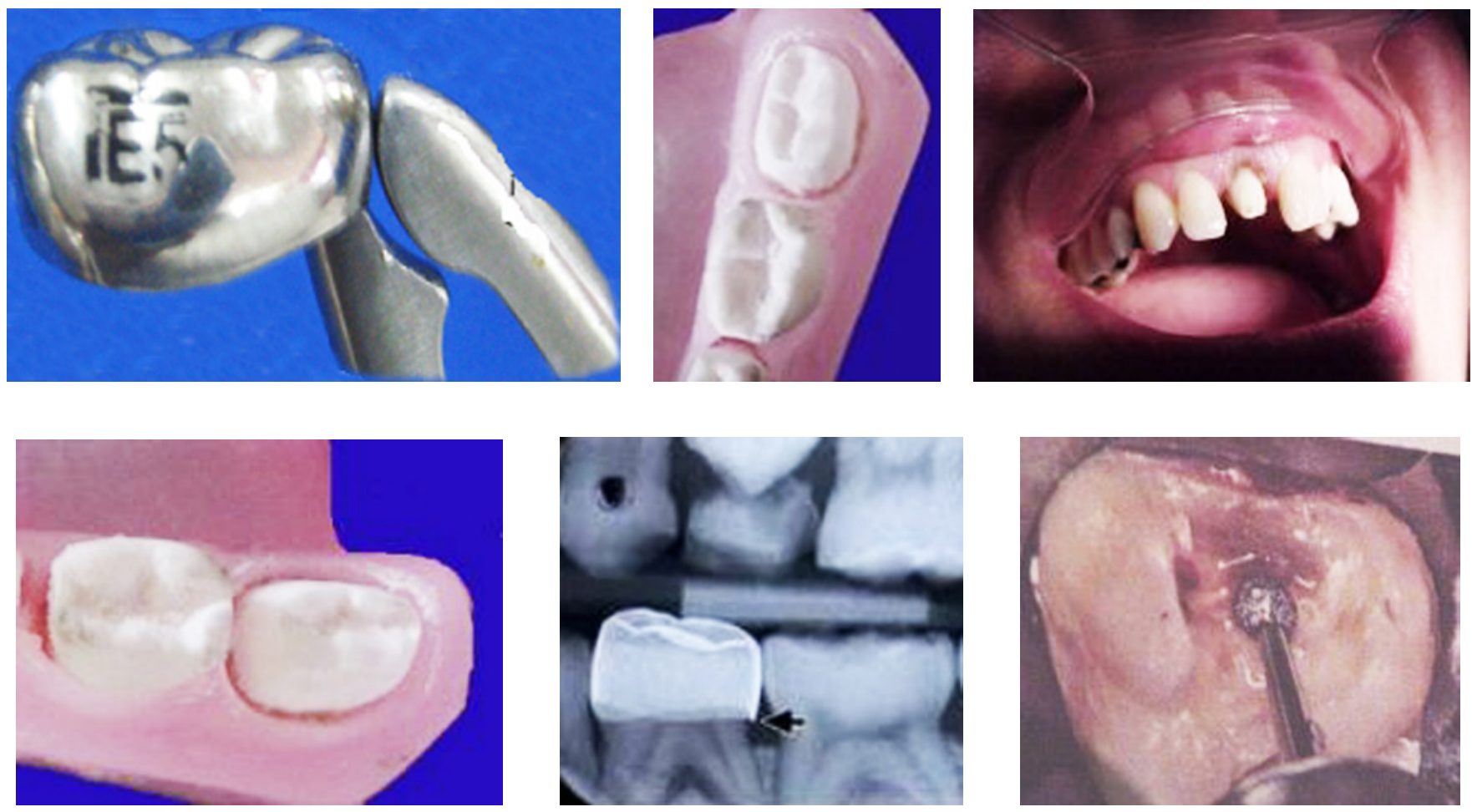

\section{Ejercicio}

De acuerdo a las cavidades que se observan en la imagen de la arcada superior y al cuadrante, coloca la clase que le corresponde.

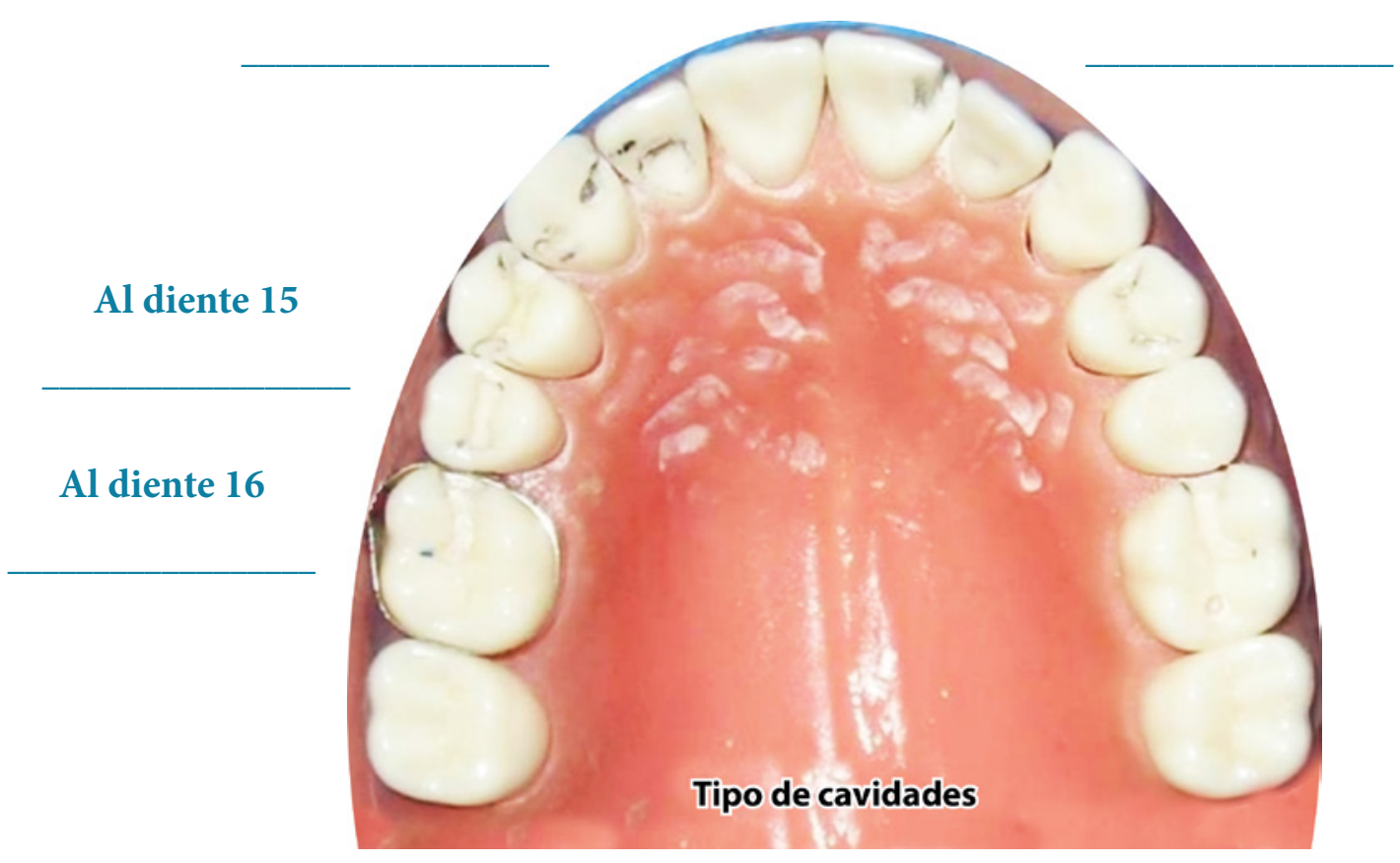




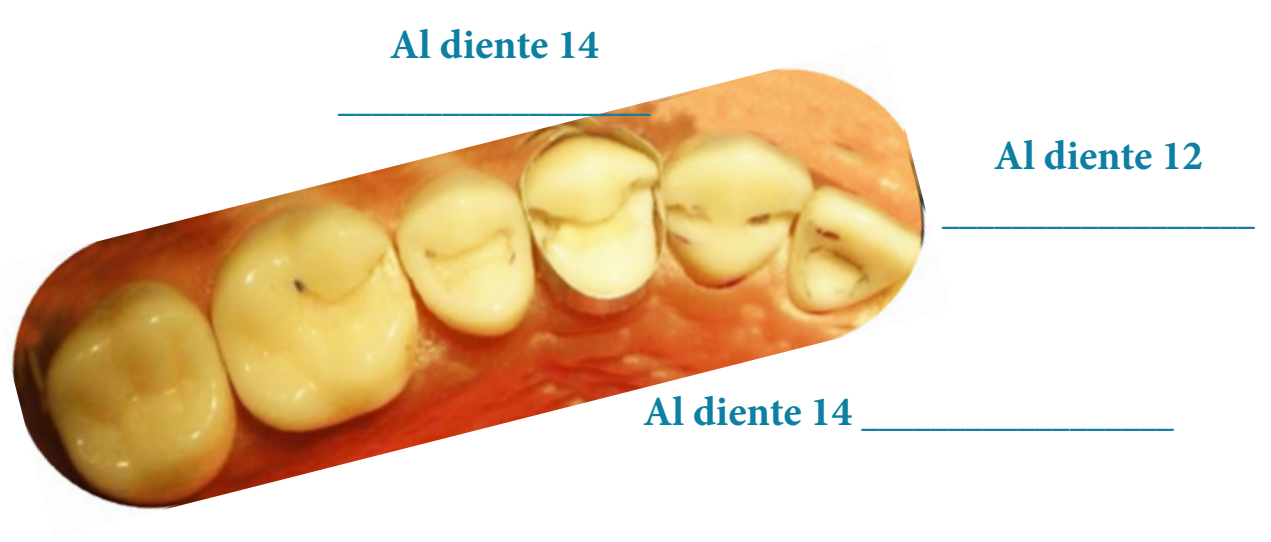

\section{Recapitulación}

La función de llevar a cabo una cavidad es retirar la caries dental de las piezas dentarias. Y tiene una clasificación: Tipo I, tipo II, y III. Afectando las superficies del diente.

\begin{tabular}{|l|l|}
\hline $\begin{array}{l}\text { Tipo I } \\
\text { Leve a moderada }\end{array}$ & $\begin{array}{l}\text { Lesiones cariosas que afectan sólo una o dos piezas dentales ya } \\
\text { sean molares o incisivos. }\end{array}$ \\
\hline $\begin{array}{l}\text { Tipo II } \\
\text { Moderada a severa }\end{array}$ & $\begin{array}{l}\text { Lesiones cariosas que afectan los incisivos maxilares. Los molares } \\
\text { pueden o no estar afectados y los incisivos mandibulares están } \\
\text { sanos. }\end{array}$ \\
\hline $\begin{array}{l}\text { Tipo III } \\
\text { Severa }\end{array}$ & Lesiones cariosas que afectan todas las piezas dentales. \\
\hline
\end{tabular}

\section{¿Cuáles son los objetivos de una preparación cavitaria?}

1. Apertura de los tejidos duros para tener acceso a la lesión.

2. Extensión de la cavidad, hasta obtener paredes sanas y fuertes sin debilitar el esmalte remanente dentario.

3. Debe proporcionar soporte dentinario, así como retención y anclaje a la restauración.

4. Eliminación de los tejidos deficientes (cariados, descalcificados, etc.).

5. Extensión del perímetro cavitario hasta zonas adecuadas para evitar la reiniciación de caries.

6. No debe dañar los tejidos blandos, intra o periodentales. 
7. Protección de la biología pulpar.

8. Debe facilitar la obturación mediante formas y maniobras complementarias.

\section{¿Cuál es la finalidad de realizar una cavidad?}

Las cavidades y las obturaciones tienen diferentes finalidades: terapéutica, estética, protética, preventiva o mixta.

- Finalidad terapéutica: cuando se pretende devolver al diente su función perdida por un proceso patológico o traumático o por un defecto congénito.

- Finalidad estética: para mejorar o modificar las condiciones estéticas del diente.

- Finalidad protética: para servir de sostén a otro diente, para ferulizar, para modificar la forma, para cerrar diastemas o como punto de apoyo para una reposición protética.

- Finalidad preventiva: para evitar una posible lesión.

- Finalidad mixta: cuando se combinan varios factores.

- Tiempos operatorios.

\begin{tabular}{|c|c|c|}
\hline Terapéutica y protésica & $\begin{array}{c}\text { Por su finalidad } \\
\text { Preventiva y estética }\end{array}$ & Mixta \\
\hline $\begin{array}{l}\text { - Para devolver la función } \\
\text { perdida. } \\
\text { Para tratar una lesión cariosa } \\
\text { extensa. } \\
\text { Para tratar una lesión con } \\
\text { una restauración pequeña y } \\
\text { conservadora. } \\
\text { - Para sustituir o reparar } \\
\text { restauraciones con defectos } \\
\text { importantes. } \\
\text { - Contactos proximales } \\
\text { inadecuados. } \\
\text { - Excesos gingivales. } \\
\text { Márgenes con riesgo de } \\
\text { caries. } \\
\text { Dientes fracturados que } \\
\text { han perdido poca o mucha } \\
\text { estructura dental. } \\
\text { Malformación congénita. } \\
\text { - Restauración para permitir el } \\
\text { funcionamiento correcto de la } \\
\text { prótesis. }\end{array}$ & $\begin{array}{l}\text { Para evitar una posible lesión } \\
\text { limitando su diseminación } \\
\text { potencial. } \\
\text { - Se debe valorar la } \\
\text { profundidad, tipo y número de } \\
\text { microorganismos involucrados, } \\
\text { posibilidades, eficacia y } \\
\text { motivación del paciente, } \\
\text { necesidades de tratamiento } \\
\text { antimicrobiano y factores } \\
\text { nutricionales. } \\
\text { Para mejorar o modificar } \\
\text { las condiciones estéticas } \\
\text { inadecuadas. } \\
\text { Colocación y sustitución de } \\
\text { restauraciones. }\end{array}$ & $\begin{array}{l}\text { - Restauración realizada cuando } \\
\text { combinan varios factores. }\end{array}$ \\
\hline
\end{tabular}




\section{Recomendaciones}

\section{Forma del contorno}

L

a forma del contorno es la forma del ángulo cavo-superficial que se obtendrá después de haber preparado la cavidad. Se obtiene por la eliminación del esmalte despegado por la caries o sin soporte dentinario. También en todas las cavidades en las que intervienen fisuras, éstas, bien sean cariosas o no, deben seccionarse hasta que el borde de la cavidad termine sobre una superficie lisa.

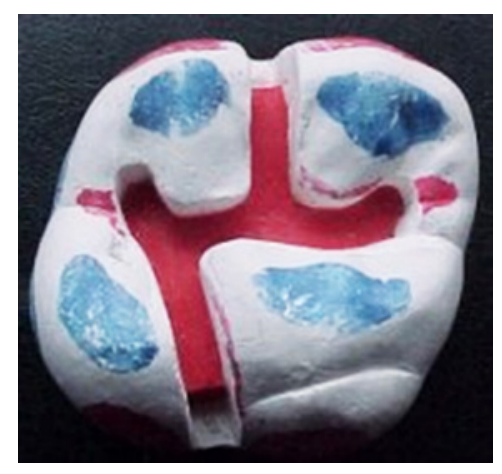

Los bordes de las cavidades de las superficies de aproximación deben extenderse hasta áreas de menor susceptibilidad, es decir, hasta el interior de las aberturas bucal y lingual, por debajo de la cresta del borde de la encía, sobre la superficie de oclusión en los dos tercios oclusales de las superficies bucal y lingual de los molares y premolares y las superficies correspondientes de los dientes anteriores. Sin exagerar en la extensión, por la ventaja que se tiene ahora con los nuevos materiales dentales. El operador debe guiarse por factores tales como la edad del paciente, propensión a la caries, disposición de los dientes y estado general del paciente.

La caries puede afectar las diferentes partes del diente, por lo que tienen que seccionarse las cavidades separadas, las cuales no deben dejarse distanciadas si la sustancia que las separa es delgada y débil.

Si los bordes de la cavidad alcanzan un surco de desarrollo, el borde deberá extenderse ligeramente más allá del surco, donde no exista esmalte sin soporte dentinario.
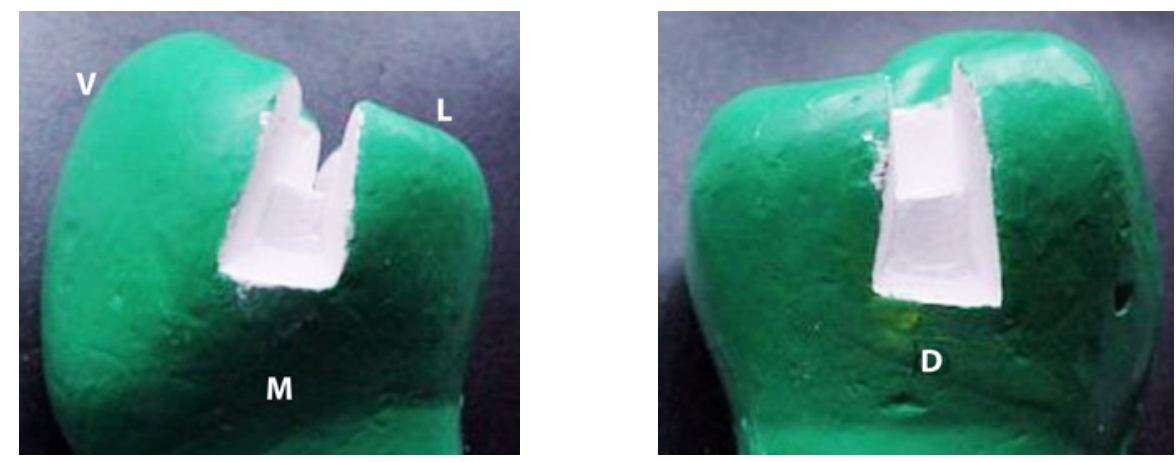


\section{Forma de resistencia y retención}

Una cavidad tiene forma de resistencia si se prepara de tal manera que la sustancia dentaria restante queda protegida contra la fractura durante la masticación. Tiene forma de retención si se dispone de tal modo que no puede desprenderse la obturación. Si bien se habla separadamente de forma de resistencia y de forma de retención, se obtienen, por regla general, en el curso de la misma operación. Por consiguiente, es bastante correcto considerarlas conjuntamente. Sin embargo, debe comprenderse que la forma de resistencia puede aplicarse sólo a las restauraciones que están sometidas directamente a las fuerzas de oclusión.

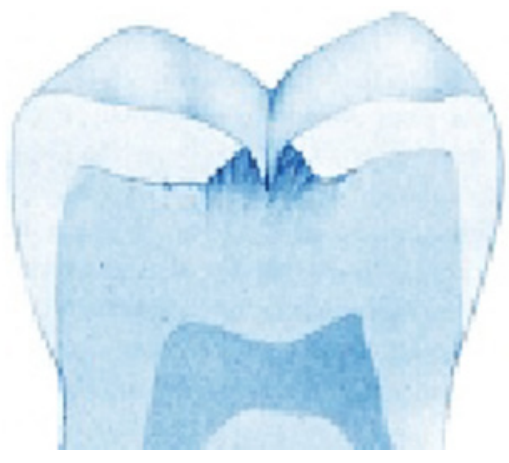

Debemos insistir en que para que una cavidad tenga una buena forma de resistencia, todo el esmalte de sus paredes debe sostenerse sobre dentina sana. Todos los prismas del esmalte deben apoyarse sobre la dentina, puesto que de no ser así fragmentos de sustancia dentaría se desprenderán del borde de la cavidad después de haber insertado la restauración.

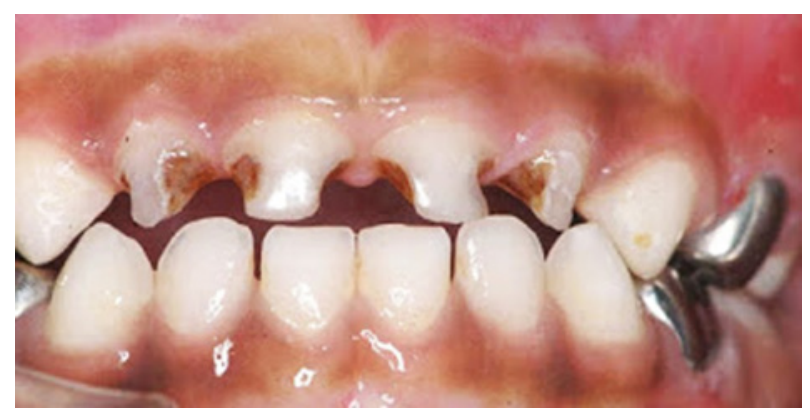

En todo el transcurso de la preparación de la cavidad ha de ponerse siempre mucho cuidado en evitar la destrucción indiscriminada de la sustancia del diente, por lo que el relleno no debe estar rodeado por las paredes que se romperían por la sobre carga de la masticación, formas de retención.

Las restauraciones pueden desprenderse por la tracción de alimentos adherentes o por las fuerzas de oclusión, si bien la forma general de la cavidad no conduce por sí misma a la retención ésta aumenta si se prepara con ángulos agudos de esquina y de rincón.

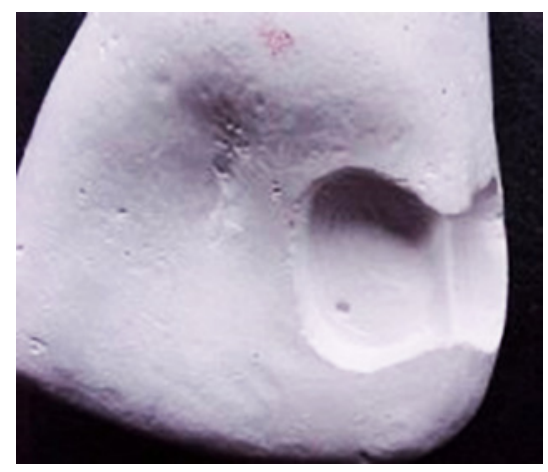


En ocasiones, las cúspides están grandemente socavadas y constan sólo de esmalte, el cual aunque esté sostenido con material de relleno, no será capaz de soportar las fuerzas de la masticación. Es aconsejable eliminar esta débil sustancia dentaría para que pueda ser reemplazada con material de relleno. Este procedimiento se conoce como recubrimiento de las cúspides y debe realizarse con bastante liberalidad si se aplica amalgama, pero en menor grado si se recurre al oro como material de restauración.

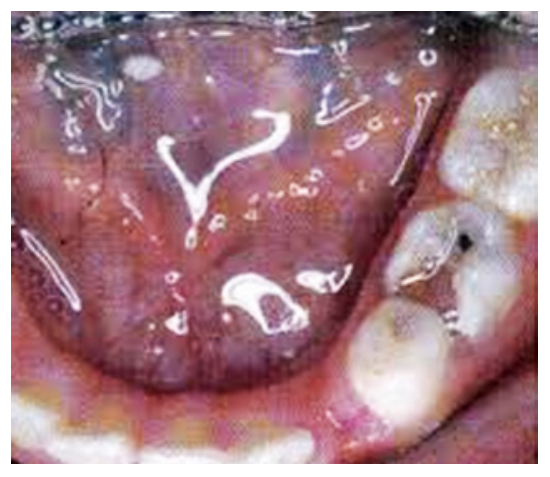

En las cavidades de la clase II es importante la preparación correcta del suelo cervical para prevenir la tendencia de la torsión a desplazarlas restauraciones de aproximación-oclusión. El suelo cervical debe seccionarse en ángulo recto a la pared axial por lo que el plano inclinado, que se separa en forma sesgada de la pared axial, no se prolonga hasta permitir que el material de restauración se desaloje en el interior del espacio de aproximación.

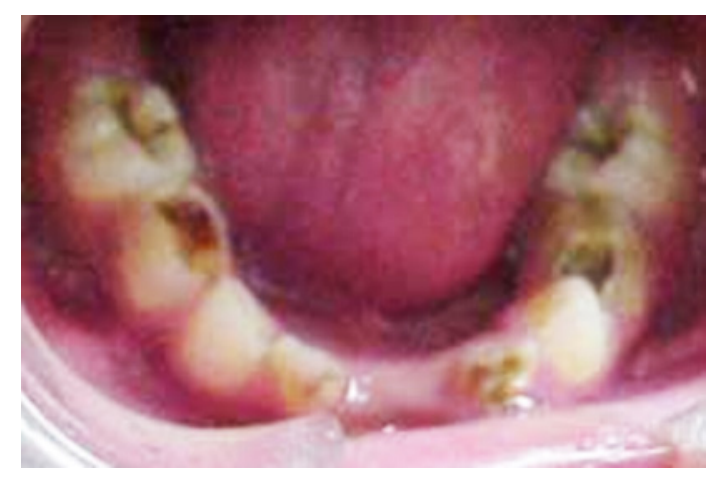

El mismo principio se aplica a la parte interna de la cavidad puesto que, si el suelo pulpar forma un ángulo distinto al recto, con la masticación puede desarrollarse una fuerza capaz de desplazar la restauración, salvo en el caso de que ésta sea retenida por una pared lateral convergente o por un bloqueo mecánico, como es el caso de las cavidades tipo Bronner.

Por consiguiente, las cavidades deben prepararse de tal forma que los pisos de las restauraciones se dispongan en ángulo recto a la dirección de la fuerza de masticación. Esto es cuando realizamos cavidades Black con pisos planos y ángulos a 90 grados 


\section{Forma de conveniencia}

Por forma de conveniencia se quiere significar la forma que se da a la cavidad de modo que se logre un acceso adecuado a todas sus partes, mientras se prepara la cavidad y se va a introducir el relleno. En algunos casos deberá sacrificarse parte de la pared bucal o lingual cuando los dientes están en relación anormal entre sí.

Puesto que la forma de conveniencia se realiza sólo por conveniencia del operador, únicamente se recurrirá a ella en casos de necesidad y se practicará en forma discriminada y limitada.

La cantidad de destrucción de sustancia dentaría sana se reduce en extremo si se consigue la separación de los dientes antes de empezar la operación. La pérdida excesiva de tejido dentario puede evitarse también si se usan los instrumentos apropiados.
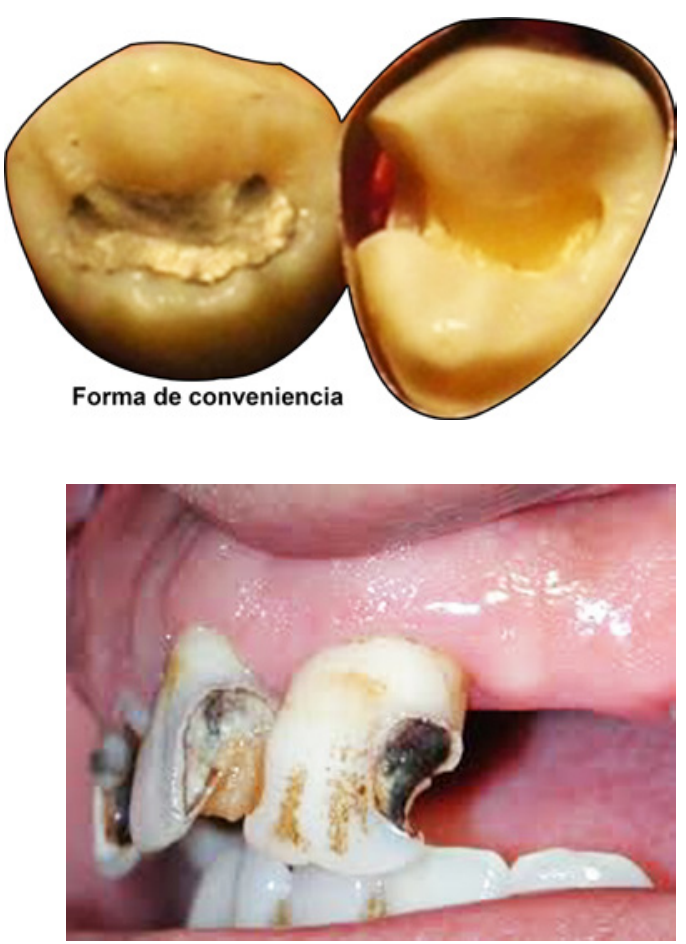

\section{Eliminación de la caries}

\footnotetext{
1 comienzo de la preparación de la cavidad deberá extirparse la mayor parte de la caries, esto es especialmente importante si la historia del diente sugiere una enfermedad de la pulpa.
}

Al eliminar la caries en esta fase puede comprobarse si la pulpa está al descubierto y de esta forma se podrá escoger el tratamiento más apropiado. Si la cavidad es pequeña, se extirpará toda la caries, al paso que se logra la resistencia y la retención.

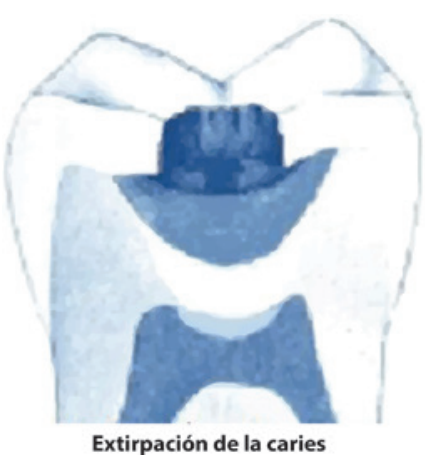


Convendrá excavar cuidadosamente todo cuanto haya quedado.

En ocasiones, se observa dentina teñida y parcialmente descalcificada en el fondo de una cavidad profunda, y en este caso el operador deberá decidir si extirparla o conservarla.

Si la dentina es dura y no puede extraerse más que con excavadores de cucharilla, y si la historia no sugiere una participación previa de la pulpa, es una buena práctica respetar esta dentina dura y teñida.

El estado de la pulpa puede determinarse por las pruebas térmicas y eléctricas en las visitas subsiguientes del paciente.
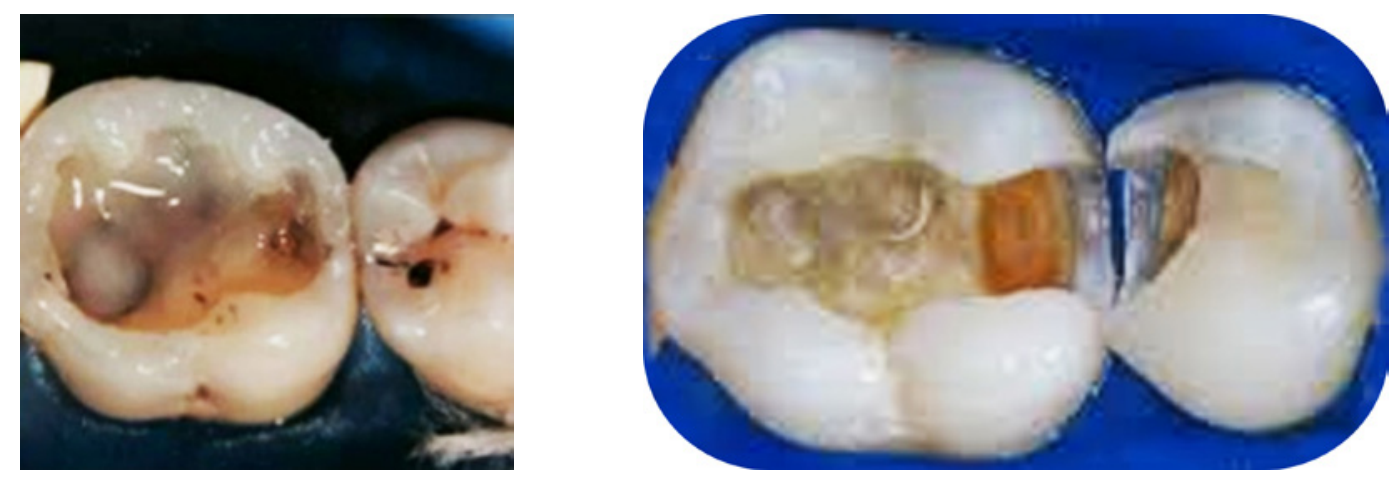

\section{Tallado de los bordes del esmalte}

Puesto que todas las restauraciones deben tener un buen cierre marginal, esta fase de la preparación de la cavidad es una de las maniobras más importantes. Sin una apropiada preparación de los bordes es imposible un buen cierre marginal. El examen de la estructura microscópica del esmalte revela una disposición de la cavidad que debe seguir la forma de los prismas del esmalte. Por lo que en algunos casos es necesario realizar diferentes tipos de biselado: los cuales pueden ser corto, mediano, largo. ${ }^{29}$

\section{Bisel corto}

Se practica a lo largo del ángulo cavo-superficie en un ángulo de $45^{\circ}$ y ocupa menos de la mitad del grosor del esmalte.

Este nivel produce un reborde de la cavidad que es difícil de definir y un inlay (cavidad para incrustación clase I) y se realizan en pacientes adultos con un contorno áspero y desigual. El inconveniente de este procedimiento es que pueden romperse los delgados rebordes del metal dejando un borde defectuoso para la restauración.

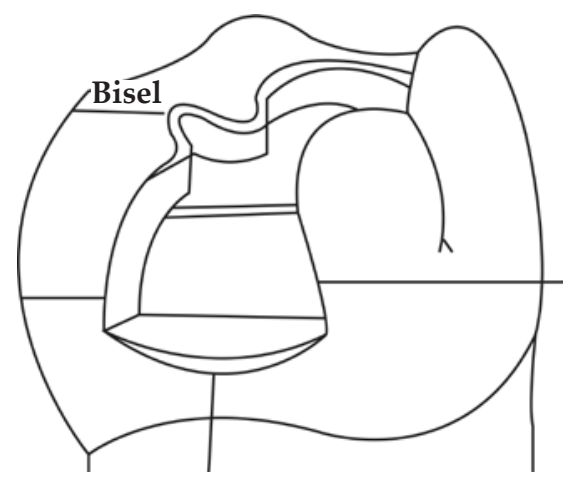




\section{Gurrola Martínez B \& Álvarez Bañuelos VJ}

\section{Bisel largo}

A causa del perfeccionamiento de los métodos empleados en la actualidad para el moldaje de las aleaciones de oro, el bisel largo ha sustituido al bisel corto, ya que ocupa la totalidad del grosor del esmalte y forma un ángulo de 30ㅜㅡㅇ o menos con la pared del esmalte. Se consigue así un contorno de la cavidad mejor definido y se produce un reborde resistente.

\section{Bisel completo}

El bisel completo abarca toda la longitud de la pared de la cavidad incluidos el esmalte y la dentina. Como en el caso del bisel largo, este bisel completo produce un contorno bien definido y un reborde resistente. Las cavidades preparadas con un bisel completo presentan una pared de la cavidad con un afilamiento cónico de 5․ En la práctica moderna se obtienen biseles largos o completos con un afilamiento de $5^{\circ}$.

\section{Limpieza de la cavidad}

$\mathrm{E}$ sta es la última fase en la preparación de la cavidad y consiste en la extracción de todos los restos que se eliminan con aire caliente o con agua. Cuando la cavidad está seca puede examinarse y el operador está en condiciones de observar si se han llevado a cabo en forma apropiada todas las fases previas.

Los primeros libros de texto de técnica odontológica aconsejaban que las cavidades terminadas debían limpiarse con sustancias cáusticas potentes como el fenol o debían ser lavadas con alcohol. Sí bien es uno de los propósitos de la aplicación de fenol era esterilizar la dentina, es improbable que se destruyan todas las bacterias situadas profundamente en los túbulos debido a que el fenol se combina con las proteínas y tiene una acción auto limitadora.

La enseñanza moderna recomienda el uso de sustancias menos irritantes, como por ejemplo una solución débil de peróxido de hidrógeno en lugar de las sustancias del grupo del fenol o del alcohol.

Por otra parte considerando lo aportado por Carrillo ${ }^{18}$ quien señala que aun ya en nuestros días, es factible analizar lo que los avances en la odontología adhesiva nos permiten valorar en relación con la aplicación de los principios científicos de la preparación de una cavidad previo a su obturación: • La apertura de la cavidad y la remoción necesaria de la lesión • La eliminación del esmalte sin soporte (principio de resistencia) • Biselado del esmalte (terminado de las paredes del esmalte) • La limpieza de la cavidad con agentes humectantes o bactericidas • El acondicionamiento del esmalte y la dentina, la colocación de un primer y un adhesivo para lograr la unión a estos tejidos (principio de retención). Es preciso hacer notar que aun cuando la finalidad de todo procedimiento es la simplificación, actualmente un procedimiento restaurador adhesivo requiere de mayor tiempo y de más pasos clínicos que los tratamientos tradicionales. Además de que se puede seguir considerando a la aplicación de la odontología adhesiva como técnica más sensible. ${ }^{26,29}$ 
Esto, nos da una idea de la importancia del presagio de Phillips, que aunque no es factible decir que sea perenne, sí es válido mencionar, la revisión de los principios de preparación de cavidades www. medigraphic.com realizada por Carrillo ${ }^{18}$ complicado llevar a cabo la aplicación de los principios modificados por la odontología adhesiva en comparación con los aplicados en la odontología tradicional.

Con la entrada a la utilización de los materiales estéticos adhesivos con que se cuenta, actualmente es necesario pensar en la eliminación

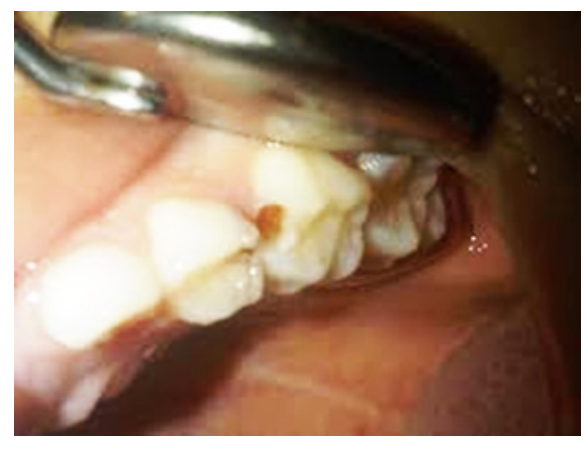
profiláctica de defectos del desarrollo, pudiendo ser profunda en caso de presencia de lesión y tener que ser restaurados, o en caso de que sean superficiales, ser únicamente sellados.

¿No es esto una forma de extensión por prevención actual? Se sugiere en nuestros días, que al tratar una lesión oclusal, además de remover el tejido carioso y previo a la colocación del agente acondicionador del esmalte y la dentina, se deben ensanchar ligeramente las fosas y fisuras remanentes para ser cubiertas posteriormente con selladores de fosetas y fisuras. ${ }^{21,26}$

Algunos métodos han sido sugeridos para lograr este propósito: fresas de alta velocidad muy pequeñas, láser, abrasión por aire y todos estos, han demostrado que mejoran la retención de la restauración y de los selladores. ${ }^{27}$

¿Pero, no es esto una forma de hacer extensión por prevención en la actualidad? Lo más importante es que al llevar a cabo un análisis de riesgo de caries, se haga una validación del historial previo de caries del paciente y considerar aspectos como: análisis de saliva, interacción con fluoruros, dieta, así como condiciones microbiológicas y de conducta. ${ }^{21,28}$

En base a esto, considerar el tratamiento restaurador a aplicar. El estado actual que guarda la odontología restauradora, considera como parte importante de la prevención, a la aplicación de métodos que favorezcan al proceso de remineralización, la evaluación y el seguimiento de las lesiones incipientes no cavitadas, y la intervención mínima de tipo quirúrgico, únicamente cuando sea requerido. ${ }^{29}$

Con estos avances en la odontología restauradora, es factible pensar en la aplicación de técnicas que realmente preserven la mayor parte de la estructura del diente íntegra. Y saber, que es viable en nuestros días, remover la lesión y colocar la restauración sin eliminar demasiado tejido dental. Esto ha marcado el surgimiento de la aplicación de un nuevo término: la prevención de la extensión. ${ }^{23}$

Actualmente, menciona Carrillo: contamos con toda la ciencia y tecnología para practicar odontología preventiva y restauradora como lo profetizó G. V. Black en 1896. Justo es, hacerle reconocimiento a su destacada labor en el progreso de la aplicación científica en la odontología restauradora y a su entusiasmo por hacer de ésta, una forma de "Odontología preventiva moderna". ${ }^{18}$ 


\section{Gurrola Martínez B \& Álvarez Bañuelos VJ}

\section{Glosario}

\section{Black clasificación según localización del tipo de cavidad}

Clase I, fosas y fisuras oclusales y molares, cara lingual o platina de incisivos y caninos. Fosas y surcos bucales o linguales de molares. Clase II, superficies proximales de premolares y molares cavidades MOD. Clase III, superficies proximales de incisivos y caninos que no abarquen el ángulo incisal. Clase IV, superficies proximales de incisivos y caninos que abarcan el ángulo incisal. Clase V, tercio gingival de todos los dientes. Clase VI, con finalidad protésica, coronas tres cuartos.

Clase I. Cavidades tipo Black las observamos en la superficie oclusal del primer molar permanente, tenemos las paredes paralelas pisos planos, con ángulos de $90^{\circ}$ en el escalón palatino. En el primer premolar sólo se localiza en la cara oclusal y en los dientes incisivos superiores en la pared lingual y palatina, en el cíngulo.
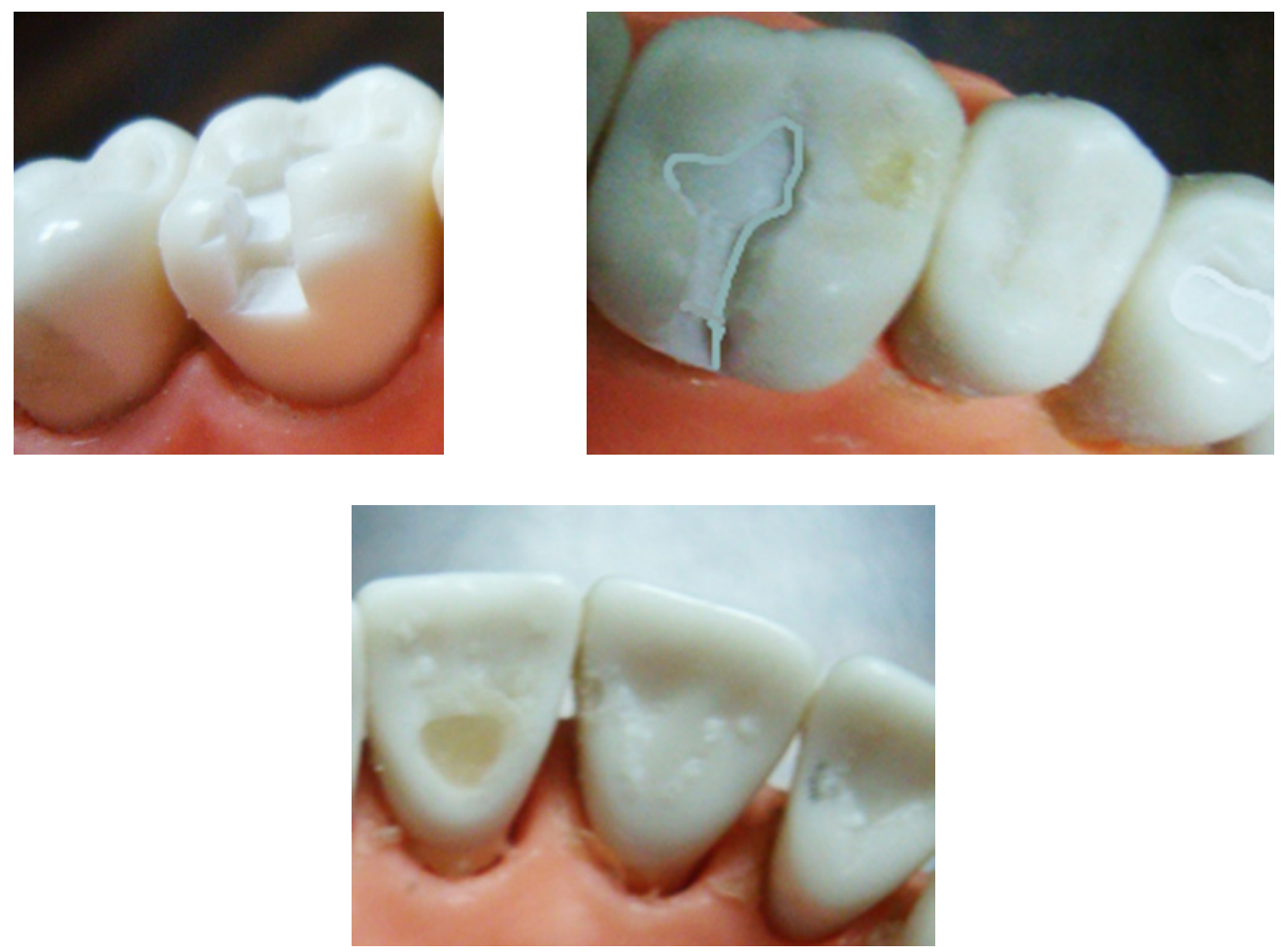

Clase II. Cavidades tipo Black, se localizan abarcando las superficies de las piezas posteriores en las caras proximales, de molares y premolares.

Se puede ver el molar con la afectación de 3 de las caras: distal, oclusal y mesial. En el premolar se ve en 2 de las superficies, la pared disto y oclusal, véanse las paredes paralelas, pisos, planos, y la colocación correcta de la fresa para formar lo ángulos de $90^{\circ}$ grados. 


\section{Cavidades para dentición infantil}
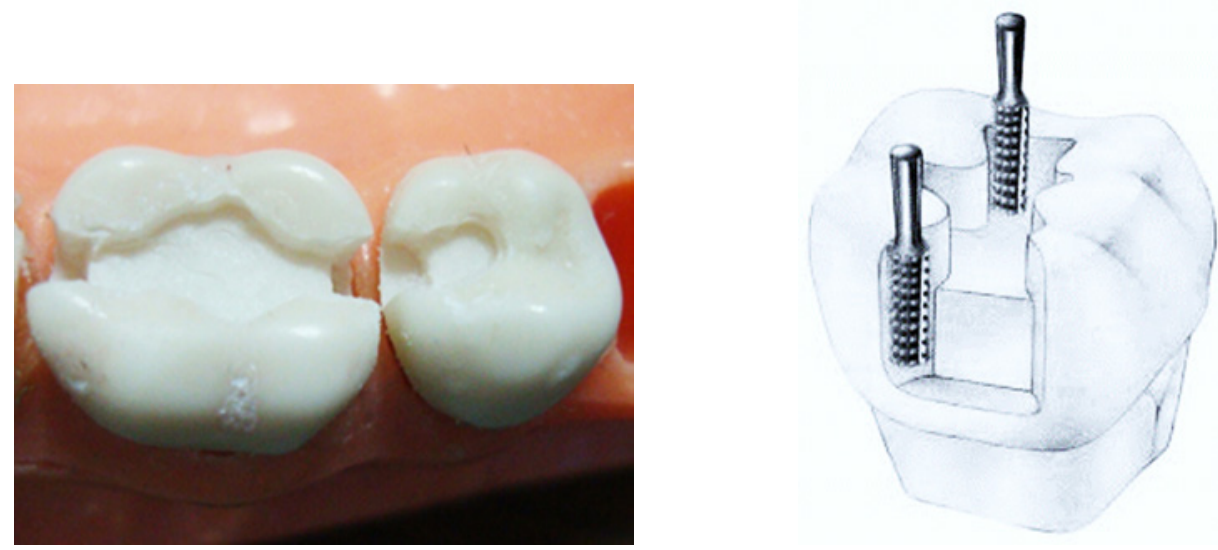

Clase III. Cavidades tipo Black, se realizan en las superficies proximales de dientes anteriores, superiores e inferiores abarcando sólo el tercio medio.
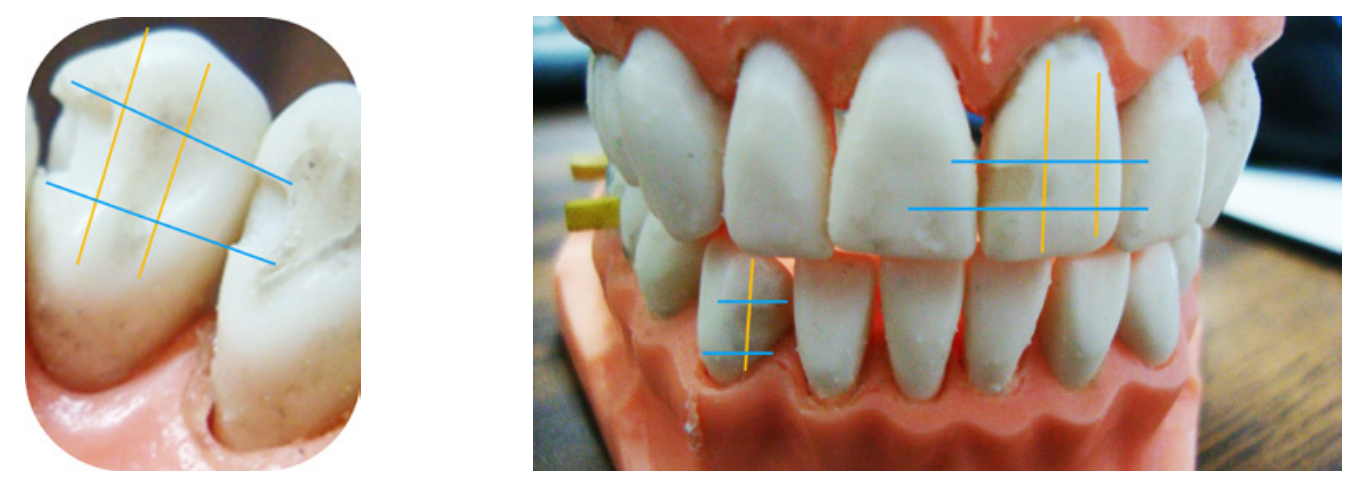

\section{Clase IV. Cavidad tipo Black.}

Se encuentran en dientes anteriores en paredes proximales abarcando el ángulo incisal. A este tipo de cavidades se les restauran colocando pins, o postes para dar soporte al borde incisal o cuando se trata de traumatismos por lo general se colocan coronas.
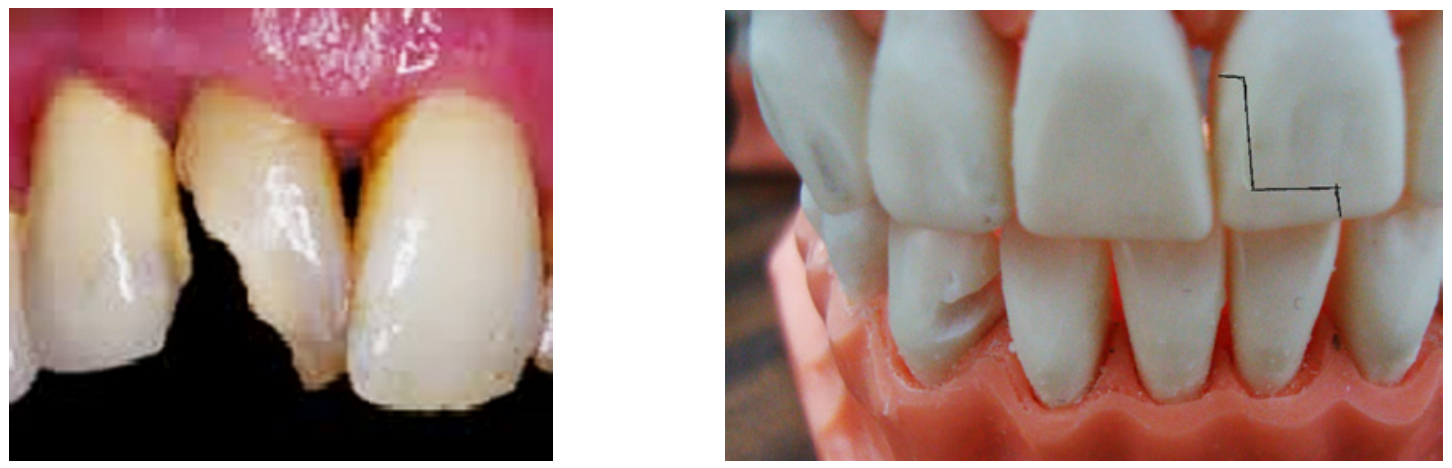

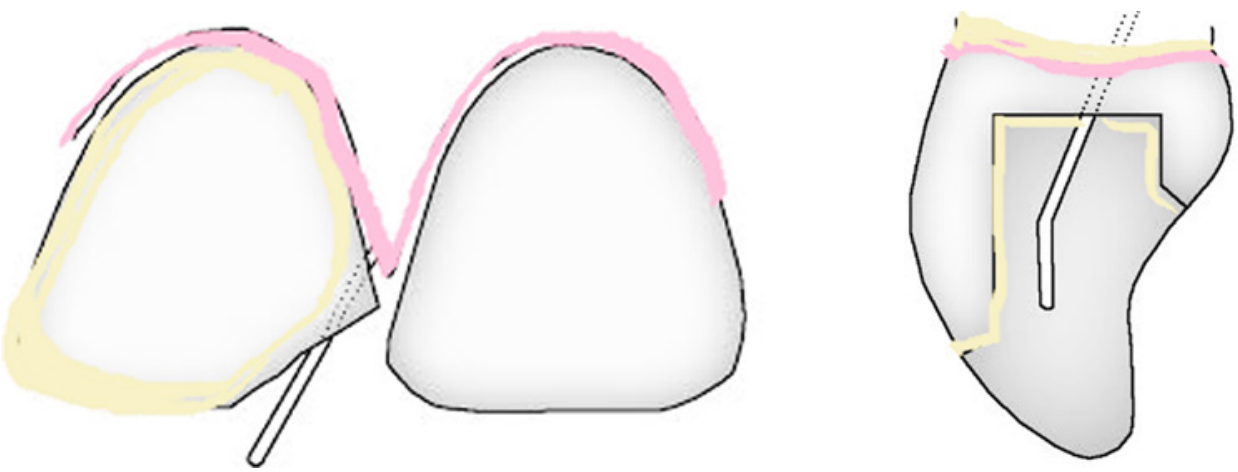

En una de la primera imagen podemos observar que la pared proximal está casi destruida, hasta el tercio medio del diente lateral y en la segunda la caries casi hasta el tercio gingival.
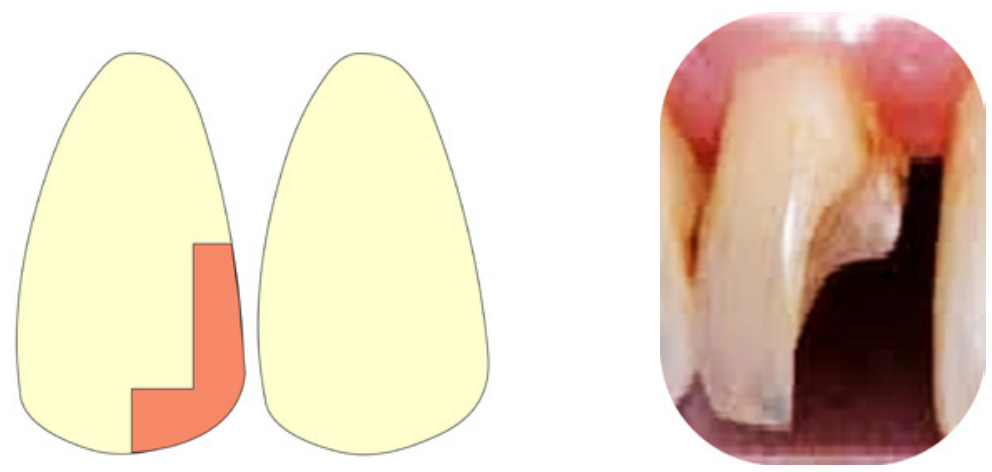

\section{Clase V. Cavidades tipo Black.}

Se encuentran localizadas en el tercio gingival o cervical de las caras bucales o labiales, palatinas o linguales de todas las piezas dentarias.

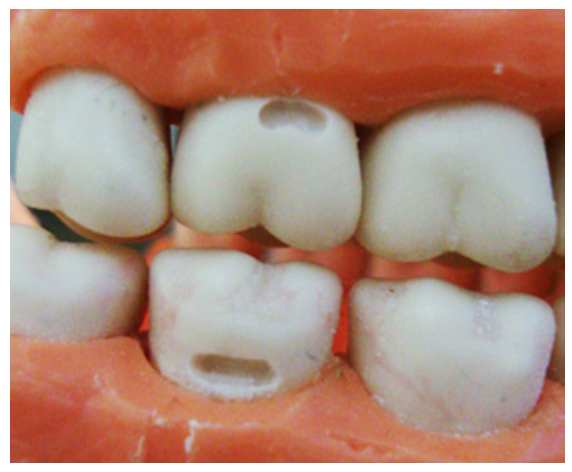

Superficies vestibulares

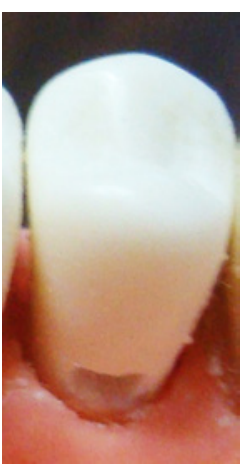

Cara palatina 


\section{Mount}

\section{Clasificación según su localización, Mount señala que las} lesiones cariosas ocurren en tres sitios de la corona o de la raíz del diente, son áreas sujetas a la acumulación de placa dentobacteriana o biofilm.

Zona 1. Fosas, fisuras y defectos del esmalte en las superficies oclusales de los dientes posteriores y otros defectos en superficies lisas como cíngulos y fosas de los dientes anteriores.

Zona 2. Proximal de cualquier diente anterior o posterior situada inmediatamente por debajo del punto de contacto de dientes adyacentes.

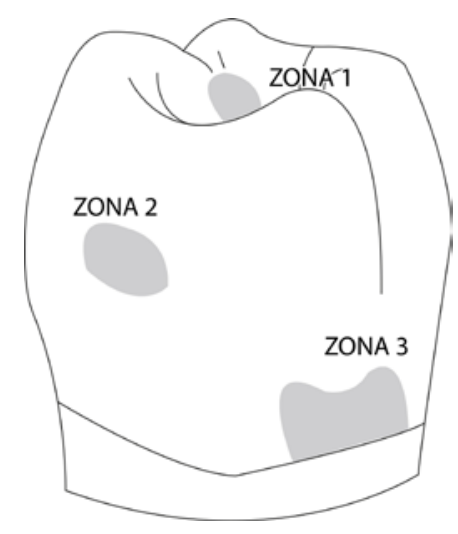

Zona 3. Tercio gingival de la corona o en caso de recesión gingival, raíz expuesta.

Progresión origen Mount de la lesión cariosa, es posible diferenciar 4 tamaños: 0= lesión en su etapa temprana, puede ser identificada como estadio inicial de la desmineralización.

Tamaño 1, mínima cavitación superficial del esmalte, involucra dentina.

El tratamiento se puede intentar remineralizar o puede ser necesario algún tipo de restauración para restituir la fisura superficial y evitar la acumulación de placa dentobacteriana.
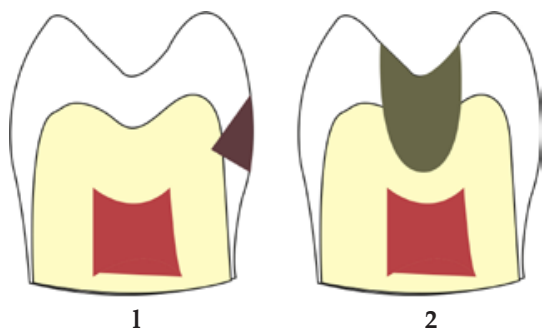

Tamaño 2, lesión cariosa localizada con afectación moderada de la dentina. Una vez hecha la preparación cavitaria, el esmalte remanente está en buen estado, adecuadamente soportado por la dentina sana y no es probable que ceda bajo las cargas oclusales normales. El diente es bastante fuerte como para soportar la restauración.

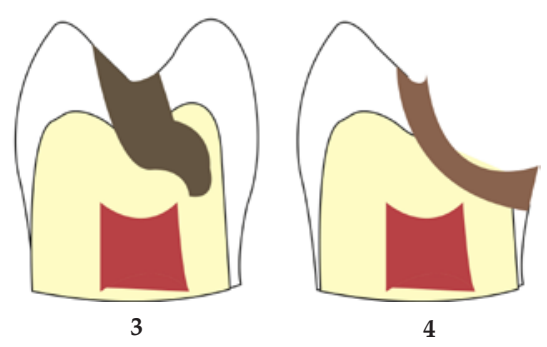

Tamaño 3, la cavidad está más que moderadamente afectada, lo que queda de la estructura dental está debilitada, hasta el punto de que las cúspides o bordes incisales presentan grietas que pueden llegar a ceder bajo las cargas oclusales. Hay que ampliar la cavidad para que la restauración pueda soportar la estructura dental.

Tamaño 4, caries extensa, se ha producido una pérdida importante de estructura dental, como una cúspide o el borde incisal. 


\section{Gurrola Martínez B \& Álvarez Bañuelos VJ}

\section{Bibliografía}

1. Programa académico del módulo de Prevención en Estomatología 2016. México: Facultad de Estudios Superiores Zaragoza, UNAM; 2006.

2. Organización Mundial de la Salud (OMS). Encuestas de salud bucodental. Métodos básicos. $4^{a}$ ed. Ginebra: OMS; 1997. Consulta marzo 2017. Disponible en: http://www.whocollab.odont.lu.se/index.html

3. Pitts NB, Fyffe HE. The effect of varying diagnostic thresholds upon clinical caries data for a low prevalence group. J Dent Res. 1988; 67(3):592-596.

4. Mount GJ, Hume WR. A new cavity classification. Australian Dental Journal. 1998; 43(3):153-159.

5. Ismail AI, Sohn W, Tellez M, Amaya A, Sen A, Hasson H, Pitts NB. The International Caries Detection and Assessment System (ICDAS): an integrated system for measuring dental caries. Community Dent Oral Epidemiol. 2007; 35(3):170-178.

6. Nyvad B, Fejerskov O. Assessing the stage of caries lesion activity on the basis of clinical and microbiological examination. Community Dent Oral Epidemiol. 1997; 25(1):69-75. PMI: 9088694.

7. Nyvad B, Machiulskiene V, Baelum V. Reliability of a new caries diagnostic system differentiating between active and inactive caries lesions. Caries Research. 1999; 33(4):252-260. PMID: 10343087. Disponible en: http:// www.sdpt.net/ID/nyvad.htm

8. Casanova-Rosado AJ, Medina-Solís CE, Casanova-Rosado JF, Vallejo Sánchez, AA, Maupomé G, Ávila-Burgos L. Dental caries and associated factors in mexican school children aged 6-13 years. Acta Odontol Scand. 2005; 63(4):245-251.

9. Pereira SM, Tagliaferro EP, Ambrosano GM, Cortelazzi KL, Meneghim Mde C, Pereira AC. Dental caries in 12-year-old school children and its relationship with socioeconomic and behavioural variables. Oral Health Prev Dent. 2007; 5(4):299-306.

10. Juárez-López LA, Murrieta-Pruneda F, Ortiz-Cruz E. Prevalencia de caries y su asociación con el estado nutricional y hábitos higiénicos en preescolares. Revista de la Academia de Odontopediatría. 2006; 18:28-32.

11. Ismail A, Woosung S. The impact of universal access to dental cares on disparities in caries experience in children. J Am Dent Assoc. 2001; 132(3):295-303.

12. Schulte AG, Buchalla W, Huysmans MC, Amaechi BT, Sampaio F, Vougiouklakis G, Pitts NB. A survey on education in cariology for undergraduate dental students in Europe. Eur J Dent Educ. 2011;15 Suppl 1:3-8. doi: 10.1111/j.1600-0579.2011.00708.x 
13. Nyvad B, citado por Iruretagoyena MA. Sistema Internacional para la detección y evaluación de caries (ICDAS). Salud dental para todos. Consulta febrero 2017. Disponible en: http://www.sdpt.net/CCMS/ICDAS/ icdasbibliografia.htm

14. Nyvad B, Machiulskiene V, Baelum V. Construct and predictive validity of clinical caries diagnostic criteria assessing lesion activity. J Dent Res. 2003; 82:117-12212.

15. Black, citado por Nocchi Conceicao E. Odontología restauradora. Salud y estética. 2a. Ed. Argentina: Médica Panamericana; 2008.

16. Piovano S, Squassi A, Bordoni N. Estado del arte de indicadores para la medición de caries dental. Revista de la Facultad de Odontología (UBA). 2010; 25(58):38-43. Disponible en: http://www.uba.ar/archivos_internacionales/ image/Revista\%20odontolog\%C3\%ADa.pdf

17. Finn SB. Odontología pediátrica. México: Interamericana; 1989.

18. Carrillo Sánchez C. Revisión de los principios de preparación de cavidades Extensión por prevención o prevención de la extensión. Revista ADM. 2008; LXV(5):263-271.

19. Bronner FJ. Engineering principles applied to cavities. J Dent. Res. 1930; 10:115-119.

20. Bronner FJ. Mechanical, physiological and pathological aspects of operative procedures. Dental Cosmos. 1931; 73:577-584.

21. Mount GJ. Changes in operative dentistry - Beyond GV Black. p. 47-64. In: Roulet JF, Vanherle G (eds.). Adhesive technology for restorative dentistry. 2005: Chicago: Quintessence Publishing.

22. Parula N. Técnica de operatoria dental. Buenos Aires: Editorial Mundi; 1980.

23. Lanata EJ. Atlas de operatoria dental. Argentina: Editorial Alfaomega; 2008.

24. Welk DA, Laswell HR. Conceptos básicos para el diseño de preparaciones de cavidad a la luz de los conocimientos y tecnología actuales. p. 231-239. In operative dentistry. Dent Clin of North America. 20(2). Philadelphia: W.B. Saunders; 1976.

25. Chaple Gil AM. Comparación de dos clasificaciones de preparaciones cavitarias y lesiones cariosas: Mount y Hume, y Black. Rev Cubana Estomatol. 2015;52(2):33-41. Disponible en: http://scielo.sld.cu/scielo.php?script=sci_ arttext\&pid=S0034-75072015000200005

26. Maldonado A, Osborne JW, Summitt JB. Es actualmente la extensión por prevención un concepto válido. Acta Odontológica Venezolana. 2000; 38(3). Disponible en: http://www.actaodontologica.com/ediciones/2000/3/ extension_prevencion_concepto_valido.asp consulta feb 2017 


\section{Gurrola Martínez B \& Álvarez Bañuelos VJ}

26. Anusavice KJ. Buonocore memorial lecture. Materials of the future: Preservative or restorative? Oper Dent. $1998 ; 23: 162-167$.

27. Ortega Espinosa MC, Guerrero Morales M, Gurrola Martínez B, Orozco Cuanalo L, Taboada Aranza O. Restauración de dientes temporales con coronas de acero cromo. México: Facultad de Estudios Superiores Zaragoza, UNAM; 1999.

28. Kenneth DS. Manual de odontopediatría clínica. Barcelona: Editorial Labor; 1982.

29. Escobar MF. Odontología pediátrica. 2ª ed. Colombia: Amoloca; 2004.

30. Peters MC, McLean ME. Minimally invasive operative care. I. Minimal intervention and concepts for minimally invasive cavity preparations. J Adhesive Dent. 2001;3(1):7-16.

31. Gurrola Martínez B, Bernal Magaña J. Preparación de cavidades para pacientes infantiles. México: Facultad de Estudios Superiores Zaragoza, UNAM; 2004.

32. Andlaw RJ, Rock MP. Manual de odontopediatría. 4ª ed. México: McGraw-Hill Interamericana; 2006.

33. Boj JR, Catalá M. Odontopediatría. España: Masson; 2004.

34. Brenna, F. Odontología restauradora. Procedimientos terapéuticos y perspectivas de futuro. España: Elsevier; 2010.

35. Henostroza HG. Adhesión en odontología restauradora. España: Ripano; 2010.

36. Hubertus JM. Atlas de odontología pediátrica. España: Masson; 2002.

37. Passanezi SE. Odontología clínica. Práctica contemporánea. Vol. 2. Argentina: Médica Panamericana; 2004.

38. Qualtrough AJE, Satterthwaite J, Morrow L, Brunton P. Principles of operative dentistry. Oxford: Blackwell Publishing; 2005.

39. Ricketts D, Bartlett D. Odontología operatoria avanzada. Un abordaje clínico. Colombia: Amolca; 2013.

40. Studervant TR. Arte y ciencia de la odontología conservadora. 5ª ed. España: Elsevier; 2008.

41. Van Waes HM, Stöckli PW. Atlas de odontología pediátrica. España: Masson; 2002. 


\section{Cavidades para dentición infantil}

Beatriz Gurrola Martínez Víctor Javier Álvarez Bañuelos
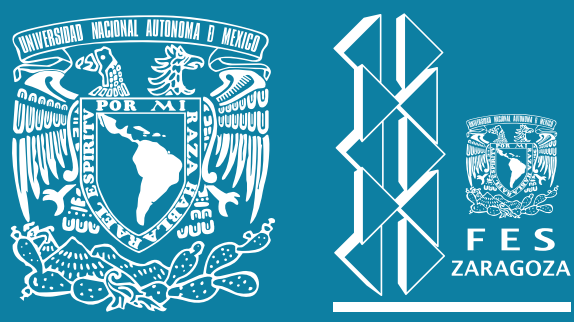

Facultad de Estudios Superiores Zaragoza, Campus I. Av. Guelatao No. 66

Col. Ejército de Oriente,

Campus II. Batalla 5 de Mayo s/n Esq. Fuerte de Loreto. 